\title{
Clinical and economical aspects of chemotherapy in patients with breast cancer
}

Citation for published version (APA):

Aarts - Essers, M. (2015). Clinical and economical aspects of chemotherapy in patients with breast cancer. [Doctoral Thesis, Maastricht University]. Maastricht University. https://doi.org/10.26481/dis.20151126ma

Document status and date:

Published: 01/01/2015

DOI:

10.26481/dis.20151126ma

Document Version:

Publisher's PDF, also known as Version of record

\section{Please check the document version of this publication:}

- A submitted manuscript is the version of the article upon submission and before peer-review. There can be important differences between the submitted version and the official published version of record. People interested in the research are advised to contact the author for the final version of the publication, or visit the DOI to the publisher's website.

- The final author version and the galley proof are versions of the publication after peer review.

- The final published version features the final layout of the paper including the volume, issue and page numbers.

Link to publication

\footnotetext{
General rights rights.

- You may freely distribute the URL identifying the publication in the public portal. please follow below link for the End User Agreement:

www.umlib.nl/taverne-license

Take down policy

If you believe that this document breaches copyright please contact us at:

repository@maastrichtuniversity.nl

providing details and we will investigate your claim.
}

Copyright and moral rights for the publications made accessible in the public portal are retained by the authors and/or other copyright owners and it is a condition of accessing publications that users recognise and abide by the legal requirements associated with these

- Users may download and print one copy of any publication from the public portal for the purpose of private study or research.

- You may not further distribute the material or use it for any profit-making activity or commercial gain

If the publication is distributed under the terms of Article $25 \mathrm{fa}$ of the Dutch Copyright Act, indicated by the "Taverne" license above, 
Clinical and economical aspects of chemotherapy in patients with breast cancer 
The research descibed in this thesis was funded by the Netherlands Organization for Health Research and Development (ZonMw) (grant 170882102), Sanofi B.V. and supported by the Dutch Breast Cancer Trialists' Group (BOOG).

Copyright @ 2015 Maureen Aarts. All rights reserved.

ISBN:

Cover design: Maureen Aarts

Lay-out: Tiny Wouters

Printed by: GVO drukkers\& vormgevers B.V. |Ponsen \& Looijen

Printing of this thesis was financially supported by: Sanofi B.V., Astellas B.V., Bayer B.V., Janssen-Cilag B.V., Pfizer B.V., Amgen B.V. 


\section{Clinical and economical aspects of chemotherapy in patients with breast cancer}

\section{PROEFSCHRIFT}

Ter verkrijging van de graad van doctor aan de Universiteit Maastricht, op gezag van de Rector Magnificus, Prof. dr. L.L.G. Soete, volgens het besluit van het College van Decanen, in het openbaar te verdedigen op donderdag 26 november om 12.00 uur

door

Maureen Joanna Bettina Aarts 
Promotor

Prof. dr. V.C.G. Tjan-Heijnen

Copromotor

Dr. M.A. Joore

Beoordelingscommissie

Prof. dr. M. van Engeland (voorzitter)

Prof. dr. E. Boven (Vrije Universiteit Medisch Centrum, Amsterdam)

Prof. dr. C.D. Dirksen

Dr. E.M. Heuts

Dr. G. Vreugdenhil (Maxima Medisch Centrum) 


\section{Contents}

$\begin{array}{lll}\text { Chapter } 1 & \text { Introduction and outline of the thesis. } & 7\end{array}$

Chapter 2 Primary granulocyte colony-stimulating factor prophylaxis 13 during the first two cycles only or throughout all chemotherapy cycles in patients with breast cancer at risk for febrile neutropenia. J Clin Oncol. 2013;31:4290-6

Chapter 3 Cost-effectiveness of primary pegfilgrastim prophylaxis in patients with breast cancer at risk of febrile neutropenia.

J Clin Oncol. 2013;31:4283-9

Chapter 4 Cost-effectiveness of primary and secondary granulocyte colony-stimulating factor prophylaxis for breast cancer patients at risk of febrile neutropenia: A model-based approach.

Submitted

Chapter 5 Neutrophil recovery in breast cancer patients receiving docetaxel-containing chemotherapy with and without G-CSF prophylaxis.

Submitted

Chapter 6 Doxorubicin/cyclophosphamide with concurrent versus sequential docetaxel as neoadjuvant treatment in patients with breast cancer. Eur J Cancer. 2013;49:3102-10

Chapter 7 Summary, general conclusions, and future perspectives.

Valorisation

Curriculum vitae

Dankwoord 



\section{Chapter 1}

Introduction and outline of the thesis 
Chapter 1 
Breast cancer is the number one death cause for women between 30 and 50 years old, although over the past decade the mortality has clearly decreased. ${ }^{1}$ This improved outcome can be explained by both more early detection in the national screening program and better treatment. Surgery is the mainstay of early breast cancer treatment, but eventually in more than one-third of patients distant metastases occur if not treated with additional systemic therapies such as chemotherapy, endocrine therapy and/or HER2 targeted therapy. For that reason, we offer systemic treatments to patients considered at risk of distance recurrence. The risk estimation is based on prognostic factors such as age, tumor size, histological grade, number of positive lymph nodes, hormone receptor and HER2 status. ${ }^{2}$ Chemotherapy can be applied in the neoadjuvant or adjuvant setting. Neo-adjuvant chemotherapy is preferred with locally advanced or borderline resectable disease. ${ }^{3}$ Moreover, this approach is currently also extended to less advanced disease stages.

During the past decades several polychemotherapy regimens were developed. First CMF (cyclophosphamide, methotrexate, 5-fluorouracil), followed by anthracyclinebased chemotherapy e.g. FAC (5-fluorouracil, doxorubicine, cyclophosphamide), AC (doxorubicin, cyclophosphamide) and FEC (5-fluorouracil, epirubicin, cyclophosphamide). ${ }^{4}$ Adding of docetaxel to anthracyclines further improved overal survival. ${ }^{5}$ However, anthracycline/taxane combination chemotherapy is associated with an increased risk of myelotoxicity and febrile neutropenia (FN).

Severity and duration of neutropenia and patient-related factors such as age or comorbidities correlate not only with the risk of infection but also with infection-related mortality. ${ }^{6}$ Therefore, patients with FN are generally recommended to be admitted to the hospital for treatment with intravenous antibiotics. Prevention of FN episodes can be considered as vital. Prophylactic use of antibiotics and of Granulocyte ColonyStimulating Factor (G-CSF) have shown to significantly reduce the incidence of FN. ${ }^{7,8}$ EORTC and ASCO guidelines recommend to administer primary G-CSF prophylaxis if the risk of $\mathrm{FN}$ is more than $20 \%$. Previously this risk threshold was $40 \%{ }^{9,10}$

In an earlier study, we showed that for the Netherlands primary G-CSF prophylaxis comes with considerable extra costs: altogether 5,123 euro per patient who had a baseline risk of $\mathrm{FN}$ of $32 \% .{ }^{11}$ As a consequence, guidelines and resulting changes in daily clinical practice were expected to have a huge impact on our health care budget. For the Netherlands, this would annually concern many thousands of patients for all tumour types with a costs increase of at least 10-20 million euros each year.

Moreover, we noticed, that irrespective of chemotherapy regimen or tumour type, the risk of FN was shown to be highest during the first two cycles of chemotherapy. Thereafter, the benefit of G-CSF largely seemed to disappear as the risk of FN rapidly declined. ${ }^{12,13}$ So, we hypothesized that to increase the cost-effective administration of 
primary G-CSF prophylaxis, G-CSF use should be limited to the first chemotherapy cycles in contrast to the common practice of G-CSF prophylaxis throughout all chemotherapy cycles. However, prospective evidence on the safety of such an approach were lacking. That's why we performed a randomized phase III study, the Dutch 'Two-to-Six' Study. The data presented in this thesis are predominantly based on this randomized clinical trial.

In chapter 2 we present the clinical results of the multicenter 'Two-to-Six' study. Breast cancer patients who received 3-weekly polychemotherapy, with more than $20 \%$ risk of FN, were randomly enrolled to primary G-CSF prophylaxis during the first two chemotherapy cycles only (experimental arm, G-CSF 1-2 arm) or to primary G-CSF prophylaxis throughout all chemotherapy cycles (standard arm, G-CSF 1-6 arm). The $\mathrm{H} 1$ (non-inferiority) hypothesis was that the incidence of FN was maximally $7.5 \%$ higher in the experimental arm in comparison to the patients treated within the standard treatment arm. In total 167 patients were included. The study protocol provided strict definitions of FN and its management. In addition, before a patient could be released from the hospital standardized criteria had to be met. In case of fever without neutropenia, physicians were free to act according to local hospital policy, however cultures were required. If therapeutic antibiotics were given, prophylactic antibiotics (when applicable) needed to be discontinued.

The percentage of patients who developed FN was the primary endpoint. Secondary endpoints were the FN rates per cycle number, incidence of other grade III/IV haematological and non-haematological toxicities (according to $\mathrm{NCl}-\mathrm{CTC}$ criteria version 3.0), the number of deaths due to toxicity, the number of chemotherapy cycles delivered, and the dose-intensity and the cumulative dose of administered chemotherapy.

Even if primary G-CSF prophylaxis during all chemotherapy cycles would be more effective, one may still argue effectiveness is an insufficient reason for continued GCSF prophylaxis as costs have not been taken into account. The primary objective of the cost-effectiveness analysis was, therefore, to evaluate the difference in costs in relation to the difference in effects (proportion of patients with episodes of FN prevented) between the two strategies. In chapter 3, the results regarding costeffectiveness along the randomized clinical trial are presented.

From our trial-based economic analysis, it may be difficult to conclude whether G-CSF prophylaxis can be considered cost-effective or not, as the willingness to pay (WTP) per patient with episode of FN prevented is not known. Moreover, the role of secondary prophylaxis was not investigated. Therefore, we used a model-based economic evaluation to incorporate quality-adjusted life-years (QALYs; for which informal WTP values exist) as an outcome. We used the model also to assess whether 
limiting primary G-CSF prophylaxis to the first two chemotherapy cycles only (without or with secondary prophylaxis) was cost-effective compared to continued primary GCSF prophylaxis. The results of the model-based economic evaluation are reported in chapter 4.

The primary goal of the study presented in chapter $\mathbf{5}$ was to determine whether there is a protective effect of prior chemotherapy or of prior G-CSF on the blood cell counts of the next cycle.

We evaluated the hematologic toxicity, based on the randomized phase III study presented in chapter 2 . For the current analyses, patients who developed FN during treatment, or who underwent modifications of chemotherapy or G-CSF treatment during treatment were excluded. The primary endpoint was the nadir blood cell counts over cycles 1 through 6 for patients in the standard arm and over cycles 3 through 6 for patients in the experimental arm.

The study presented in chapter 6 was designed to determine whether delivering neoadjuvant chemotherapy at a higher dose in a shorter period of time improves outcome of breast cancer patients. In this study, women with newly diagnosed breast cancer were randomly assigned to neoadjuvant chemotherapy consisting of four cycles of doxorubicin and cyclophosphamide followed by four cycles of docetaxel (AC $\left.60 / 600-\mathrm{T} 100 \mathrm{mg} / \mathrm{m}^{2}\right)$ or six cycles of TAC $\left(75 / 50 / 500 \mathrm{mg} / \mathrm{m}^{2}\right)$ every three weeks. Patients who were treated with sequential chemotherapy did not receive primary GCSF prophylaxis. During TAC chemotherapy primary G-CSF prophylaxis was mandatory to obtain a higher dose-intensity over 18 weeks of treatment. Primary endpoint was the pathologic complete response ( $\mathrm{pCR}$ ) rate, defined as no invasive tumor present.

Chapter $\mathbf{7}$ describes a summary, general conclusions, and future perspectives. 


\section{References}

1. http://www.cijfersoverkanker.nl

2. Goldhirsch A, Ingle JN, Gelber RD, Coates AS, Thürlimann B, Senn HJ; Panel members. Thresholds for therapies: highlights of the St Gallen International Expert Consensus on the primary therapy of early breast cancer 2009. Ann Oncol 2009;20:1319-29.

3. Kaufmann M, von Minckwitz G, Bear HD, Buzdar A, McGale P, Bonnefoi H, Colleoni M, Denkert C, Eiermann W, Jackesz R, Makris A, Miller W, Pierga JY, Semiglazov V, Schneeweiss A, Souchon R, Stearns V, Untch M, Loibl S. Recommendations from an international expert panel on the use of neoadjuvant (primary) systemic treatment of operable breast cancer: new perspectives. Ann Oncol 2007;18:1927-34.

4. Early Breast Cancer Trialists' Collaborative Group (EBCTCG). Effects of chemotherapy and hormonal therapy for early breast cancer on recurrence and 15-year survival: an overview of the randomized trials. Lancet 2005;365:1687-717.

5. Martin M, Pienkowski T, Mackey J, Pawlicki M, Guastalla JP, Weaver C, Tomiak E, Al-Tweigeri T, Chap L, Juhos E, Guevin R, Howell A, Fornander T, Hainsworth J, Coleman R, Vinholes J, Modiano M, Pinter T, Tang SC, Colwell B, Prady C, Provencher L, Walde D, Rodriguez-Lescure A, Hugh J, Loret C, Rupin M, Blitz S, Jacobs P, Murawsky M, Riva A, Vogel C; Breast Cancer International Research Group 001 Investigators. Adjuvant Docetaxel for node-positive breast cancer. N Engl J Med 2005;22:2302-13.

6. Kuderer NM, Dale DC, Crawford J, Cosler LE, Lyman GH. Mortality, morbidity, and cost associates with febrile neutropenia in adult cancer patients. Cancer 2006;106:2258-66.

7. Cullen M, Baijal S. Prevention of febrile neutropenia: use of prophylactic antibiotics. Br J Cancer 2009;101 Suppl 1:S11-4.

8. Crawford J, Ozer H, Stoller R, Johnson D, Lyman G, Tabbara I, Kris M, Grous J, Picozzi V, Rausch G, Smith R, Gradishar W, Yahanda A, Vincent M, Stewart M, Glaspy J. Reduction by granulocyte colonystimulating factor of fever and neutropenia induced by chemotherapy in patients with small-cell lung cancer. N Engl J Med 1991;325:164-70.

9. Smith TJ, Khatcheressian J, Lyman GH, Ozer H, Armitage JO, Balducci L, Bennett CL, Cantor SB, Crawford J, Cross SJ, Demetri G, Desch CE, Pizzo PA, Schiffer CA, Schwartzberg L, Somerfield MR, Somlo G, Wade JC, Wade JL, Winn RJ, Wozniak AJ, Wolff AC. 2006 Update of recommendations for the use of white blood cell growth factors: an evidence-based clinical practice guideline. J Clin Oncol 2006;24:3187-205.

10. Aapro MS, Bohlius J, Cameron DA, Dal Lago L, Donnelly JP, Kearney N, Lyman GH, Pettengell R, TjanHeijnen VC, Walewski J, Weber DC, Zielinski C; European Organisation for Research and Treatment of Cancer. 2010 update of EORTC guidelines for the use of granulocyte colony-stimulating factor to reduce the incidence of chemotherapy-induced febrile neutropenia in adult patients with lymphoproliferative disorders and solid tumors. Eur J Cancer 2011;47:8-32.

11. Timmer-Bonte JN, Adang EM, Smit HJ, Biesma B, Wilschut FA, Bootsma GP, de Boo TM, Tjan-Heijnen VC. Cost-effectiveness of adding granulocyte-colony stimulating factor to primary prophylaxis with antibiotics in patients with small cell lung cancer. J Clin Oncol 2006;24:2991-7.

12. Vogel CL, Wojtukiewicz MZ, Carroll RR, Tjulandin SA, Barajas-Figueroa $\amalg$, Wiens BL, Neumann TA, Schwartzberg LS. First and subsequent cycle use of pegfilgrastim prevents febrile neutropenia in patients with breast cancer: a multicenter, double-blind, placebo-controlled phase III study J Clin Oncol 2005;23:1178-84.

13. Martín M, Lluch A, Seguí MA, Ruiz A, Ramos M, Adrover E, Rodríguez-Lescure A, Grosse R, Calvo L, Fernandez-Chacón C, Roset M, Antón A, Isla D, del Prado PM, Iglesias L, Zaluski J, Arcusa A, LópezVega JM, Muñoz M, Mel JR. Toxicity and health-related quality of life in breast cancer patients receiving adjuvant docetaxel, doxorubicin, cyclophosphamide (TAC) or 5-fluorouracil, doxorubicin and cyclophosphamide (FAC): impact of adding primary prophylactic granulocyte-colony stimulating factor to the TAC regimen. Ann Oncol 2006;17:1205-12. 


\section{Chapter 2}

Primary granulocyte colony-stimulating factor prophylaxis during the first two cycles only or throughout all chemotherapy cycles in patients with breast cancer at risk for febrile neutropenia

Maureen J. Aarts, Frank P. Peters, Caroline M. Mandigers, M. Wouter Dercksen, Jacqueline M. Stouthard, Hans J. Nortier, Hanneke W. van Laarhoven, Laurence J. van Warmerdam, Agnes J. van de Wouw, Esther M. Jacobs, Vera Mattijssen, Carin C. van der Rijt, Tineke J. Smilde, Annette W. van der Velden, Mehmet Temizkan, Erdogan Batman, Erik W. Muller, Saskia M. van Gastel, George F. Borm, and Vivianne C.G. Tjan-Heijnen Journal of Clinical Oncology 2013;31:4290-6 


\section{Abstract}

Purpose

Early breast cancer is commonly treated with anthracyclines and taxanes. However, combining these drugs increases the risk of myelotoxicity and may require granulocyte colony-stimulating factor (G-CSF) support. The highest incidence of febrile neutropenia (FN) and largest benefit of G-CSF during the first cycles of chemotherapy lead to questions about the effectiveness of continued use of G-CSF throughout later cycles of chemotherapy.

\section{Patients and methods}

In a multicenter study, patients with breast cancer who were considered fit enough to receive 3-weekly polychemotherapy, but also had $>20 \%$ risk for $\mathrm{FN}$, were randomly assigned to primary G-CSF prophylaxis during the first two chemotherapy cycles only (experimental arm) or to primary G-CSF prophylaxis throughout all chemotherapy cycles (standard arm). The noninferiority hypothesis was that the incidence of $\mathrm{FN}$ would be maximally $7.5 \%$ higher in the experimental compared with the standard arm.

\section{Results}

After inclusion of 167 eligible patients, the independent data monitoring committee advised premature study closure. Of 84 patients randomly assigned to G-CSF throughout all chemotherapy cycles, eight (10\%) experienced an episode of FN. In contrast, of 83 patients randomly assigned to G-CSF during the first two cycles only, 30 (36\%) had an $\mathrm{FN}$ episode $(95 \% \mathrm{Cl}, 0.13$ to 0.54 ), with a peak incidence of $24 \%$ in the third cycle (ie, first cycle without G-CSF prophylaxis).

\section{Conclusion}

In patients with early breast cancer at high risk for FN, continued use of primary G-CSF prophylaxis during all chemotherapy cycles is of clinical relevance and thus cannot be abandoned. 


\section{Introduction}

Febrile neutropenia (FN) is a adverse effect of cancer treatment, sometimes causing life-threatening infections. ${ }^{1}$ Given its seriousness, a majority of these patients are admitted to the hospital for treatment with intravenous antibiotics. Chemotherapyinduced FN may also result in modifications in chemotherapy dose or schedule, which may compromise treatment efficacy. Clearly, prevention of chemotherapy induced FN is a medical priority. ${ }^{2}$

Prophylactic antibiotics and granulocyte colony-stimulating factor (G-CSF) have proven efficacy in preventing chemotherapy-related FN. ${ }^{3,4}$ However, antibiotics may lead to emergence of microbial resistance. G-CSF has only a few adverse effects, but it is expensive. Initially, guidelines recommended primary G-CSF prophylaxis only for patients at substantial risk for FN (>40\%). However, updated G-CSF guidelines have concluded that primary G-CSF prophylaxis has clinical benefits for patients at $>20 \%$ risk for FN (grade A recommendation) and should therefore be offered to these patients. 5,6

We have previously reported that in the Netherlands, even for patients with considerable risk for FN, primary G-CSF prophylaxis comes with significant extra cost: on average, 5,123 euro (US $\$ 6,788$ ) per patient with a baseline risk for FN of $32 \%{ }^{7}$ With the introduction of, among others, the combined use of anthracyclines and taxanes in the neoadjuvant or adjuvant breast cancer setting, the number of patients who are candidates for prophylactic G-CSF use has sharply increased, with a resultant impact on health care resources. For the Netherlands, this will concern several thousands of patients yearly across all tumor types, involving an increase in cost of at least 10 to 20 million euros each year.

Interestingly, we and others have observed that irrespective of tumortype or chemotherapy regimen, the risk for FN is highest during the first two cycles of chemotherapy. ${ }^{3,8-10}$ Thereafter, the risk rapidly declines, and the benefit of G-CSF largely seems to disappear. Hence, we hypothesized that to improve the cost effectiveness of primary G-CSF prophylaxis, G-CSF use may be limited to the first chemotherapy cycles, in contrast to the current practice of continued G-CSF prophylaxis. However, prospective data on the safety of such an approach were lacking. Therefore, we performed an open-label randomized phase III study in patients with breast cancer, addressing whether G-CSF prophylaxis could be limited to the first two chemotherapy cycles as compared with the current practice of continuous G-CSF prophylaxis during all chemotherapy cycles. 


\section{Patients and methods}

\section{Patients}

Patients with breast cancer with an indication for every-3-weeks chemotherapy in the adjuvant, neoadjuvant, or advanced setting were eligible, if there was an increased risk for FN. The chemotherapy regimens included regimens with either $>20 \%$ risk for FN - such as TAC (docetaxel, doxorubicin, cyclophosphamide) and AT (doxorubicin, docetaxel), among others - or $10 \%$ to $20 \%$ risk for FN - such as TC (docetaxel, cyclophosphamide) $)^{11,12}$ and docetaxel monotherapy (eg, as part of FEC-D [fluorouracil, epirubicin, cyclophosphamide, docetaxel]) - in the presence of $\geq$ one patient risk factors for FN. FN risk factors included age $>65$ years, extensive bone marrow involvement or prior extensive radiotherapy on bone, prior chemotherapy, Eastern Cooperative Oncology Group (ECOG) performance status $\geq 2$, and grade $\geq 2$ liver function abnormalities. Patients who were treated with FEC-D were eligible for the final three docetaxel cycles; these patients were in fact randomly assigned to G-CSF during the first two cycles or during all three cycles of docetaxel chemotherapy. Patients were excluded for any of the following: signs of an active uncontrolled infection, any evidence or history of hypersensitivity to G-CSF or other contraindications to its use, incomplete recovery from acute toxicities from prior therapies, or absolute neutrophil count (ANC) $<1.5 \times 10^{9} / \mathrm{L}$ not caused by bone marrow involvement.

The ethical committee of each institution approved the investigational protocol. Written informed consent was obtained from each participating patient.

\section{Study design}

Eligible patients were randomly assigned at a one-to-one ratio to primary G-CSF prophylaxis throughout all chemotherapy cycles (standard arm) or to primary G-CSF prophylaxis during the first two chemotherapy cycles only (experimental arm). Pegfilgrastim at a 6-mg fixed dose was administered 24 to 30 hours after chemotherapy administration. ${ }^{5,13}$ It was advised, but not mandatory, that primary prophylactic ciprofloxacin be used in both arms throughout all six chemotherapy cycles. Centers were stratified for use of prophylactic antibiotics.

The study protocol provided stringent definitions of FN and its management, according to current standards in the Netherlands. In summary, patients with fever had to contact their responsible physician. Fever was defined as a body temperature $\geq 38.5^{\circ} \mathrm{C}$ once or $\geq 38.0^{\circ} \mathrm{C}$ for $>12$ hours. In case of fever with neutropenia (ANC $\leq 0.5 \times 10^{9} / \mathrm{L}$ or ANC $\leq 1.0 \times 10^{9} / \mathrm{L}$ and expected to fall below 0.5 within the next 24 hours), the patient had be hospitalized, cultures had to be taken, and intravenous broadspectrum antibiotics had to be administered (preferably third-generation cephalosporin). In 
addition, standardized criteria had to be met before a patient could be discharged from the hospital (ie, temperature $<37.5^{\circ} \mathrm{C}$ for two consecutive days, no clinical signs of infection, and ANC $\geq 0.5 \times 10^{9} / \mathrm{L}$ ). Treating physicians were free to act according to local hospital policy in case of fever without neutropenia; however, cultures were mandatory. Prophylactic antibiotics, when applicable, had to be discontinued if therapeutic antibiotics were administered.

We recommended that maintaining full-dose chemotherapy in both treatment arms be considered and that secondary G-CSF prophylaxis not be administered in later chemotherapy cycles in the experimental arm after an uncomplicated FN episode. However, if the FN episode was complicated by septic shock, and/or ANC remained $<0.5 \times 10^{9} / \mathrm{L}$ for $\geq 7$ days, and/or platelet nadir count was $<25 \times 10^{9} / \mathrm{L}$, and/or grade 3 to 4 nonhematologic toxicity (except nausea/vomiting) occurred, we recommended a chemotherapy dose reduction of $25 \%$.

Nadir blood cell counts had to be measured once per cycle (between days 10 and 14). Other tumor or laboratory investigations were performed according to local practice. Safety was monitored by case report forms of adverse events and changes in laboratory values. An independent data monitoring committee (IDMC) performed planned safety analyses after every 50 patients included.

\section{Study objectives}

The primary end point was the percentage of patients who developed FN. Secondary end points were the $\mathrm{FN}$ rates per cycle number, incidence of other grade 3 to 4 hematologic and nonhematologic toxicities according to National Cancer Institute Common Toxicity Criteria (version 3.0), number of deaths resulting from toxicity per treatment arm, number of chemotherapy cycles delivered, and cumulative dose and dose-intensity of administered chemotherapy.

\section{Statistical analysis}

This study was designed as a noninferiority study. The primary efficacy postulation of this study was that the incidence of FN with primary G-CSF prophylaxis during the first two chemotherapy cycles only would not be inferior to primary G-CSF prophylaxis throughout all chemotherapy cycles, using a noninferiority margin of $7.5 \%$ difference. The incidence in the experimental group was expected to be $2 \%$ to $3 \%$ per cycle for cycles three to six. To test for noninferiority, a sample size of 105 assessable patients per treatment arm was needed to ensure an overall power of $80 \%$, using a two-sided significance level of $5 \%$. To account for dropouts, we aimed to include a total of 230 patients.

Patients were stratified according to use of primary antibiotic prophylaxis (yes $v$ no), setting (neoadjuvant or adjuvant $v$ advanced), age ( $\leq 65 v>65$ years), and ECOG 
performance status ( $\geq 2 \vee 0$ to 1 ). The Cochrane-Mantel-Haenszel approach was used to analyze the incidence of FN in the intention-to-treat population.

We performed a multivariate analysis of the risk for FN and time to first FN event after adjusting for patient risk factors, including age $>65$ years, prior chemotherapy use, ECOG performance status $\geq 2$, advanced disease stage, and previous episode of FN. Because there were no patients with grade $\geq 2$ liver function abnormalities, extensive bone marrow involvement, or prior extensive radiotherapy on bone, these parameters were not included in the multivariate analysis.

\section{Results}

\section{Patients}

From March 2008 to December 2009, 167 eligible patients (of 230 planned) were included from 21 centers in the Netherlands. At that point, random assignment was prematurely stopped after the recommendation of the IDMC because of an unexpected high $\mathrm{FN}$ rate in the experimental treatment arm.

The baseline characteristics were well balanced (Table 2.1). A majority of patients were age $<65$ years, had a ECOG performance score of 0 to 1 , and were treated in the neoadjuvant or adjuvant setting with TAC chemotherapy.

\section{FN}

The percentage of patients who developed $\mathrm{FN}$ was $10 \%$ in the standard treatment arm with continued G-CSF prophylaxis and $36 \%$ in the experimental treatment arm (Figure 2.1). The highest incidence of FN occurred in the third chemotherapy cycle of the experimental arm (24\% of patients); this was the first cycle without G-CSF prophylaxis (Table 2.2). Almost all patients experienced only one FN episode. Once FN occurred, no difference between treatment arms was seen with regard to duration of FN and duration of hospital admission.

The odds ratio of risk for $\mathrm{FN}$ was $5.4(95 \% \mathrm{Cl}, 2.3$ to 12.6) for G-CSF prophylaxis limited to the first two cycles as opposed to continued G-CSF use if unadjusted for patientspecific risk factors; if adjusted for patient-specific risk factors, the odds ratio of risk for FN was $5.8(95 \% \mathrm{Cl}, 2.5$ to 13.8). The hazard ratio for the time to first FN event was $4.1(95 \% \mathrm{Cl}, 1.9$ to 9.0$)$ if unadjusted and 4.2 (95\% Cl, 1.9 to 9.1 ) if adjusted for patient-specific risk factors for G-CSF limited to the first two cycles as opposed to continued G-CSF use. 
Table 2.1 Baseline patient demographics and clinical characteristics.

\begin{tabular}{|c|c|c|c|c|}
\hline \multirow[b]{2}{*}{ Characteristic } & \multicolumn{2}{|c|}{$\begin{array}{l}\text { Standard arm } \\
\qquad \mathrm{n}=84^{*}\end{array}$} & \multicolumn{2}{|c|}{$\begin{array}{c}\begin{array}{c}\text { Experimental arm } \\
\mathrm{n}=83 \dagger\end{array} \\
\end{array}$} \\
\hline & No. & $(\%)$ & No. & $(\%)$ \\
\hline \multicolumn{5}{|l|}{ Age, years } \\
\hline Median & \multicolumn{2}{|c|}{50} & \multicolumn{2}{|c|}{50} \\
\hline Range & \multicolumn{2}{|c|}{$26-69$} & \multicolumn{2}{|c|}{$31-70$} \\
\hline$\leq 65 \mathrm{yr}$ & 79 & 94 & 78 & 94 \\
\hline$>65 \mathrm{yr}$ & 5 & 6 & 5 & 6 \\
\hline \multicolumn{5}{|l|}{ ECOG PS } \\
\hline 0 & 76 & 90 & 71 & 86 \\
\hline 1 & 5 & 6 & 10 & 12 \\
\hline unknown & 3 & 4 & 2 & 2 \\
\hline \multicolumn{5}{|c|}{ Treatment setting } \\
\hline Neoadjuvant & 11 & 13 & 12 & 14 \\
\hline Adjuvant & 73 & 87 & 68 & 82 \\
\hline Advanced & 0 & 0 & 3 & 4 \\
\hline \multicolumn{5}{|c|}{ Primary Antibiotics prophylaxis, } \\
\hline Yes & 34 & 40 & 36 & 43 \\
\hline No & 50 & 60 & 47 & 57 \\
\hline \multicolumn{5}{|l|}{ Chemotherapy } \\
\hline TAC & 81 & 96 & 77 & 93 \\
\hline FEC-D & 3 & 4 & 3 & 4 \\
\hline DOC & 0 & 0 & 2 & 2 \\
\hline TC & 0 & 0 & 1 & 1 \\
\hline \multicolumn{5}{|l|}{ WBC, $\times 10^{9} / \mathrm{L}$} \\
\hline Median & \multicolumn{2}{|c|}{7.7} & \multicolumn{2}{|c|}{7.6} \\
\hline Range & \multicolumn{2}{|c|}{$3.4-21.1$} & \multicolumn{2}{|c|}{$4.3-18.0$} \\
\hline \multicolumn{5}{|l|}{ ANC, $\left.\times 10^{9} / \mathrm{L}\right)$} \\
\hline Median & \multicolumn{2}{|c|}{4.8} & \multicolumn{2}{|c|}{4.5} \\
\hline Range & \multicolumn{2}{|c|}{$2.0-64.3$} & \multicolumn{2}{|c|}{$2.1-16.2$} \\
\hline \multicolumn{5}{|c|}{ Platelet count, (x10 /I) } \\
\hline Median & \multicolumn{2}{|c|}{296} & \multicolumn{2}{|c|}{289} \\
\hline Range & \multicolumn{2}{|c|}{$129-541$} & \multicolumn{2}{|c|}{$160-544$} \\
\hline
\end{tabular}

ANC, absolute neutrophil count; DOC, docetaxel; ECOG PS, Eastern Cooperative Oncology Group performance score; FEC-D, fluorouracil, epirubicin, cyclophosphamide-docetaxel; G-CSF, granulocyte colony stimulating factor; TAC, docetaxel, doxorubicin, cyclophosphamide; TC, docetaxel, cyclophosphamide. * GCSF administered during chemotherapy cycles one to six; +G-CSF administered during chemotherapy cycles one to two.

\section{Other grade 3 to 4 toxicities}

Fever without neutropenia occurred in $19 \%$ of patients in both treatment arms (Table 2.3). The clinically documented site of infection was predominantly respiratory, whereas in $7 \%$ of patients, no clinical site was identified. Microbiologic documented infections occurred more often in the experimental arm, in five patients, versus in two patients in the standard arm. No Gram-negative infections were documented in the standard arm versus in three patients in the experimental arm. Of the patients who developed FN, only one patient had a documented Gram-positive infection. 


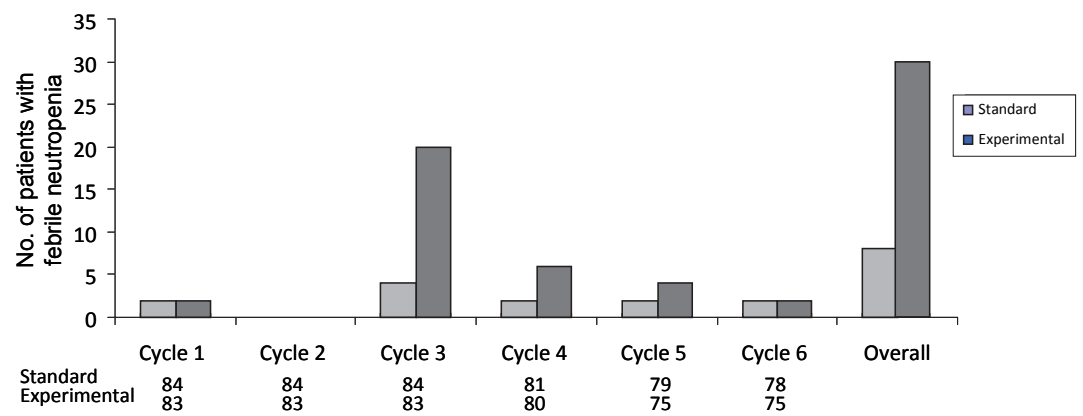

Figure 2.1 Incidence febrile neutropenia (FN) per treatment arm.

Grade 3 to 4 neutropenia occurred in $6 \%$ of patients in the standard arm versus $51 \%$ of patients in the experimental arm. Other hematologic toxicities were mild, and occurrence was low. Nonhematologic toxicity was mainly Gl. We observed nearly no grade 4 mucositis (one patient with grade 3 diarrhea); incidence of mucositis was comparable for both treatment arms.

In the standard treatment arm, 18 patients (21\%) were admitted to the hospital versus 13 patients (16\%) in the experimental arm, mainly for Gl complaints or fever. Adverse events resulting in hospitalization occurred predominantly during the first two chemotherapy cycles in the standard arm versus an equal distribution over cycles one to five in the experimental arm. No patient died as a result of infection or other toxicity.

\section{Delivered chemotherapy and secondary FN prophylaxis}

Premature chemotherapy cessation because of toxicity was not different between both treatment arms: $5 \%$ of patients in the standard arm and $6 \%$ of patients in the experimental arm. Nearly all included patients received TAC chemotherapy. For these patients, we calculated the median delivered cumulative dose and dose-intensity, which was not different between both treatment arms (Table 2.4). Chemotherapy dose delay occurred in $11 \%$ of patients in the standard arm and in $6 \%$ of patients in the experimental arm, whereas dose reductions occurred in $8 \%$ of patients in both treatment arms. In the experimental arm, $7 \%$ of 83 patients received secondary antibiotic prophylaxis, and $17 \%$ of 83 patients received secondary G-CSF prophylaxis, whereas in the standard arm, $5 \%$ of 84 patients received secondary antibiotic prophylaxis because of an FN episode. 
Table 2.2 Incidence and duration of FN

\begin{tabular}{|c|c|c|c|c|c|c|}
\hline \multirow[b]{2}{*}{ Characteristics } & \multicolumn{2}{|c|}{$\begin{array}{l}\text { Standard arm } \\
\qquad(n=84)^{*}\end{array}$} & \multicolumn{2}{|c|}{$\begin{array}{c}\text { Experimental } \\
\text { arm } \\
(\mathrm{n}=83)^{\dagger}\end{array}$} & \multirow[b]{2}{*}{$\mathrm{RR}$} & \multirow[b]{2}{*}{$95 \% \mathrm{Cl}$} \\
\hline & No. & (\%) & No. & $(\%)$ & & \\
\hline \multicolumn{7}{|c|}{ Patients with FN, clycle $¥$} \\
\hline One & 2 & 2 & 2 & 2 & & \\
\hline Two & 0 & 0 & 0 & 0 & & \\
\hline Three & 4 & 5 & 20 & 24 & & \\
\hline Four & 2 & 2 & 6 & 7 & & \\
\hline Five & 2 & 2 & 4 & 5 & & \\
\hline Six & 2 & 2 & 2 & 2 & & \\
\hline Overall incidence & 8 & 10 & 30 & 36 & 0.26 & $0.13-0.54$ \\
\hline \multicolumn{7}{|c|}{ No. of episodes per patient } \\
\hline 0 & 76 & 90 & 55 & 66 & & \\
\hline 1 & 6 & 7 & 26 & 31 & & \\
\hline 2 & 1 & 1 & 4 & 5 & & \\
\hline 3 & 0 & 0 & 0 & 0 & & \\
\hline \multirow[t]{3}{*}{4} & 1 & 1 & 0 & 0 & & \\
\hline & \multicolumn{4}{|c|}{ Standard arm $(n=84)^{*}$} & \multicolumn{2}{|c|}{ Experimental arm $(n=83)^{\dagger}$} \\
\hline & & & & & Median & Range \\
\hline \multicolumn{7}{|c|}{ Duration in days of $\mathrm{FN}$, cycle } \\
\hline One & & & & & 1 & $1-1$ \\
\hline Two & & & & & 0 & 0 \\
\hline Three & & & & & 2 & $1-6$ \\
\hline Four & & & & & 3 & $2-5$ \\
\hline Five & & & & & 3 & $2-7$ \\
\hline Six & & & & & 2 & $1-2$ \\
\hline All cycles & & & & & 2 & $1-7$ \\
\hline \multicolumn{7}{|c|}{ Duration in days of admission for FN, cycle } \\
\hline One & & & & & 3 & $2-4$ \\
\hline Two & & & & & 0 & 0 \\
\hline Three & & & & & 5 & $3-8$ \\
\hline Four & & & & & 6 & $4-7$ \\
\hline Five & & & & & 7 & $6-8$ \\
\hline Six & & & & & 0 & 0 \\
\hline All cycles & & & & & 5 & $2-8$ \\
\hline
\end{tabular}

FN, febrile neutropenia; G-CSF, granulocyte colony-stimulating factor; RR, relative risk. * G-CSF administered during chemotherapy cycles one to six. + G-CSF administered during chemotherapy cycles one to two; $¥$ Total patient numbers in cycles four to six were as follows: cycle four: standard, 81; experimental, 80; cycle five: standard, 79; experimental, 75; cycle six: standard, 78; experimental, 75. 
Table 2.3 Fever and infection and CTC grades 3 and 4 hematologic and nonhematologic toxicities.

\begin{tabular}{|c|c|c|c|c|}
\hline \multirow[b]{2}{*}{$A E$} & \multicolumn{2}{|c|}{ Standard $\operatorname{arm}(\mathrm{n}=84)^{*}$} & \multicolumn{2}{|c|}{ Experimental arm $(n=83) \dagger$} \\
\hline & No. & $(\%)$ & No. & $(\%)$ \\
\hline \multicolumn{5}{|l|}{ Fever overall } \\
\hline Without leucopenia and/or neutropenia & 16 & 19 & 16 & 19 \\
\hline With leucopenia and/or neutropenia & 13 & 15 & 39 & 47 \\
\hline \multicolumn{5}{|l|}{ Site of infection (No.of episodes) } \\
\hline All infections & 43 & 51 & 64 & 77 \\
\hline Respiratory & 21 & 25 & 37 & 45 \\
\hline Non-Respiratory & 22 & 26 & 27 & 33 \\
\hline No. clinical site identified & 5 & 6 & 6 & 7 \\
\hline \multicolumn{5}{|l|}{ Gram-positive infections over all cycles } \\
\hline No. of patients & 2 & 2 & 2 & 2 \\
\hline No. of infections & 1 & 1 & 1 & 1 \\
\hline \multicolumn{5}{|l|}{ Gram-negative infections over all cycles } \\
\hline No. of patients & 0 & 0 & 3 & 4 \\
\hline No. of infections & 0 & 0 & 2 & 2 \\
\hline \multicolumn{5}{|l|}{ Hematologic toxicity } \\
\hline \multicolumn{5}{|l|}{ Neutropenia } \\
\hline Grade 3 & 1 & 1 & 10 & 12 \\
\hline Grade 4 & 4 & 5 & 32 & 39 \\
\hline \multicolumn{5}{|l|}{ Platelet } \\
\hline Grade 3 & 2 & 2 & 0 & 0 \\
\hline Grade 4 & 0 & 0 & 0 & 0 \\
\hline \multicolumn{5}{|l|}{ Hemoglobin } \\
\hline Grade 3 & 0 & 0 & 1 & 1 \\
\hline Grade 4 & 0 & 0 & 0 & 0 \\
\hline \multicolumn{5}{|l|}{ Non-Hematologic toxicity } \\
\hline \multicolumn{5}{|l|}{$\mathrm{Gl}$} \\
\hline Mucositis & 6 & 7 & 6 & 7 \\
\hline Nausea / vomiting & 6 & 7 & 5 & 6 \\
\hline Neurological symptoms & 1 & 1 & 3 & 4 \\
\hline Musculoskeletal effect & 1 & 1 & 2 & 2 \\
\hline Other & 8 & 10 & 4 & 5 \\
\hline Death due to infection and/or toxicity, overall & 0 & 0 & 0 & 0 \\
\hline
\end{tabular}

CTC, Common Toxicity Criteria (version 3.0); G-CSF, granulocyte colony-stimulating factor. * G-CSF administered during chemotherapy cycles one to six. + G-CSF administered during chemotherapy cycles one to two.

Table 2.4 Delivered treatment for patients who received TAC chemotherapy.

\begin{tabular}{|c|c|c|c|c|}
\hline & \multicolumn{2}{|c|}{ Standard arm $(n=81)^{*}$} & \multicolumn{2}{|c|}{ Experimental arm $(\mathrm{n}=77)^{\dagger}$} \\
\hline & Median & Range & Median & Range \\
\hline \multicolumn{5}{|c|}{ No. of chemotherapy cycles delivered } \\
\hline TAC & 6 & $3-6$ & 6 & $3-6$ \\
\hline \multicolumn{5}{|c|}{ Delivered cumulative dose, $\mathrm{mg} / \mathrm{m}^{2}$} \\
\hline Docetaxel & 449 & $294-474$ & 450 & $298-473$ \\
\hline Doxorubicin & 298 & $151-319$ & 300 & $193-318$ \\
\hline Cyclophosphamide & 2,997 & $1,926-3,176$ & 3,032 & $1,935-3,188$ \\
\hline \multicolumn{5}{|c|}{ Treatment duration, weeks } \\
\hline TAC & 126 & $84-141$ & 126 & $83-137$ \\
\hline
\end{tabular}

G-CSF, granulocyte colony-stimulating factor; TAC, docetaxel, doxorubicin, cyclophosphamide. * G-CSF administered during chemotherapy cycles one to six. + G-CSF administered during chemotherapy cycles one to two. 


\section{Discussion}

Worldwide, breast cancer is one of the most frequently occurring tumor types, now commonly treated with a combination of anthracyclines and taxanes. However, these drugs are myelotoxic, and combining them requires support with G-CSF, according to updated G-CSF guidelines. ${ }^{5}$ In contrast to what was long presumed, incidence of FN is not cumulative with the number of cycles received; rather, it seems to be highest during the first two cycles of chemotherapy. Therefore, we questioned the effectiveness of continued G-CSF prophylaxis throughout later cycles of chemotherapy. To assess the safety of omitting G-CSF prophylaxis during later chemotherapy cycles, we conducted a randomized phase III study with a noninferiority design: in the standard arm, primary G-CSF prophylaxis throughout all chemotherapy cycles; in the experimental arm, primary G-CSF prophylaxis only in the first two cycles. To our knowledge, ours is the first study with such a design. We intended to include 230 patients and to accept a maximally $7.5 \%$ higher $\mathrm{FN}$ rate in the experimental arm. However, at a planned safety review, the IDMC advised premature closure of the study. The patients receiving experimental treatment had an unacceptable high FN rate of $36 \%$. Remarkably, the majority of episodes occurred in the third chemotherapy cycle-the first cycle without G-CSF prophylaxis. In the experimental arm, incidence of FN rapidly declined after cycle three, from $24 \%$ in cycle three to $7 \%, 5 \%$, and $2 \%$ in cycles four, five, and six, respectively.

Secondary G-CSF prophylaxis was used in 14 of 20 patients in the experimental arm who developed FN in the third chemotherapy cycle - the first cycle without primary GCSF prophylaxis - which may be a possible explanation for the declining incidence of $\mathrm{FN}$ in later cycles. Efficacy of secondary G-CSF prophylaxis is not well established. Use of secondary G-CSF prophylaxis was based on the landmark G-CSF registration trial, in which patients in the placebo arm who developed FN were allowed to receive openlabel G-CSF in subsequent cycles of chemotherapy, with an observed reduction in the FN rate from $100 \%$ in cycle one to $23 \%$ in cycle two. ${ }^{14}$ Because many trials report a decline in incidence of $\mathrm{FN}$ in later cycles, even without administering additional prophylaxis, no definite conclusions on the efficacy of secondary prophylaxis could be drawn from this observation. However, we observed that of six patients in the experimental arm who continued chemotherapy but did not receive secondary G-CSF prophylaxis after an FN episode in the third cycle, three patients (50\%) experienced a second FN event, whereas only $21 \%$ of patients (three of 14 ) who did receive secondary G-CSF prophylaxis had a second FN event during a later cycle of chemotherapy. This observation supports the idea that secondary G-CSF prophylaxis is indeed effective.

Also, the administration of secondary antibiotic prophylaxis, which was used in $7 \%$ of patients in the experimental arm who continued treatment, might be a contributing factor for the declining incidence of FN in later cycles. Previously, we showed that the 
addition of antibiotic prophylaxis to G-CSF prophylaxis was effective in reducing the incidence of $\mathrm{FN}^{3}$ In a German study of patients with breast cancer receiving TAC chemotherapy, pegfilgrastim with or without ciprofloxacin was significantly more effective in preventing FN than daily G-CSF or ciprofloxacin as single prophylactic measures. ${ }^{10}$ For the combination, incidence of $\mathrm{FN}$ was $5 \%$; for pegfilgrastim alone, it was $7 \%$, compared with $18 \%$ for daily G-CSF and $22 \%$ for ciprofloxacin. Hence, the absolute impact of ciprofloxacin prophylaxis seems quite small.

Finally, chemotherapy dose reductions or premature treatment cessations might in part also explain the declining $\mathrm{FN}$ incidence during later chemotherapy cycles. However, although $6 \%$ of patients prematurely stopped treatment, none did so because of an FN event, and frequency of treatment discontinuation was not different between treatment arms. Of note, among the patients who developed FN, 33\% had a chemotherapy dose reduction because of nonhematologic toxicity.

Recently, a meta-analysis by Younis et al. ${ }^{11}$ showed that FN risk with TC was higher (29\%) than originally reported by Jones et al. ${ }^{12}(5 \%)$. The incidence of FN that we observed in our experimental arm is in essence comparable to the FN incidence observed during TAC chemotherapy, if G-CSF is applied only as secondary FN prophylaxis. In the BCIRG (Breast Cancer International Research Group) 001 study, patients with node-positive breast cancer were randomly assigned to receive either TAC or FAC chemotherapy. ${ }^{15}$ Primary G-CSF prophylaxis was not permitted, whereas secondary G-CSF prophylaxis was mandatory. Incidence of FN in the TAC group was 25\%; in the FAC group, it was 3\%. In the GEICAM (Grupo Español de Investigación del Cáncer de Mama) 9805 study, patients with high-risk NO breast cancer treated with TAC chemotherapy received either secondary G-CSF prophylaxis (TAC pregroup) or, after a study amendment, primary G-CSF prophylaxis (TAC postgroup). ${ }^{9}$ Without primary prophylaxis, incidence of $\mathrm{FN}$ was $27 \%$, whereas with primary prophylaxis continued during all cycles, incidence was $7 \%$. Clearly, as can be seen from both studies, secondary G-CSF prophylaxis does not affect overall FN incidence when expressed per patient, because the patient already has developed a first episode of FN.

Patient-related risk factors that influence FN risk include older age ( $\geq 65$ years), advanced disease stage, and experience of previous episodes of FN. Also, poor performance score, prior chemotherapy, and comorbidity are relevant. ${ }^{16}$ In our patient population, we could not identify any risk factor as influential in the risk for FN or time to first FN event, because our homogenous patient population predominantly consisted of younger patients with a good performance score and neoadjuvant or adjuvant treatment setting.

In conclusion, combining myelotoxic drugs for patients with early breast cancer at high risk for FN requires G-CSF prophylaxis according to international guidelines. We tested the hypothesis that limiting primary G-CSF prophylaxis to the first two chemotherapy cycles would be a safe way to improve cost effectiveness. This study 
demonstrated that primary pegfilgrastim prophylaxis cannot be limited to the first two chemotherapy cycles because of an unacceptable high FN rate of $36 \%$. In fact, this rate is as high as that reported in previous studies of TAC chemotherapy without primary G-CSF prophylaxis. On the basis of our results, we can only recommend continued use. Whether administration should continue past the third cycle was not tested, and hence, our recommendation cannot speculate on that. Therefore, we recommend primary G-CSF prophylaxis throughout all chemotherapy cycles in patients at risk for FN. 


\section{References}

1. Kuderer NM, Dale DC, Crawford J, Cosler LE, Lyman GH. Mortality, morbidity, and cost associated with febrile neutropenia in adult cancer patients. Cancer 2006;106:2258-66.

2. Wildiers $\mathrm{H}$, Reiser $\mathrm{M}$. Relative dose intensity of chemotherapy and its impact on outcome in patients with early breast cancer or aggressive lymphoma. Crit Rev Oncol Hematol 2011;77:221-40.

3. Timmer-Bonte JN, de Boo TM, Smit HJ, Biesma B, Wilschut FA, Cheragwandi SA, Termeer A, Hensing CA, Akkermans J, Adang EM, Bootsma GP, Tjan-Heijnen VC. Prevention of chemotherapy-induced febrile neutropenia by prophylactic antibiotics plus or minus granulocyte-colony stimulating factor: A Dutch randomized phase III study. J Clin Oncol 2005;23:7974-84.

4. Cullen M, Baijal S. Prevention of febrile neutropenia: Use of prophylactic antibiotics. Br J Cancer 2009;101 Suppl 1:S11-4.

5. Aapro MS, Bohlius J, Cameron DA, Dal Lago L, Donnelly JP, Kearney N, Lyman GH, Pettengell R, TjanHeijnen VC, Walewski J, Weber DC, Zielinski C; European Organisation for Research and Treatment of Cancer. 2010 update of EORTC guidelines for the use of granulocyte colony-stimulating factor to reduce the incidence of chemotherapy-induced febrile neutropenia in adult patients with lymphoproliferative disorders and solid tumors. Eur J Cancer 2011;47:8-32.

6. Smith TJ, Khatcheressian J, Lyman GH, Ozer H, Armitage JO, Balducci L, Bennett CL, Cantor SB, Crawford J, Cross SJ, Demetri G, Desch CE, Pizzo PA, Schiffer CA, Schwartzberg L, Somerfield MR, Somlo G, Wade JC, Wade JL, Winn RJ, Wozniak AJ, Wolff AC. 2006 update of recommendations for the use of white blood cell growth factors: An evidence-based clinical practice guideline. J Clin Oncol 2006;24:3187-205.

7. Timmer-Bonte JN, Adang EM, Smit HJ, Biesma B, Wilschut FA, Bootsma GP, de Boo TM, Tjan-Heijnen VC. Cost-effectiveness of adding granulocyte-colony stimulating factor to primary prophylaxis with antibiotics in patients with small-cell lung cancer. J Clin Oncol 2006;24:2991-7.

8. Vogel CL, Wojtukiewicz MZ, Carroll RR, Tjulandin SA, Barajas-Figueroa $\amalg$, Wiens BL, Neumann TA, Schwartzberg LS. First and subsequent cycle use of pegfilgrastim prevents febrile neutropenia in patients with breast cancer: A multicenter, double-blind, placebocontrolled phase III study. J Clin Oncol 2005;23:1178-84.

9. Martín M, Lluch A, Seguí MA, Ruiz A, Ramos M, Adrover E, Rodríguez-Lescure A, Grosse R, Calvo L, Fernandez-Chacón C, Roset M, Antón A, Isla D, del Prado PM, Iglesias L, Zaluski J, Arcusa A, LópezVega JM, Muñoz M, Mel JR. Toxicity and health-related quality of life in breast cancer patients receiving adjuvant docetaxel, doxorubicin, cyclophosphamide(TAC)or5-fluorouracil,doxorubicin and cyclophosphamide (FAC): Impact of adding primary prophylactic granulocyte colony stimulating factor to the TAC regimen. Ann Oncol 2006;17:1205-12.

10. von Minckwitz G, Kümmel S, du Bois A, Eiermann W, Eidtmann H, Gerber B, Hilfrich J, Huober J, Costa SD, Jackisch C, Grasshoff ST, Vescia S, Skacel T, Loibl S, Mehta KM, Kaufmann M; German Breast Group. Pegfilgrastim +/- ciprofloxacin for primary prophylaxis with TAC (docetaxel/ doxorubicin/cyclofosphamide) chemotherapy for breast cancer: Results from the GEPARTIO study. Ann Oncol 2008;19:292-8.

11. Younis T, Rayson D, Thompson K. Primairy G-CSF prophylaxis for adjuvant TC or FEC-D chemotherapy outside of clinical trial settings; a systematic review and meta-analysis. Support Care Cancer 2012;20:2523-30.

12. Jones S, Holmes FA, O'Shaughnessy J, Blum JL, Vukelja SJ, Mclntyre KJ, Pippen JE, Bordelon JH, Kirby RL, Sandbach J, Hyman WJ, Richards DA, Mennel RG, Boehm KA, Meyer WG, Asmar L, Mackey D, Riedel S, Muss H, Savin MA. Docetaxel with cyclophosphamide is associated with an overall survival benefit compared with doxorubicin and cyclophosphamide: A 7-year follow-up of US Oncology Research Trial 9735. J Clin Oncol 2009;27:1177-83.

13. Burris HA, Belani CP, Kaufman PA, Gordon AN, Schwartzberg LS, Paroly WS, Shahin S, Dreiling L, Saven A. Pegfilgrastim on the same day versus next day of chemotherapy in patients with breast cancer, non-small-cell lung cancer, ovarian cancer, and non-Hodgkin's lymphoma: Results of four multicenter, double-blind, randomized phase II studies. J Oncol Pract 2010;6:133-40. 
14. Crawford J, Ozer H, Stoller R, Johnson D, Lyman G, Tabbara I, Kris M, Grous J, Picozzi V, Rausch G, Smith R, Gradishar W, Yahanda A, Vincent M, Stewart M, Glaspy J. Reduction by granulocyte colonystimulating factor of fever and neutropenia induced by chemotherapy in patients with small-cell lung cancer. N Engl J Med 1991;325:164-70.

15. Martin M, Pienkowski T, Mackey J, Pawlicki M, Guastalla JP, Weaver C, Tomiak E, Al-Tweigeri T, Chap L, Juhos E, Guevin R, Howell A, Fornander T, Hainsworth J, Coleman R, Vinholes J, Modiano M, Pinter T, Tang SC, Colwell B, Prady C, Provencher L, Walde D, Rodriguez-Lescure A, Hugh J, Loret C, Rupin M, Blitz S, Jacobs P, Murawsky M, Riva A, Vogel C; Breast Cancer International Research Group 001 Investigators. Adjuvant docetaxel for node-positive breastcancer. N Engl J Med 2005;352:2302-13.

16. Shayne M, Culakova E, Poniewierski MS, Wolff D, Dale DC, Crawford J, Lyman GH. Dose intensity and hematologic toxicity in older patients receiving systemic chemotherapy. Cancer 2007;110:1611-20. 


\section{Chapter 3}

\section{Cost effectiveness of primary pegfilgrastim prophylaxis in patients with breast cancer at risk of febrile neutropenia}

Maureen J. Aarts, Janneke P. Grutters, Frank P. Peters, Caroline M. Mandigers, M. Wouter Dercksen, Jacqueline M. Stouthard, Hans J. Nortier, Hanneke W. van Laarhoven, Laurence J. van Warmerdam, Agnes J. van de Wouw,

Esther M. Jacobs, Vera Mattijssen, Carin C. van der Rijt, Tineke J. Smilde, Annette W. van der Velden, Mehmet Temizkan, Erdogan Batman, Erik W. Muller, Saskia M. van Gastel, Manuela A. Joore, George F. Borm, and Vivianne C. Tjan-Heijnen 


\section{Abstract}

Purpose

Guidelines advise primary granulocyte colony-stimulating factor (G-CSF) prophylaxis during chemotherapy if risk of febrile neutropenia (FN) is more than $20 \%$, but this comes with considerable costs. We investigated the incremental costs and effects between two treatment strategies of primary pegfilgrastim prophylaxis.

\section{Methods}

Our economic evaluation used a health care perspective and was based on a randomized study in patients with breast cancer with increased risk of FN, comparing primary G-CSF prophylaxis throughout all chemotherapy cycles (G-CSF 1-6 cycles) with prophylaxis during the first two cycles only (G-CSF 1-2 cycles). Primary outcome was cost effectiveness expressed as costs per patient with episodes of $\mathrm{FN}$ prevented.

\section{Results}

The incidence of $\mathrm{FN}$ increased from 10\% in the G-CSF 1 to 6 cycles study arm (eight of 84 patients) to $36 \%$ in the G-CSF 1 to 2 cycles study arm (30 of 83 patients), whereas the mean total costs decreased from $€ 20,658(95 \% \mathrm{Cl}, € 20,049$ to $€ 21,247)$ to $€ 17,168(95 \% \mathrm{Cl} € 16,239$ to $€ 18,029)$ per patient, respectively. Chemotherapy and G-CSF determined $80 \%$ of the total costs. As expected, FN-related costs were higher in the G-CSF 1 to 2 cycles arm. The incremental cost effectiveness ratio for the G-CSF 1 to 6 cycles arm compared with the G-CSF 1 to 2 cycles arm was $€ 13,112$ per patient with episodes of FN prevented.

\section{Conclusion}

We conclude that G-CSF prophylaxis throughout all chemotherapy cycles is more effective, but more costly, compared with prophylaxis limited to the first two cycles. Whether G-CSF prophylaxis throughout all chemotherapy cycles is considered cost effective depends on the willingness to pay per patient with episodes of FN prevented. 


\section{Introduction}

A major complication of cancer treatment is febrile neutropenia (FN). Treatment of this complication consumes a large part of direct medical costs of cancer care, primarily owing to hospitalization costs. The risk of infection and mortality increases in direct relation to the duration and severity of neutropenia and patient-related factors. ${ }^{1}$ Prophylactic use of granulocyte colony-stimulating factor (G-CSF) significantly reduces the duration and severity of neutropenia and, thereby, the number of days of hospitalization. ${ }^{2}$

Anthracyclines and docetaxel, now commonly used drugs for the adjuvant treatment of early breast cancer, are myelotoxic and need G-CSF support. Other chemotherapy regimens with lower risk of $\mathrm{FN}$ are available but have other undesirable adverse effects.

The initial guidelines on G-CSF prophylaxis recommended primary G-CSF prophylaxis for patients with an estimated risk of FN of more than $40 \%{ }^{3}$ Updated guidelines from European Organisation for Research and Treatment of Cancer, the American Society of Clinical Oncology, and the National Comprehensive Cancer Network lowered the FN risk threshold from $40 \%$ to $20 \%$ for primary G-CSF prophylaxis, based on clinical grounds. ${ }^{4-6}$ Obviously, this had a tremendous impact on health care resource use, leading to an estimated cost increase over the last decade of at least 10 to 20 million euros per year in the Netherlands.

Recently, we reported the results of a multicenter randomized phase III trial that evaluated the effectiveness of primary G-CSF prophylaxis during all chemotherapy cycles compared with primary G-CSF prophylaxis limited to the first two chemotherapy cycles only for patients with breast cancer who had more than $20 \%$ risk of FN. ${ }^{7}$ The rationale for our clinical trial was that we and others had shown that the risk of FN is highest during the first two cycles of chemotherapy, with a rapid decline thereafter. ${ }^{8-10}$ So, we hypothesized that G-CSF use might be limited to the first two chemotherapy cycles in contrast to the current practice of continued G-CSF prophylaxis throughout all cycles, to improve the cost effectiveness of primary G-CSF prophylaxis. As prospective data on the safety were lacking, we conducted a randomized phase III trial in 21 centers in the Netherlands from March 2008 until December 2009 (Figure 3.1). We decided to accept a noninferiority margin of $7.5 \%$ increase of the incidence of FN in the G-CSF 1 to 2 cycles study arm compared with the G-CSF 1 to 6 cycles arm. In December 2009, the randomization was prematurely stopped per the recommendation of the independent data monitoring committee, because of an unexpected high FN rate in the experimental arm. The trial showed that the incidence of FN was increased from $10 \%$ in the G-CSF 1 to 6 cycles arm to $36 \%$ in the G-CSF 1 to 2 cycles arm (Table 3.1). ${ }^{7}$

Although from this clinical trial it has become clear that G-CSF prophylaxis throughout all chemotherapy cycles is more effective, one may still argue effectiveness is an 
insufficient argument for continued prophylaxis as costs have not been taken into consideration. Of relevance, both strategies seemed to be safe as no toxic deaths occurred in either treatment group.

The primary objective of the cost-effectiveness analysis was, therefore, to assess the difference in costs in relation to the difference in effects between the two strategies.

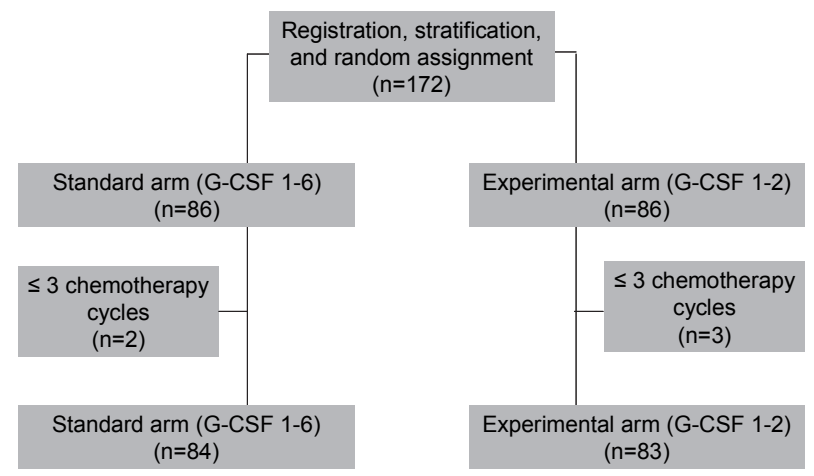

Figure 3.1 CONSORT diagram. G-CSF, granulocyte colony-stimulating factor.

\section{Methods}

\section{Measurement of effects and costs}

The economic evaluation was performed prospectively from a health care perspective alongside the clinical trial, with a time horizon of 6 months. The primary efficacy parameter was the number of patients with episodes of FN prevented. The study protocol provided stringent definitions of FN and its management and standardized criteria had to be met before a patient could be discharged from the hospital, all according to current standards in the Netherlands. ${ }^{7}$ Case report forms were used to collect resource utilization data during the trial period. Specific costs that were evaluated included actually delivered chemotherapy, prophylactic antibiotics, prophylactic G-CSF, all costs related to a period of FN (diagnostics, hospitalization, general practitioner or outpatients visits, and medication including delivered transfusions), and all health care costs for any other reason. These other costs may consist of hospitalizations, visits to general practitioner or outpatient department, therapeutic antibiotics, laboratory investigations, and cultures and radiologic procedures.

Prices were based on the Dutch Manual for Cost Research, ${ }^{11}$ and prices for medication were derived from the Dutch Pharmacotherapeutic Compass. ${ }^{12}$ When necessary, prices were converted to the price level of 2010 by means of national price index 
figures (Table 3.2)..$^{13}$ Costs were given in euros. The monthly euro exchange rate in 2010 fluctuated between $\$ 1.22$ and $\$ 1.42$ (US dollars).

Table 3.1 Main patient characteristics and results of the clinical trial.

\begin{tabular}{|c|c|c|c|c|}
\hline & \multicolumn{2}{|c|}{$\begin{array}{c}\text { G-CSF } 1-6 \text { arm } \\
N=84\end{array}$} & \multicolumn{2}{|c|}{$\begin{array}{c}\text { G-CSF 1-2 arm } \\
N=83\end{array}$} \\
\hline & No & $\%$ & No & $\%$ \\
\hline \multicolumn{5}{|l|}{ Patients characteristics } \\
\hline Median age, (range) years & \multicolumn{2}{|c|}{$50(26-69)$} & \multicolumn{2}{|c|}{$50(31-70)$} \\
\hline$\leq 65$ year & 79 & 94 & 78 & 94 \\
\hline ECOG PS 0-1 & 81 & 96 & 81 & 98 \\
\hline (Neo)-adjuvant treatment setting & 84 & 100 & 80 & 96 \\
\hline Antibiotics prophylaxis & 34 & 40 & 36 & 43 \\
\hline \multicolumn{5}{|l|}{ No. cycles of patients with $A B / G-C S F$ prophylaxis } \\
\hline 6 & \multicolumn{2}{|c|}{$29 / 74$} & \multicolumn{2}{|c|}{$31 / 14$} \\
\hline 5 & \multicolumn{2}{|c|}{$6 / 3$} & \multicolumn{2}{|c|}{$2 / 18$} \\
\hline 4 & \multicolumn{2}{|c|}{$1 / 1$} & \multicolumn{2}{|c|}{$2 / 2$} \\
\hline 3 & \multicolumn{2}{|c|}{$1 / 2$} & \multicolumn{2}{|c|}{$3 / 2$} \\
\hline 2 & \multicolumn{2}{|c|}{$1 / 3$} & \multicolumn{2}{|c|}{$0 / 47$} \\
\hline 1 & \multicolumn{2}{|c|}{$1 / 1$} & \multicolumn{2}{|c|}{$2 / 0$} \\
\hline \multicolumn{5}{|l|}{ Chemotherapy } \\
\hline TAC & 81 & 96 & 77 & 93 \\
\hline FEC-D & 3 & 4 & 3 & 4 \\
\hline DOC & 0 & 0 & 2 & 2 \\
\hline TC & 0 & 0 & 1 & 1 \\
\hline \multicolumn{5}{|l|}{ No. of patients with FN } \\
\hline Cycle 1 & 2 & 2 & 2 & 2 \\
\hline Cycle 2 & 0 & 0 & 0 & 0 \\
\hline Cycle 3 & 4 & 5 & 20 & 24 \\
\hline Cycle 4 & 2 & 2 & 6 & 7 \\
\hline Cycle 5 & 2 & 2 & 4 & 5 \\
\hline Cycle 6 & 2 & 2 & 2 & 2 \\
\hline Overall incidence & 8 & 10 & 30 & 36 \\
\hline \multicolumn{5}{|l|}{ Duration hospitalisation } \\
\hline All causes, median (range) & \multicolumn{2}{|c|}{$5(1-14)$} & \multicolumn{2}{|c|}{$5(1-13)$} \\
\hline FN, median (range) & \multicolumn{2}{|c|}{$5(3-14)$} & \multicolumn{2}{|c|}{$5(2-8)$} \\
\hline Due to fever/infection, no FN, median (range) & \multicolumn{2}{|c|}{$3(1-5)$} & \multicolumn{2}{|c|}{$2(2-2)$} \\
\hline
\end{tabular}

$A B$, antibiotic prophylaxis; DOC, docetaxel; ECOG PS, Eastern Cooperative Oncology Group performance score; FEC-D, fluorouracil, epirubicin, cyclophosphamide-docetaxel; FN, febrile neutropenia; G-CSF, granulocyte colony-stimulating factor; TAC, docetaxel, doxorubicin, cyclophosphamide; TC, docetaxel, cyclophosphamide.

\section{Data analyses}

The costs and effects were combined into an incremental costeffectiveness ratio (ICER), which divides the difference in costs between the two strategies by the difference in effect between the strategies. An ICER can be interpreted as the costs per patient with episodes of FN prevented. 
As cost data are generally highly skewed and not normally distributed, we used nonparametric bootstrap simulations performed in Microsoft Excel with 1,000 replications to estimate uncertainty intervals around the costs and effects. ${ }^{14}$ Bootstrapping was performed using case resampling in a customized macro using Microsoft Excel and Visual Basic. The $95 \% \mathrm{Cl}$ of the costs and effects was estimated using the percentile method. Missing items were imputed with the overall mean for the respective variable. For medication, standard doses were imputed where possible. In addition, we used a Mann-Whitney $U$ test to test whether the distribution of costs differed between the groups. The results of ICER bootstraps are presented in costeffectiveness planes and cost-effectiveness acceptability curves (CEACs). ${ }^{15}$ Costeffectiveness planes show differences in costs on the vertical axis and differences in effect on the horizontal axis. The CEAC represents the probability that, given a certain threshold for the willingness to pay for a patient with episodes of FN prevented, the intervention is cost effective. A CEAC is constructed by taking a certain threshold and calculating the percentage of the 1,000 bootstrapped ICERs that are below that threshold, and therefore cost effective, given that threshold. By repeating this procedure for various thresholds, a curve is generated, with threshold on the $x$-axis and probability of the intervention being cost effective on the $y$-axis.

Table $3.2 \quad$ Unit cost prices and sources.

\begin{tabular}{lcl}
\hline Unit Parameter & Unit cost $€$ & Source \\
\hline General practitioner visit & 28,36 & Guideline price* \\
Outpatient department visit & $72,92^{\dagger}$ & $\begin{array}{l}\text { Guideline price* } \\
\text { Guideline price* }\end{array}$ \\
Hospitalization day & $393,95{ }^{\dagger}$ & Guideline price* \\
Blood transfusion, unit of plasma & 203,56 & \\
Radiology & & Guideline price* \\
X-ray thorax & 50,97 & Guideline price* \\
Ultrasound & 77,74 & Guideline price* \\
CT scan & $235,41 \ddagger$ & $\S$ \\
G-CSF & 1521,86 & $\S$ \\
Other medication & Dependent on type, dose, duration & \\
\hline
\end{tabular}

The monthly euro exchange rate in 2010 fluctuated between $\$ 1.22$ and $\$ 1.42$. CT, computed tomography; G-CSF, granulocyte colonystimulating factor. ${ }^{*}$ Hakkart-van Roijen et al. ${ }^{11}+$ Because guideline prices in university hospitals and general hospitals differ, a weighted mean price was calculated based upon the distribution in the study of patients admitted to a university or general hospital ( $12 \%$ and $88 \%$, respectively). $¥$ Average of CT scan thorax and CT scan abdomen. § College voor Zorgverzekeringen. ${ }^{12}$

\section{Results}

\section{Clinical trial}

For detailed information we refer to our clinical article by Aarts et al. ${ }^{7}$ Baseline characteristics were well balanced (Table 3.1). Median delivered chemotherapy dose and dose intensity was not different between treatment arms. The chemotherapy 
schedules are known to be associated with an increased risk of FN, but the included patients had a low-risk profile with regarding risk of complicated $\mathrm{FN}^{16}$ There were no toxic deaths.

\section{Economic evaluation}

In the G-CSF 1 to 6 cycles arm, eight of 84 patients $(10 \% ; 95 \% \mathrm{Cl}, 4 \%$ to $17 \%)$ experienced at least one FN event, whereas in the G-CSF 1 to 2 cycles arm, FN was experienced in 30 of 83 patients (36\%; $95 \% \mathrm{Cl}, 26 \%$ to $46 \%)$.

Over all cycles, the mean total costs were $€ 20,658$ per patient in the G-CSF 1 to 6 cycles arm $(95 \% \mathrm{Cl}, € 20,049$ to $€ 21,247)$ and $€ 17,168$ in the $\mathrm{G}-\mathrm{CSF} 1$ to 2 cycles arm $(95 \% \mathrm{Cl}$, $€ 16,239$ to $€ 18,029$ ).

This resulted in mean extra costs of $€ 3,491$ per patient ( $95 \% \mathrm{Cl}, € 2,461$ to $€ 4,548$ ) when GCSF was continued over all cycles (Table 3.3). The ICER of G-CSF 1 to 6 cycles versus G CSF 1 to 2 cycles is $€ 13,112$ per patient with episodes of FN prevented (Figure 3.2).

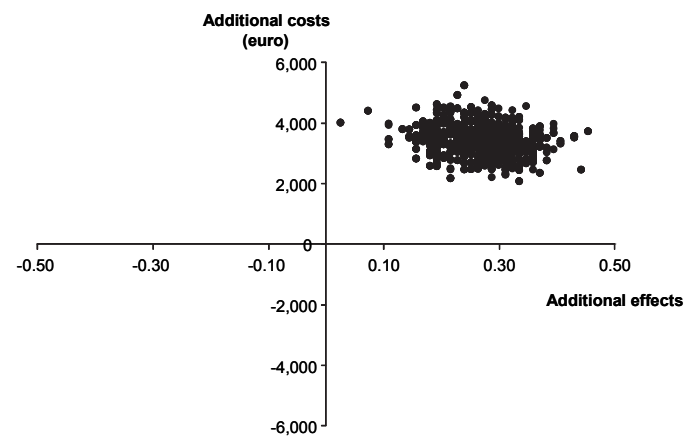

Figure 3.2 Cost-effectiveness plane. Bootstrapped costs and effects for costs per patient with febrile neutropenia (FN) prevented, showing 1,000 bootstrap replications for incremental cost effectiveness of granulocyte colony-stimulating factor (G-CSF) 1 to 6 cycles compared with GCSF 1 to 2 cycles. Additional costs are on the $y$-axis and additional effects on the $x$-axis. The northeast quadrant indicates G-CSF 1 to 6 cycles is more effective (more patients with FN prevented) but are more costly in every replication. If results would have been in one of the other quadrants, the interpretation would have been as follows. The northwest quadrant indicates G-CSF 1 to 6 cycles to be inferior, that is, more costly and less effective; the southwest quadrant indicates lower costs for lower effectiveness; the southeast quadrant indicates G-CSF 1 to 6 cycles to be more effective and less costly.

Chemotherapy and G-CSF costs contributed substantially to the total costs ( $83 \%$ in the G-CSF 1 to 6 cycles arm versus 78\% in the G-CSF 1 to 2 cycles arm; Table 3.3). Mean costs of chemotherapy, including delivery at the outpatient day care, amounted to approximately $€ 10,300$, which was not statistically significantly different between the two arms. As expected, the mean costs of G-CSF prophylaxis were substantially lower in the G-CSF 1 to 2 cycles arm as compared with G-CSF 1 to 6 cycles arm: $€ 5,171$ (95\% 
$\mathrm{Cl}, € 4,602$ to $€ 5,726)$ versus $€ 8,643$ (95\% Cl, $€ 8,299$ to $€ 8,933)$ per patient, which was $42 \%$ and $30 \%$ of all costs, respectively. The cost of prophylactic antibiotics was low.

The mean FN-related costs per episode of FN were $€ 2,767$ per patient in the G-CSF 1 to 6 cycles arm $(95 \% \mathrm{Cl}, € 2,518$ to $€ 3,033)$ and $€ 1,786$ per patient in the G-CSF 1 to 2 cycles arm (95\% Cl, €1,497 to €2,051; Table 3.4). These costs were primarily dominated by hospitalization costs. Notably, the mean duration of FN-related hospitalization was higher in the G-CSF 1 to 6 cycles arm with 5.8 days compared with 3.4 days in the G-CSF 1 to 2 cycles arm, and the mean duration of therapeutic antibiotics was comparable in both treatment arms.

The mean FN-related costs per patient were $€ 395$ in the G-CSF 1 to 6 cycles arm (95\% $\mathrm{Cl}, € 140$ to $€ 728)$ and $€ 732$ in the G-CSF 1 to 2 cycles arm $(95 \% \mathrm{Cl}, € 464$ to $€ 1,014$; Table 3.3). The associated costs for non-FN related issues tended to be slightly higher in the G-CSF 1 to 6 cycles arm when compared with the G-CSF 1 to 2 cycles arm: $€ 1,244(95 \% \mathrm{Cl}, € 860$ to $€ 1,665)$ and $€ 1,041$ (95\% Cl, $€ 743$ to $€ 1,376)$ per patient, respectively. Main reasons for hospitalization were fever and gastrointestinal complaints.

The uncertainty surrounding the expected incremental costs and effects is presented in Figure 3.2. All 1,000 replications are in the northeast quadrant, implying that it is certain that the G-CSF 1 to 6 cycles arm is more costly, but also more effective. The uncertainty about whether the G-CSF 1 to 6 cycles arm is cost effective is presented in Figure 3.3, illustrating the probability that the G-CSF 1 to 6 cycles arm is cost effective across a range of values for a patient with FN prevented.

This figure indicates that if this value is low $(<€ 10,000)$, the probability that the G-CSF 1 to 6 cycles arm is considered cost effective is low $(<20 \%)$, whereas at higher values this probability increases. If a patient with FN prevented would be valued $€ 40,000$ or more, there is a $100 \%$ probability that the G-CSF 1 to 6 cycles arm is cost effective.

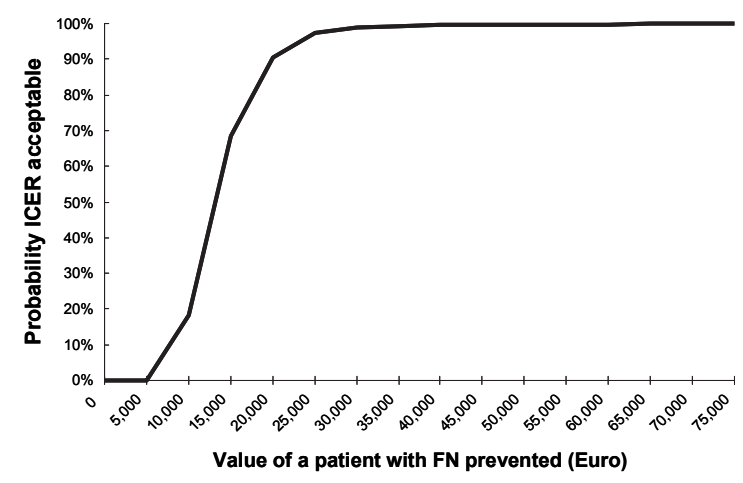

Figure 3.3 Cost-effectiveness acceptability curve, showing costs per patient with febrile neutropenia (FN) prevented. The curve indicates the probability ( $y$-axis) of granulocyte colony-stimulating factor (G-CSF) 1 to 6 being cost effective compared with G-CSF 1 to 2, given the threshold value ( $X$-axis) for prevention for a patient with FN. ICER, incremental cost-effectiveness ratio. 


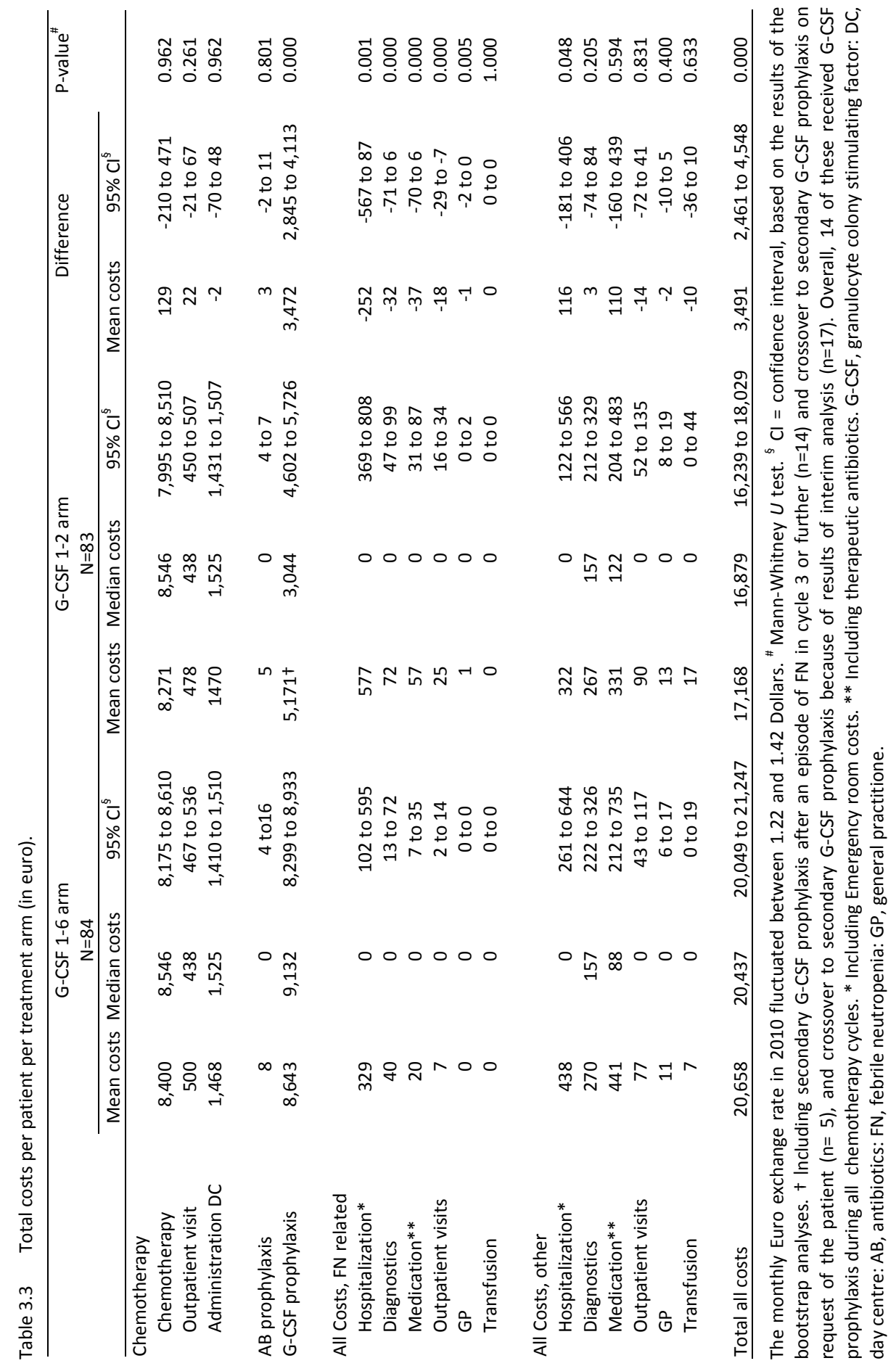




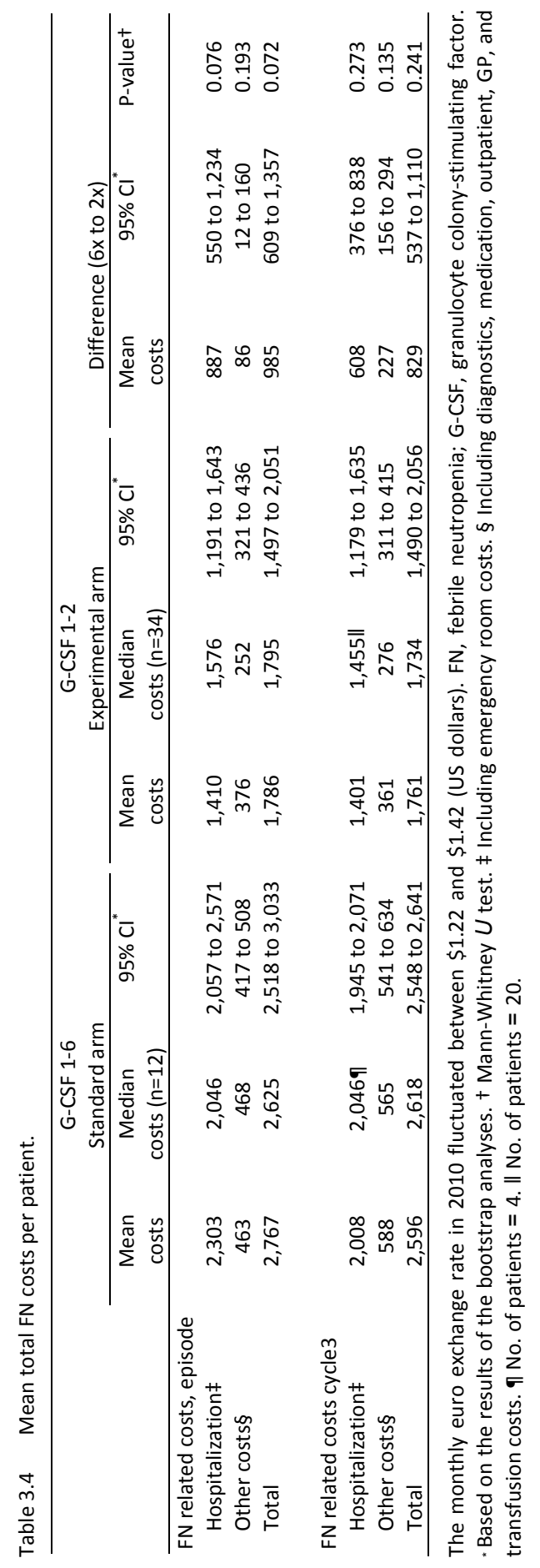




\section{Discussion}

G-CSF prophylaxis during chemotherapy is advised if risk of FN is more than $20 \%{ }^{4-6}$ Prophylaxis of this complication of cancer care consumes, however, a large part of direct medical costs. Previous studies showed that the incidence of FN occurs mainly in the first chemotherapy cycles with a declining risk thereafter. So, the rationale for our study was quite plausible; with the decreasing incidence of $\mathrm{FN}$, costs might be saved when primary G-CSF prophylaxis could be limited to the first two chemotherapy cycles. Indeed, we demonstrated in our phase III breast cancer trial that limiting G-CSF prophylaxis to the first two chemotherapy cycles resulted in a mean cost saving of $€ 3,491(95 \% \mathrm{Cl},-2,461$ to $€ 4,548)$ per patient, however, with an unexpected substantial increase in incidence of FN.

In our study, we observed chemotherapy costs to be equivalent to the costs of prophylactic G-CSF when administered throughout all chemotherapy cycles. However, because new antitumor drugs in the adjuvant setting are associated with a survival benefit, the ICER is obviously more favorable for these anticancer treatments than for supportive care measures. Taxanes in the adjuvant breast cancer setting, as an example, yield a $15 \%$ relative survival benefit over second generation chemotherapy regimens, ${ }^{17}$ resulting in an estimated ICER varying from $€ 2,631$ in Spain ${ }^{18}$ to $€ 14,102$ in the United Kingdom. ${ }^{19}$

In contrast, a survival benefit has not been shown for G-CSF prophylaxis, ${ }^{20}$ resulting in no life-years gained and an associated ICER of an infinite amount per life year gained.

In the Netherlands, the annual incidence of invasive breast cancer is approximately 12,000 patients. Of these patients, at least $40 \%$ are expected to be offered adjuvant chemotherapy, $^{21}$ and probably $50 \%$ are assumed to have an indication for G-CSF prophylaxis. We estimated that the $\mathrm{FN}$ rate would slightly increase by an acceptable $2 \%$ to $3 \%$ per cycle for cycles 3 to 6 (5\% to $10 \%$ of patients) without G-CSF prophylaxis. For the Netherlands, this would imply approximately 192 additional FN episodes ( $0.02 \times$ four cycles $\times 2,400$ patients). With an estimated mean cost of an episode of FN of $€ 3,200$, based on a prior Dutch study, ${ }^{19} 192$ more FN episodes would account for $€ 292,224$ in additional costs per year. In contrast, when four cycles of G-CSF prophylaxis could be saved, this would lead to total cost-savings of $€ 14.3$ million. A major cost reduction was indeed achieved, considering the $€ 3,500$ cost-savings per patient. This is $€ 290,500$ for the 83 patients included in the G-CSF 1 to 2 cycles arm and extrapolated to 2,400 patients with breast cancer in the Netherlands, results in yearly cost-savings of $€ 8.4$ million. Whether society is willing to pay this amount of money to prevent $26 \%$ additional $\mathrm{FN}$ events is open for discussion. By presenting the expected ICER as well as the uncertainty for any value of willingness to pay, we have given the decision maker as much information as possible. Depending on their willingness to pay, six cycles of G-CSF may or may not be cost-effective, and this may or may not be uncertain. 
The mean total FN-related costs per episode were $€ 2,767$ per patient in the G-CSF 1 to 6 cycles arm and $€ 1,786$ per patient in the G-CSF 1 to 2 cycles arm, largely consisting of hospitalization costs. Previous studies also showed that the major economic impact of neutropenic complications concerned costs associated with hospitalization were predominantly determined by the length of stay. ${ }^{22}$ Lingaratnam et al. ${ }^{23}$ reported an average length of stay of 6 days with a mean cost per FN episode of $€ 7,063$. Wenoticed that the FN episodes that occurred with G-CSF prophylaxis seemed more severe and requiring longer hospital stays than the FN episodes without G-CSF prophylaxis, an observation not reported before and, therefore, considered as merely accidental. For the economic analysis, we have corrected more or less for this by including the costs of FN.

In our study, we analyzed a Dutch estimate of cost effectiveness of continued G-CSF prophylaxis. Our resource volume data may be used as a proxy for other countries with comparable clinical practice. However, we like to stress that it is unjust to imply that Dutch costs can be directly converted to US costs, because there are many differences in the health care and reimbursement policies between the Netherlands and the United States. ${ }^{24}$

Costs were collected of actually delivered treatment, which in a number of patients was different from treatment allocated to by randomization. For instance, in the experimental arm, 36 patients crossed-over to secondary G-CSF prophylaxis, and 14 of those 36 patients received G-CSF during all chemotherapy cycles. If protocol adherence would have been perfect, the number of FN events might have been higher for the experimental arm. Hence, cost-effectiveness outcome might have been different. The use of prophylactic antibiotics was comparable for both arms. If not used, FN rates might have been higher, but probably not largely affecting costeffectiveness ratio between treatment arms.

Considering the fact that FN costs are dominated by hospitalization costs, one might consider a more selective admission policy or an earlier discharge for patients with FN.

Clinical prediction models such as those by the Multinational Association of Supportive Care in Cancer are developed to select patients that might not need to be hospitalized. ${ }^{16}$ For our population, mainly patients younger than 60 years with minor symptoms, the Multinational Association of Supportive Care in Cancer risk index score was on average $\geq 21$, which indicates that the patients were at low risk for FN complications. In general, mortality risk increases in proportion to the number of comorbidities and other treatment related complications, from $2 \%$ up to $22 \%$, and also depends on tumor type. Breast cancer has an FN mortality rate of 3.6\%, much lower than for example the reported $13.4 \%$ in lung carcinoma. ${ }^{1}$ Obviously, especially in the adjuvant setting, every toxic death should be prevented whenever possible. Fortunately, we did not observe any toxic deaths. Also, none of the patients with an FN event was admitted to the intensive care. Therefore, for our population, 
outpatient treatment may be a reasonable option based on the low risk score for complicated FN. As an alternative option, one might consider a short stay as a safer policy. Such an outpatient FN policy would further increase the relative investment for prophylactic G-CSF use, making it even more important to discuss to what level benefits are considered worthwhile.

In our study, we used pegfilgrastim, a pegylated form of filgrastim, as primary prophylaxis. Current guidelines indicate that filgrastim, lenograstim, and pegfilgrastim are equally effective in reducing the incidence of $\mathrm{FN}$ and related complications. ${ }^{4-6}$ In the Netherlands, the costs of pegfilgrastim and filgrastim for 10 days per cycle are more or less the same. Recently, the unit cost price of pegfilgrastim has been decreased, and this will, of course, positively influence the ICER, as $42 \%$ of all costs were owing to G-CSF.

Of note, the missing items that were imputed were the average number of general practitioner visits and outpatient visits, as well as standard doses for medication. General practitioner visits ranged from zero to three visits and constituted only a small part $(0.05 \%)$ of the total costs. Outpatient visits were missing in only three of a total of 976 cycles. These visits ranged from zero to 10, implying a difference of at maximum $€ 2$, if the maximum value instead of the mean value was imputed. Medication standard doses were applied in accordance with the current policy in the Netherlands. Although the mean imputation method underestimates the existing uncertainty, multiple imputation therefore would not have affected our results or conclusions.

In conclusion, we performed an economic evaluation alongside a multicenter, randomized phase III trial of primary G-CSF prophylaxis in patients with breast cancer at risk of FN. Limiting primary pegfilgrastim prophylaxis to the first two chemotherapy cycles was compared with continuous pegfilgrastim prophylaxis throughout all cycles, causing cost-savings with a mean difference of $€ 3,491$, but a rise in $F N$ incidence from $10 \%$ of patients in the G-CSF 1 to 6 cycles arm to $36 \%$ in the G-CSF 1 to 2 cycles arm. When one is willing to pay at least $€ 13,112$ per patient with episodes of FN prevented, six cycles of G-CSF prophylaxis is considered a cost-effective strategy. 


\section{References}

1. Kuderer NM, Dale DC, Crawford J, Cosler LE, Lyman GH. Mortality, morbidity, and cost associated with febrile neutropenia in adult cancer patients. Cancer 2006;106:2258-66.

2. Crawford J, Ozer H, Stoller R, Johnson D, Lyman G, Tabbara I, Kris M, Grous J, Picozzi V, Rausch G, Smith R, Gradishar W, Yahanda A, Vincent M, Stewart M, Glaspy J. Reduction by granulocyte colonystimulating factor of fever and neutropenia induced by chemotherapy in patients with smallcell lung cancer. N Engl J Med 1991;325: 164-70.

3. Ozer H, Armitage JO, Bennett CL, Crawford J, Demetri GD, Pizzo PA, Schiffer CA, Smith TJ, Somlo G, Wade JC, Wade JL 3rd, Winn RJ, Wozniak AJ, Somerfield MR; American Society of Clinical Oncology. 2000 update of recommendations for the use of haematopoietic colony-stimulating factors: Evidencebased, clinical practice guidelines-American Society of Clinical Oncology Growth Factors Expert Panel. J Clin Oncol 2000;18:3558-85.

4. Aapro MS, Bohlius J, Cameron DA, Dal Lago L, Donnelly JP, Kearney N, Lyman GH, Pettengell R, TjanHeijnen VC, Walewski J, Weber DC, Zielinski C; European Organisation for Research and Treatment of Cancer. 2010 update of EORTC guidelines for the use of granulocyte colony-stimulating factor to reduce the incidence of chemotherapy-induced febrile neutropenia in adult patients with lymphoproliferative disorders and solid tumours. Eur J Cancer 2011;47:8-32.

5. Smith TJ, Khatcheressian J, Lyman GH, Ozer H, Armitage JO, Balducci L, Bennett CL, Cantor SB, Crawford J, Cross SJ, Demetri G, Desch CE, Pizzo PA, Schiffer CA, Schwartzberg L, Somerfield MR, Somlo G, Wade JC, Wade JL, Winn RJ, Wozniak AJ, Wolff AC. 2006 update of recommendations for the use of white blood cell growth factors: An evidence-based clinical practice guideline. J Clin Oncol 2006;24:3187-205

6. National Comprehensive Cancer Network: Myeloid growth factors: Practice guidelines in the oncology, version 1.2010. www.nccn.org/professionals/ physician_gls/f_guidelines.asp\#supportive

7. Aarts MJ, Peters FP, Mandigers CM, Dercksen MW, Stouthard JM, Nortier HJ, van Laarhoven HW, van Warmerdam LJ, van de Wouw AJ, Jacobs EM, Mattijssen V, van der Rijt CC, Smilde TJ, van der Velden AW, Temizkan M, Batman E, Muller EW, van Gastel SM, Borm GF, Tjan-Heijnen VC. Primary G-CSF prophylaxis during the first two cycles only or throughout all chemotherapy cycles in breast cancer patients at risk of febrile neutropenia. J Clin Oncol 2013;31:4290-6.

8. Martín M, Lluch A, Seguí MA, Ruiz A, Ramos M, Adrover E, Rodríguez-Lescure A, Grosse R, Calvo L, Fernandez-Chacón C, Roset M, Antón A, Isla D, del Prado PM, Iglesias L, Zaluski J, Arcusa A, LópezVega JM, Muñoz M, Mel JR. Toxicity and health-related quality of life in breast cancer patients receiving adjuvant docetaxel, doxorubicin, cyclophosphamide (TAC) or 5-fluorourail, doxorubicin and cyclophosphamide (FAC): Impact of adding primary prophylactic granulocyte-colony stimulating factor to the TAC regimen. Ann Oncol 2006;17:1205-12.

9. Nabholtz JM, Cantin J, Chang J, Guevin R, Patel R, Tkaczuk K, Vodvarka P, Lindsay MA, Reese D, Riva A, Mackey J. Phase III trial comparing granulocyte colony-stimulating factor to leridistim in the prevention of neutropenic complications in breast cancer patients treated with docetaxel/doxorubicin/cyclophosphamide: Results of the BCIRG 004 trial. Clinical Breast Cancer 2002;3:268-75.

10. Tjan-Heijnen VC, Postmus PE, Ardizzoni A, Manegold CH, Burghouts J, van Meerbeeck J, Gans S, Mollers M, Buchholz E, Biesma B, Legrand C, Debruyne C, Giaccone G; European Organisation for Research and Treatment of Cancer-Lung Cancer Group. Reduction of chemotherapy-induced febrile leucopenia by prophylactic use of ciprofloxacin and roxithromycin in small-cell lung cancer patients: An EORTC double-blind placebo-controlled phase III study. Ann Oncol 2001;12:1359-68.

11. Hakkart-van Roijen L, Tan SS, Bouwmans CAM. Manual for cost research. Dutch Health Care Insurance Board, 2010. (in Dutch). www.cvz.nl/binaries/content/documents/cvzinternet/nl/documenten/lossepublicaties/ handleiding-kostenonderzoek-2010.pdf

12. College voor Zorgverzekeringen. Pharmacotherapeutic Compass (in Dutch). www.fk.cvz.nl

13. Central Bureau for Statistics. Statline (in Dutch). Available from http://statline.cbs.nl 
14. Briggs AH, Wonderling DE, Mooney CZ. Pulling cost-effectiveness analysis up by its bootstraps: A nonparametric approach to confidence interval estimation. Health Econ 1997;6:327-40.

15. van Hout BA, Al MJ, Gordon GS, Rutten FF. Costs, effects and C/E-ratios alongside a clinical trial. Health Econ 1994;3:309-19.

16. Klastersky J, Paesmans M, Rubenstein EB, Boyer M, Elting L, Feld R, Gallagher J, Herrstedt J, Rapoport B, Rolston K, Talcott J. The Multinational Association for Supportive Care in Cancer risk index: A multinational scoring system for identifying low-risk febrile neutropenic cancer patients. J Clin Oncol 2000;18:3038-51.

17. Vriens BE, Lobbezoo DJ, de Hoon JP, Veeck J, Voogd AC, Tjan-Heijnen VC. If there is no overall survival benefit in metastatic breast cancer: Does it imply lack of efficacy? Taxanes as an example. Cancer Treat Rev 2013;39:189-98.

18. Martín-Jiménez $M$, Rodríguez-Lescure A, Ruiz-Borrego M, Seguí-Palmer MA, Brosa-Riestra M. Costeffectiveness analysis of docetaxel (Taxotere) vs. 5-fluorouracil in combined therapy in the initial phases of breast cancer. Clin Transl Oncol 2009;11:41-7.

19. Ward S, Simpson E, Davis S, Hind D, Rees A, Wilkinson A. Taxanes for the adjuvant treatment of early breast cancer: Systematic review and economic evaluation. Health Technol Assess 2007;11:1-144.

20. Timmer-Bonte JN, Adang EM, Smit HJ, Biesma B, Wilschut FA, Bootsma GP, de Boo TM, Tjan-Heijnen VC. Cost-effectiveness of adding granulocyte colonystimulating factor to primary prophylaxis with antibiotics in small-cell lung cancer. J Clin Oncol 2006;24:2991-7.

21. Geurts SM, van Dijck JAAM, de Vegt F, et al. Huge decrease in risk of breast cancer relapse in the Netherlands over the last 3 decades. Eur J Cancer 2012:48 (suppl 1):S82-3.

22. Schelenz S, Giles D, Abdallah S. Epidemiology, management and economic impact of febrile neutropenia in oncology patients receiving routine care at a regional UK cancer centre. Ann Oncol 2012;23:1889-93.

23. Lingaratnam S, Thursky KA, Slavin MA, Kirsa SW, Bennett CA, Worth $L$. The disease and economic burden of neutropenic fever in adult patients in Australian cancer treatment centres 2008: Analysis of the Victorian Admitted Episodes Dataset. Intern Med J 2011;41:121-9.

24. Essers BA, Seferina SC, Tjan-Heijnen VC, Severens JL, Novák A, Pompen M, Oron UH, Joore MA. Transferability of model-based economic evaluations: The case of trastuzumab for the adjuvant treatment of HER2-positive early breast cancer in the Netherlands. Value Health 2010;13:375-80. 


\section{Chapter 4}

Cost-effectiveness of primary and secondary granulocyte colony-stimulating factor prophylaxis for breast cancer patients at risk of febrile neutropenia: A model-based approach

Bram LT Ramaekers, Maureen J Aarts, Frank P Peters, Caroline M Mandigers, M Wouter Dercksen, Jacqueline M Stouthard, Hanneke W van Laarhoven, Laurence J van Warmerdam, Agnes J van de Wouw, Esther M Jacobs, Carin C van der Rijt, Tineke J Smilde, Annette W van der Velden, Vivianne CG Tjan-Heijnen, Manuela A Joore

Submitted 


\section{Abstract}

\section{Background}

To assess the cost-effectiveness of limiting primary Granulocyte Colony-Stimulating Factor Prophylaxis (G-CSF) prophylaxis to the first two chemotherapy cycles only (without or with secondary prophylaxis) compared to primary G-CSF prophylaxis throughout all chemotherapy cycles for breast cancer patients at risk of febrile neutropenia.

\section{Methods}

A probabilistic Markov model was developed, based on a multicenter randomized phase III trial, to compare the costs and effects (i.e. quality-adjusted life-years [QALYs]) of the following strategies: 1) Primary G-CSF prophylaxis during the first two chemotherapy cycles only ('G-CSF 2 cycles') without secondary G-CSF prophylaxis; 2) 'G-CSF 2 cycles' with secondary G-CSF prophylaxis and; 3) Primary G-CSF prophylaxis throughout all chemotherapy cycles ('G-CSF 6 cycles').

\section{Results}

'G-CSF 2 cycles' without and with secondary G-CSF prophylaxis yielded 0.213 and 0.214 QALYs and costed $€ 17,014$ and $€ 18,848$, respectively. 'G-CSF 6 cycles' was both the most effective $(0.215 \mathrm{QALYs})$ and most expensive $(€ 22,778)$ strategy. Based on a willingness to pay threshold of $€ 80,000$ per QALY, 'G-CSF 2 cycles' without secondary G-CSF prophylaxis was considered cost-effective (probability of being cost-effective $=100 \%$ ).

\section{Conclusion}

From a cost-effectiveness perspective, it is recommended to limit primary G-CSF prophylaxis to the first two chemotherapy cycles without secondary prophylaxis. 


\section{Introduction}

Chemotherapy-related febrile neutropenia (FN) is a serious complication, prophylactic antibiotics as well as granulocyte colony-stimulating factor (G-CSF) significantly decrease the incidence of FN. ${ }^{1,2}$ Guidelines on the use of G-CSF initially recommended primary prophylaxis for patients with an FN risk of $>40 \%{ }^{3}$ Based on clinical grounds, this threshold was lowered to an FN risk of $>20 \%{ }^{4-6}$ Chemotherapy regimen and the associated adverse events (e.g. FN) affects patients' Health-related Quality of Life (QoL). Primary G-CSF prophylaxis reduces FN incidence and other (extra) haematological side-effects, and subsequently improves QoL. ${ }^{7}$

Previous studies demonstrated an increased FN incidence during the first two chemotherapy cycles with a rapid decline thereafter. ${ }^{2,7-9}$ Hence, it was hypothesized, in a recent multicenter randomized phase III trial (RCT), that it would be cost-effective to limit the use of G-CSF to the first two chemotherapy cycles for breast cancer patients at risk of $\mathrm{FN}$ as this would lead to cost-savings of approximately $€ 8.4$ million in the Netherlands. ${ }^{10,11}$ Results from this trial showed, however, that limiting the use of primary G-CSF prophylaxis to the first two chemotherapy cycles only (G-CSF 1-2 arm) increased the FN incidence compared to primary G-CSF prophylaxis throughout all chemotherapy cycles (G-CSF 1-6 arm) from $10 \%$ to $36 \%{ }^{11}$ while decreasing the total costs per patient (from $€ 20,658$ to $€ 17,168$ ). This resulted in an incremental costeffectiveness ratio (ICER) of $€ 13,112 .{ }^{10}$ It is however unclear whether the savings as a result of limiting primary G-CSF prophylaxis can be considered cost-effective as the willingness to pay (WTP) per patient with FN episode prevented is unknown. Moreover, the role of secondary G-CSF prophylaxis was not examined in this prior analysis. Therefore, the present paper aims to incorporate quality-adjusted life-years (QALYs; for which informal WTP values exist) ${ }^{12}$ as an additional outcome and assess whether limiting primary G-CSF prophylaxis to the first two chemotherapy cycles only (without or with secondary prophylaxis) is cost-effective compared to primary G-CSF prophylaxis throughout all chemotherapy cycles for breast cancer patients at risk of $\mathrm{FN}$.

\section{Methods}

\section{Model description}

A probabilistic decision-analytic Markov cohort model ${ }^{13}$ was developed to compare the cost-effectiveness of primary G-CSF prophylaxis during the first two chemotherapy cycles only (without or with secondary prophylaxis) with primary G-CSF prophylaxis throughout all six chemotherapy cycles in breast cancer patients who had an increased risk (>20\%) of FN. 
The Markov cohort model consisted of three health states: 'No FN', 'Post 1st FN event', and 'Post $\geq 2$ nd FN events' (Figure 1). Patients start in the 'No FN' state and transit to the 'Post 1st FN event' state after an FN event. After another FN event, patients transit to the 'Post $\geq 2$ nd FN events' state were they stay (with or without additional FN events) for the remaining of the model duration. For the primary G-CSF prophylaxis during the first two chemotherapy cycles only strategy, a distinction was made between strategies without and with secondary prophylaxis (i.e. the administration of G-CSF after an FN event occurred). Hence, three G-CSF prophylaxis strategies were examined:

1. Primary G-CSF prophylaxis during the first two chemotherapy cycles only ('G-CSF 2 cycles') without secondary G-CSF prophylaxis;

2. Primary G-CSF prophylaxis during the first two chemotherapy cycles only cycles ('G-CSF 2 cycles') with secondary G-CSF prophylaxis;

3. Primary G-CSF prophylaxis throughout all chemotherapy cycles ('G-CSF 6 cycles'). A cycle time of 3 weeks (duration of one chemotherapy cycle) and a time horizon of 18 weeks (duration of six chemotherapy cycles, assuming no delay) was used. Longterm effects after 18 weeks were not modeled as the short term effects (i.e. occurrence of FN) were not expected to impact long-term morbidity and/or mortality. Therefore, the 18 week time horizon was considered sufficient to capture all relevant costs and effects. Future costs and effects were not discounted as the time horizon was less than 1 year.

\section{Model parameters}

Input parameters were mainly retrieved from the abovementioned multicenter RCT. ${ }^{11,10}$ Consistent with the model population described above, included patients were treated with chemotherapy regimens with either $>20 \%$ risk of FN (e.g. TAC; docetaxel, doxorubicin and cyclophosphamide) or with a $10-20 \%$ risk of FN (e.g. docetaxel monotherapy) combined with one or more patient factors for an increased FN risk. $^{11}$

\section{Transition probabilities}

Transition probabilities (probabilities of the first FN event and $\geq$ second FN event) were directly calculated based on the events observed in the abovementioned clinical trial. ${ }^{11}$ The probability of the first FN event was equal for the two 'G-CSF 2 cycles' strategies as secondary prophylaxis only plays a role after an FN event occurred. Moreover, the probability of an FN event after experiencing a previous FN event (i.e. probability of $\geq$ second FN event) was estimated based on the data from cycles 3-6 combined because of the low number of events (i.e. this probability was assumed to be constant over time). Furthermore, a continuity correction was applied in case of no events (Table 4.1). 


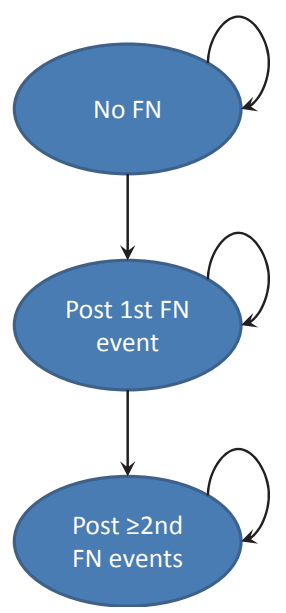

Figure 4.1 Model structure.

\section{Effects and costs}

Next to FN incidence and the number of FN events, QoL in terms of utility scores was used as outcome measure. Utilities are generic QoL measures ranging from 1 (full health) to 0 (death) and can be combined with life expectancy to calculate QALYs. The baseline utility $(0.728)$ in the current study was retrieved from an unpublished crosssectional survey, which estimated the utility score (using the Euro-QoL questionnaire) among 145 Dutch disease-free breast cancer patients in their first year after curative treatment. In case of FN, a disutility of -0.150 was applied for the duration of 10 days (Table 4.1).

The healthcare perspective was applied to calculate costs. The health state costs (calculated per cycle) and costs related to an FN event (calculated per event) are retrieved from a previous cost-effectiveness study that was based on the abovementioned RCT (Table 4.1). ${ }^{10}$ All costs were converted to the 2013 price level using price indices. ${ }^{14}$ 
Table $4.1 \quad$ Input parameters.

\begin{tabular}{|c|c|c|c|c|c|}
\hline Probabilities $^{a}$ & Estimate & $\mathrm{Se}$ & Distribution & Alpha & Beta \\
\hline \multicolumn{6}{|l|}{ Probability of first FN event } \\
\hline \multicolumn{6}{|l|}{ G-CSF 2 cycles } \\
\hline Cycle 1 & $2.4 \%$ & $1.7 \%$ & Beta & 2 & 81 \\
\hline Cycle 2 & $0.6 \%$ & $0.9 \%$ & Beta & 0.5 & 81 \\
\hline Cycle 3 & $23.5 \%$ & $4.7 \%$ & Beta & 19 & 62 \\
\hline Cycle 4 & $6.8 \%$ & $3.2 \%$ & Beta & 4 & 55 \\
\hline Cycle 5 & $5.7 \%$ & $3.1 \%$ & Beta & 3 & 50 \\
\hline Cycle 6 & $4.0 \%$ & $2.7 \%$ & Beta & 2 & 48 \\
\hline \multicolumn{6}{|l|}{ G-CSF 6 cycles } \\
\hline Cycle 1 & $2.4 \%$ & $1.7 \%$ & Beta & 2 & 82 \\
\hline Cycle 2 & $0.6 \%$ & $0.8 \%$ & Beta & 0.5 & 82 \\
\hline Cycle 3 & $4.9 \%$ & $2.4 \%$ & Beta & 4 & 78 \\
\hline Cycle 4 & $0.7 \%$ & $0.9 \%$ & Beta & 0.5 & 76 \\
\hline Cycle 5 & $1.3 \%$ & $1.3 \%$ & Beta & 1 & 75 \\
\hline Cycle 6 & $1.4 \%$ & $1.3 \%$ & Beta & 1 & 73 \\
\hline \multicolumn{6}{|l|}{ Probability of $\geq$ second FN event } \\
\hline \multicolumn{6}{|l|}{ G-CSF 2 cycles no $2^{\text {nd }}$ prop } \\
\hline Cycles $1-2^{b}$ & $0.0 \%$ & & Fixed & & \\
\hline Cycles 3-6 & $14.3 \%$ & $6.5 \%$ & Beta & 4 & 24 \\
\hline \multicolumn{6}{|l|}{ G-CSF 2 cycles $2^{\text {nd }}$ prop } \\
\hline Cycles $1-2^{b}$ & $0.0 \%$ & & Fixed & & \\
\hline Cycles 3-6 & $1.1 \%$ & $1.5 \%$ & Beta & 0.5 & 45 \\
\hline \multicolumn{6}{|l|}{ G-CSF 6 cycles } \\
\hline Cycles $1-2^{b}$ & $0.0 \%$ & & Fixed & & \\
\hline Cycles 3-6 & $16.0 \%$ & $7.2 \%$ & Beta & 4 & 21 \\
\hline Utility scores $^{c}$ & Estimate & Se & Distribution & Minimum & Maximum \\
\hline Baseline utility & 0.728 & 0.016 & Beta & & \\
\hline Disutility for an FN event & -0.150 & & Beta PERT & -0.190 & -0.110 \\
\hline Duration of FN-related hospitalization ${ }^{d}$ & 5 & & Beta PERT & 1 & 14 \\
\hline Additional 'sick days' at home ${ }^{d}$ & 5 & & & & \\
\hline Costs $^{e}$ & Estimate & Se & Distribution & & \\
\hline Chemotherapy & $€ 1,893$ & $€ 16$ & Gamma & & \\
\hline G-CSF & $€ 1,636$ & & Fixed & & \\
\hline Antibiotics & $€ 1$ & $€ 0$ & Gamma & & \\
\hline Healthcare costs (not related to $\mathrm{FN})^{f}$ & $€ 210$ & $€ 20$ & Gamma & & \\
\hline Healthcare costs FN related (per event) ${ }^{f}$ & $€ 2,195$ & $€ 101$ & Gamma & & \\
\hline
\end{tabular}

Se, standard error; FN, febrile neutropenia; G-CSF, granulocyte colony-stimulating factor; $2^{\text {nd }}$ prop, secondary G-CSF prophylaxis; Eo, expert opinion. ${ }^{a}$ The probabilities were retrieved from a clinical trial, ${ }^{11}$ where the alpha represent the number patients with an event and the beta represents the number of patients at risk without an event. Continuity corrections were applied in case of no events. ${ }^{b}$ No continuity correction was applied for the probability of second or more FN events as there were only two patients at risk (during the second cycle), applying a continuity correction would lead to a probability of $25 \%$ instead of $0 \%$ as observed in the trial. ${ }^{c}$ Baseline utility represented the average utility for disease free breast cancer patients in the first year after their curative treatment $(\mathrm{N}=145)$ and was retrieved from a unpublished crosssectional study. The disutility for an FN event was retrieved from a Single Technology Appraisal on Eribulin for the treatment of locally advanced breast cancer or metastatic breast cancer submitted to the National Institute of Health and Clinical Excellence. ${ }^{21 \mathrm{~d}}$ The duration of the FN-related hospitalization (based on trial data $^{11}$ ) and additional 'sick days' at home (based on export opinion) will be added and used to estimate the duration of the disutility for an FN event. ${ }^{e}$ All costs were based on a previous cost study ${ }^{10}$ and converted to the 2013 price level. ${ }^{14}$ Weighted mean costs were calculated based on the treatment specific costs. ${ }^{f}$ Included costs for hospitalization, diagnostics, medication, outpatient visits, GP and transfusion. 


\section{Model assumptions}

Decision-analytic models are a simplified representation of reality and assumptions about reality are inherent to modeling. The main model assumptions are:

- No difference in long term costs and effects (morbidity and mortality) between the strategies and thus that a time horizon of 18 weeks captures all relevant costs and effects.

- All patients will receive six chemotherapy cycles without delay.

- That the probability of $a \geq$ second FN event is constant during chemotherapy cycles 3-6.

- No $\geq$ second FN events in cycles 1-2 (consistent with the trial data).

- Equal health state costs and event costs for all strategies.

\section{Model analysis}

Expected costs and effects per patient (i.e. FN incidence, number of FN events and QALYs) were estimated for all strategies. The ICER was calculated by dividing the incremental costs by the incremental effects to compare the cost-effectiveness of the three strategies. The ICER represents the costs of an additional unit of effect (e.g. QALY) gained. A WTP threshold of $€ 80,000$ per QALY was adopted as this is the informal ceiling ratio for a high burden of disease in the Netherlands. ${ }^{12}$ This indicates that society is willing to pay $€ 80,000$ per gained QALY and a treatment is cost-effective if the ICER is below this WTP threshold.

The Markov model was build and analyzed in Microsoft Excel 2010.

\section{Scenario analysis}

In addition to the base case analysis, one scenario analysis was performed excluding hospitalization costs from the FN event costs as selected patients might not be admitted to the hospital based on clinical prediction models (e.g. by the Multinational Association of Supportive Care in Cancer). Excluding hospitalization costs would reduce the expected $\mathrm{FN}$ event costs from $€ 2,195$ to $€ 429$. $^{10}$

\section{Parameter uncertainty}

Probabilistic sensitivity analysis was performed (10,000 iterations) to explore the impact of parameter uncertainty on the estimated (cost-)effectiveness. Distributions were assigned to the input parameters for this purpose (Table 4.1). Subsequently, cost-effectiveness acceptability curves were created to show the probability that a treatment is cost-effective for different WTP thresholds. 


\section{Sensitivity analysis}

In addition to the probabilistic sensitivity analysis, all stochastic input parameters were varied in deterministic one-way sensitivity analyses using their $95 \%$ confidence interval or their range (Table 4.1). Only sensitivity analyses in which the most costeffective strategy (based on QALYs) was altered were reported.

\section{Threshold analysis}

Threshold analyses were performed wherein the G-CSF costs, FN disutility and its duration were altered separately until the cost-effectiveness (based on QALYs) of 'G-CSF 6 cycles' was altered.

\section{Results}

For 'G-CSF 2 cycles' without and with secondary G-CSF prophylaxis the expected FN incidence was $37 \%$ for both strategies and the number of FN events was 0.508 without secondary G-CSF prophylaxis and 0.384 with secondary G-CSF prophylaxis. For 'G-CSF 6 cycles' this was $11 \%$ and 0.153 respectively. Thus, FN occurred in 1 out of 2.7 patients for 'G-CSF 2 cycles' versus 1 out of 9.4 for 'G-CSF 6 cycles' and the expected number of FN events per patient were 3.3 and 2.5 times higher for 'G-CSF 2 cycles' without or with secondary G-CSF prophylaxis respectively. The QALYs ranged between 0.213 and 0.215 for all three strategies, whereas the costs were $€ 17,014$, $€ 18,842$ and $€ 22,778$ for the 'G-CSF 2 cycles' without and with secondary G-CSF prophylaxis and the 'G-CSF 6 cycles' strategies, respectively (Table 4.2).

Incremental analyses showed that 'G-CSF 6 cycles' is cost-effective if society would be willing to pay more than $€ 21,639$ per patient with $F N$ episode prevented (FN incidence), 'G-CSF 2 cycles' without secondary G-CSF prophylaxis is cost-effective for lower WTP thresholds. Moreover, the 'G-CSF 2 cycles' strategies were cost-effective up to WTP thresholds of $€ 14,760$ (without secondary prophylaxis) and $€ 17,008$ (with secondary prophylaxis) per FN event prevented (number of FN events) (Table 4.2).

When considering QALYs, 'G-CSF 2 cycles' without secondary G-CSF prophylaxis was cost-effective until a WTP threshold of approximately €3.6 million. The 'G-CSF 6 cycles' strategy would become cost-effective for WTP threshold higher than approximately $€ 4.1$ million. These estimates are above the adopted WTP threshold of $€ 80,000$ per QALY. Thus, 'G-CSF 2 cycles' without secondary G-CSF prophylaxis can be considered cost-effective. Moreover, the cost-effectiveness acceptability curves showed (Figure not shown) that 'G-CSF 2 cycles' without secondary G-CSF prophylaxis had a $100 \%$ probability of being cost-effective (up to WTP thresholds of approximately $€ 0.9$ million). 


\section{Scenario analysis}

When excluding the hospitalization costs from the FN event costs, the costs decreased to $€ 16,113, € 18,161$ and $€ 22,504$ for the 'G-CSF 2 cycles' without and with secondary G-CSF prophylaxis and the 'CSF 6 cycles' strategies respectively (Table 4.2). The abovementioned ICERs increased to $€ 24,039$ (from €21,639) per patient with FN episode prevented, $€ 18,788$ (from $€ 17,008$ ) per $F N$ event prevented and $€ 4.0$ million (from €3.6 million) per QALY, respectively.

\section{Sensitivity analysis}

No sensitivity analyses were identified in which the most cost-effective strategy (based on QALYS) was altered.

\section{Threshold analysis}

In order for 'G-CSF 6 cycles' to be cost-effective (based on a WTP threshold of $€ 80,000$ per QALY), G-CSF was allowed to cost maximum $€ 214$ per cycle (original value: $€ 1,636)$. With regards to the FN disutility (original value: -0.150 ) and its duration (original value: 10 days), 'G-CSF 6 cycles' only becomes cost-effective for implausible disutility (-7.8 or smaller) and duration (520 days or larger) values.

\section{Discussion}

To examine the cost-effectiveness (in terms of cost per QALY) of primary G-CSF prophylaxis, without or with secondary G-CSF prophylaxis, a Markov model was constructed based on a recent RCT for breast cancer patients at risk for FN. Based on a WTP threshold of $€ 80,000$ per QALY, 'G-CSF 2 cycles' without secondary prophylaxis was considered cost-effective. This finding was considered robust as the probability of being cost-effective was $100 \%$ and the most cost-effective treatment strategy was not altered in the scenario analysis or any of the sensitivity analyses. The threshold analyses showed that 'G-CSF 6 cycles' would be cost-effective if the costs of G-CSF per cycle would be reduced from $€ 1,636$ to $€ 214$ or lower per cycle. Given the robustness of the results, the study conclusions can most likely be generalized beyond the Netherlands. 


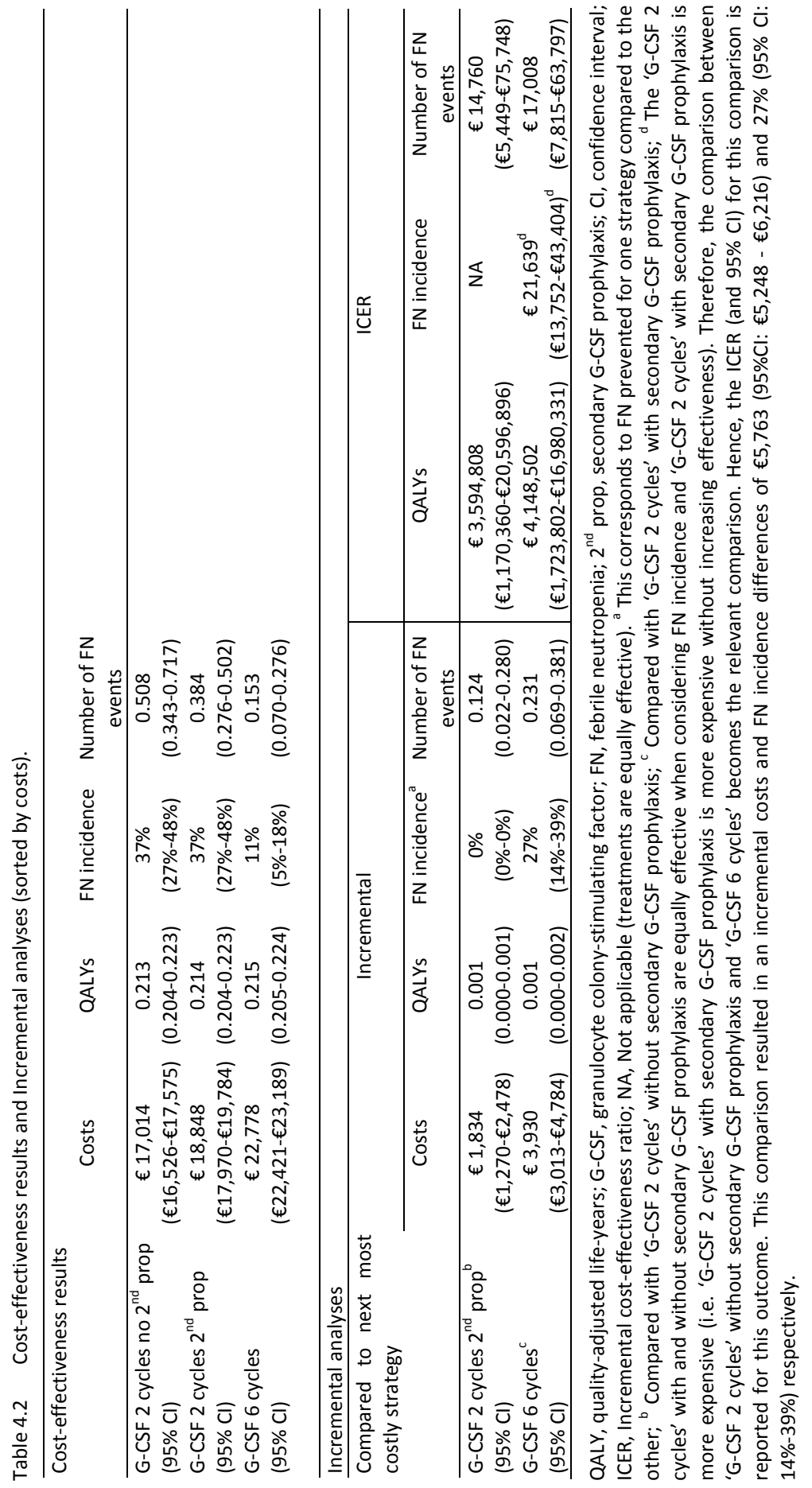


The present study had a few limitations. Firstly, the health care perspective was used for the calculation of costs instead of the societal perspective which includes productivity losses. Nevertheless, most breast cancer patients stop working during the chemotherapy cycles, so productivity losses would be equal for all strategies and thus not affecting the incremental outcomes. Secondly, the current analysis did not take into account long term costs and effects, assuming that FN events would not affect long term morbidity and mortality. Finally, it was assumed that all patients would receive all six chemotherapy cycles without delay. This was in line with observations in the trial as a delay occurred in only $6 \%$ of the patients in the G-CSF2 cycles arm and $11 \%$ in the 'G-CSF 6 cycles' arm (all non-hematological or non-therapy related).

Obviously, other aspects than cost-effectiveness are of relevance. Occurrence of an FN episode may result in chemotherapy dose reductions or schedule modifications which could affect treatment efficacy. ${ }^{15}$ In our patient population no difference was seen in dose reductions (8\%) nor in dose delay (6\% in 'G-CSF 2 cycles' compared to $11 \%$ in 'G-CSF 6 cycles'). Additionally, QoL is a relevant aspect in antitumor therapy which is negatively influenced by FN events and positively by G-CSF prophylaxis. ${ }^{7,16,17}$ Hence, both FN related mortality and morbidity should be taken into account. Although no patients died in our study, of whom most had an excellent performance score and were of young age, in-hospital mortality is 3.6\% for unselected (all stages) breast cancer patients admitted with FN. For chemotherapy regimen with more than $20 \%$ FN risk, without primary but with secondary G-CSF prophylaxis, the mortality risk is less than $1 \% .{ }^{18}$ It can be questioned what the minimally acceptable mortality risk should be for patients at risk of FN. ${ }^{17,19}$

From a cost-effective perspective primary G-CSF prophylaxis during all chemotherapy cycles should not be recommended. Other expensive cancer drugs (e.g. trastuzumab ${ }^{20}$ ), have been associated with lower ICERs than $€ 4$ million and thus probably provide better value for money. Given that available resources in health care are scarce, it is more efficient to limit primary G-CSF prophylaxis to the first two chemotherapy cycles without secondary prophylaxis.

In conclusion, limiting primary G-CSF prophylaxis saves costs, but leads to an increase in FN incidence. In clinical practice the latter may result in chemotherapy treatment effectiveness loss due to dose reductions and/or delay. Clinical guidelines advise primary G-CSF prophylaxis during all six chemotherapy cycles in patients with an increased risk of FN. Nonetheless, the current study indicates that it is cost-effective to limit primary G-CSF prophylaxis to the first two chemotherapy cycles strategy without secondary prophylaxis for breast cancer patients at risk of FN. 


\section{References}

1. Cullen M, Baijal S. Prevention of febrile neutropenia: use of prophylactic antibiotics. Br J Cancer 2009; 101 Suppl 1:S11-4.

2. Timmer-Bonte JN, de Boo TM, Smit HJ, Biesma B, Wilschut FA, Cheragwandi SA, Termeer A, Hensing CA, Akkermans J, Adang EM, Bootsma GP, Tjan-Heijnen VC. Prevention of chemotherapy-induced febrile neutropenia by prophylactic antibiotics plus or minus granulocyte colony-stimulating factor in small-cell lung cancer: a Dutch Randomized Phase III Study. J Clin Oncol 2005;23:7974-84.

3. Ozer H, Armitage JO, Bennett CL, Crawford J, Demetri GD, Pizzo PA, Schiffer CA, Smith TJ, Somlo G, Wade JC, Wade JL 3rd, Winn RJ, Wozniak AJ, Somerfield MR; American Society of Clinical Oncology. 2000 update of recommendations for the use of hematopoietic colony-stimulating factors: evidencebased, clinical practice guidelines. American Society of Clinical Oncology Growth Factors Expert Panel. J Clin Oncol 2000;18:3558-85.

4. Aapro MS, Bohlius J, Cameron DA, Dal Lago L, Donnelly JP, Kearney N, Lyman GH, Pettengell R, TjanHeijnen VC, Walewski J, Weber DC, Zielinski C; European Organisation for Research and Treatment of Cancer. 2010 update of EORTC guidelines for the use of granulocyte-colony stimulating factor to reduce the incidence of chemotherapy-induced febrile neutropenia in adult patients with lymphoproliferative disorders and solid tumours. Eur J Cancer 2011;47:8-32.

5. National Comprehensive Cancer Network. Myeloid growth factors. Practice guidelines in the oncology. http://www.nccn.org/professionals/physician_gls/f_guidelines.asp\#supportive (Date last accessed: April 17th, 2014).

6. Smith TJ, Khatcheressian J, Lyman GH, Ozer H, Armitage JO, Balducci L, Bennett CL, Cantor SB, Crawford J, Cross SJ, Demetri G, Desch CE, Pizzo PA, Schiffer CA, Schwartzberg L, Somerfield MR, Somlo G, Wade JC, Wade JL, Winn RJ, Wozniak AJ, Wolff AC. 2006 update of recommendations for the use of white blood cell growth factors: an evidence-based clinical practice guideline. J Clin Oncol 2006;24:3187-205.

7. Martín M, Lluch A, Seguí MA, Ruiz A, Ramos M, Adrover E, Rodríguez-Lescure A, Grosse R, Calvo L, Fernandez-Chacón C, Roset M, Antón A, Isla D, del Prado PM, Iglesias L, Zaluski J, Arcusa A, LópezVega JM, Muñoz M, Mel JR. Toxicity and health-related quality of life in breast cancer patients receiving adjuvant docetaxel, doxorubicin, cyclophosphamide (TAC) or 5-fluorouracil, doxorubicin and cyclophosphamide (FAC): impact of adding primary prophylactic granulocyte-colony stimulating factor to the TAC regimen. Ann Oncol 2006;17:1205-12.

8. Vogel CL, Wojtukiewicz MZ, Carroll RR, Tjulandin SA, Barajas-Figueroa $\amalg$, Wiens BL, Neumann TA, Schwartzberg LS. First and subsequent cycle use of pegfilgrastim prevents febrile neutropenia in patients with breast cancer: a multicenter, double-blind, placebo-controlled phase III study. J Clin Oncol 2005;23:1178-84.

9. von Minckwitz G, Kümmel S, du Bois A, Eiermann W, Eidtmann H, Gerber B, Hilfrich J, Huober J, Costa SD, Jackisch C, Grasshoff ST, Vescia S, Skacel T, Loibl S, Mehta KM, Kaufmann M; German Breast Group. Pegfilgrastim +/- ciprofloxacin for primary prophylaxis with TAC (docetaxel/ doxorubicin/cyclophosphamide) chemotherapy for breast cancer. Results from the GEPARTRIO study. Ann Oncol 2008;19:292-8.

10. Aarts MJ, Grutters JP, Peters FP, Mandigers CM, Dercksen MW, Stouthard JM, Nortier HJ, van Laarhoven HW, van Warmerdam LJ, van de Wouw AJ, Jacobs EM, Mattijssen V, van der Rijt CC, Smilde TJ, van der Velden AW, Temizkan M, Batman E, Muller EW, van Gastel SM, Joore MA, Borm GF, TjanHeijnen VC. Cost effectiveness of primary pegfilgrastim prophylaxis in patients with breast cancer at risk of febrile neutropenia. J Clin Oncol 2013;31:4283-9.

11. Aarts MJ, Peters FP, Mandigers CM, Dercksen MW, Stouthard JM, Nortier HJ, van Laarhoven HW, van Warmerdam LJ, van de Wouw AJ, Jacobs EM, Mattijssen V, van der Rijt CC, Smilde TJ, van der Velden AW, Temizkan M, Batman E, Muller EW, van Gastel SM, Borm GF, Tjan-Heijnen VC. Primary granulocyte colony-stimulating factor prophylaxis during the first two cycles only or throughout all chemotherapy cycles in patients with breast cancer at risk for febrile neutropenia. J Clin Oncol 2013;31:4290-6. 
12. Council for Public Health and Health Care. Sensible and sustainable care (in Dutch). Zoetermeer: Council for Public Health and Health Care 2006.

13. Briggs A, Sculpher M, Claxton K. Decision modelling for health economic evaluation. Oxford: Oxford University Press 2006.

14. Statistics Netherlands. Consumentenprijzen; prijsindex. http://statline.cbs.nl/ (Date last accessed: April 17th, 2014).

15. Wildiers $\mathrm{H}$, Reiser $\mathrm{M}$. Relative dose intensity of chemotherapy and its impact on outcomes in patients with early breast cancer or aggressive lymphoma. Crit Rev Oncol Hematol 2011;77:221-40.

16. Barcenas $\mathrm{CH}$, Niu J, Zhang N, Zhang Y, Buchholz TA, Elting LS, Hortobagyi GN, Smith BD, Giordano SH. Risk of hospitalization according to chemotherapy regimen in early-stage breast cancer. J Clin Oncol 2014;32:2010-7.

17. Kuderer NM, Dale DC, Crawford J, Cosler LE, Lyman GH. Mortality, morbidity, and cost associated with febrile neutropenia in adult cancer patients. Cancer 2006;106:2258-66.

18. Brain EG, Bachelot T, Serin D, Kirscher S, Graic Y, Eymard JC, Extra JM, Combe M, Fourme E, Noguès C, Rouëssé J; RAPP-01 Trial Investigators. Life-threatening sepsis associated with adjuvant doxorubicin plus docetaxel for intermediate-risk breast cancer. JAMA 2005;293:2367-71.

19. Kuderer NM, Wolff AC. Enhancing therapeutic decision making when options abound: Toxicities matter. J Clin Oncol 2014;32:1990-3.

21. Eisai. Eribulin for the treatment of locally advanced breast cancer or metastatic breast cancer: submission to National Institute of Health and Clinical Excellence. Single technology appraisal (STA). 2011. 
Chapter 4 


\section{Chapter 5}

\section{Neutrophil recovery in breast cancer patients receiving docetaxel-containing chemotherapy with and without G-CSF prophylaxis}

Maureen J Aarts, Birgit E Vriens, Maaike de Boer, Frank P Peters, Caroline M Mandigers, M Wouter Dercksen, Jacqueline M Stouthard, Jolien Tol, Laurence J van Warmerdam, Agnes J van de Wouw, Esther M Jacobs, Carin C van der Rijt, Tineke J Smilde, Annette W van der Velden, Nelly Peer, Vivianne C Tjan-Heijnen

Submitted 


\section{Abstract}

Purpose

Chemotherapy-induced febrile neutropenia (FN) is the highest during the first cycles of chemotherapy, thereafter the risk rapidly declines. Primary aim of current study was to assess whether there is a protective effect of prior chemotherapy or of prior G-CSF on the next cycle blood cell counts.

\section{Methods}

We evaluated the hematologic toxicity, based on a randomized phase III study in breast cancer patients $(n=167)$ with $>20 \%$ risk of $F N$ treated with primary pegfilgrastim prophylaxis throughout all chemotherapy cycles (G-CSF 1-6 arm) or primary pegfilgrastim prophylaxis during the first two chemotherapy cycles only (G-CSF 1-2 arm). For the current analyses, patients with FN, chemotherapy or G-CSF treatment modifications were excluded. The primary endpoint was the nadir blood cell counts over cycles 1 through 6 for patients in the G-CSF 1-6 arm and over cycles 3 through 6 for patients in the G-CSF 1-2 arm.

\section{Results}

For the present analyses, 32 patients in the G-CSF 1-6 arm were eligible and 15 patients in G-CSF 1-2 arm. In the G-CSF 1-6 arm, the median white blood cell count (WBC) and absolute neutrophil count (ANC) nadir slowly decreased from $10.8 \times 10^{9} / \mathrm{I}$ in cycle 1 to $7.5 \times 10^{9} / \mathrm{l}$ in cycle 6 and from $7.1 \times 10^{9} / I$ to $5.5 \times 10^{9} /$, respectively. The median WBC nadir in the G-CSF $1-2$ arm decreased from $1.2 \times 10^{9} / \mathrm{I}$ in cycle 3 to $0.9 \times 10^{9} / \mathrm{I}$ in cycle 6 and the ANC nadir showed a grade 4 neutropenia of $0.1 \times 10^{9} / I$ in cycle 3 to 6 . All patients had ANC recovery to normal levels $\left(\geq 1.5 \times 10^{9} /\right.$ l) without delay at day 1 of next cycle.

\section{Conclusion}

We conclude that there is no protective effect of prior G-CSF or prior chemotherapy use on nadir blood counts in subsequent cycles. 


\section{Introduction}

An anthracycline-taxane chemotherapy regime is effective in breast cancer, but it is also very myelotoxic with a substantial risk of febrile neutropenia (FN). ${ }^{1,2}$ The FN incidence of myelosuppressive chemotherapy regimes without primary G-CSF prophylaxis is reported to be highest in the first (two) chemotherapy cycles, with declining incidence thereafter. ${ }^{1-4}$

One might hypothesize that chemotherapy-induced myelosuppression leads to intrinsic hematopoietic growth factor production and as such protects against FN during later chemotherapy cycles. ${ }^{5}$

At the same time, for patients who are treated with primary G-CSF prophylaxis (i.e. from the first cycle onwards) one may conclude that continuation of prophylaxis during later chemotherapy cycles may be less effective because of the lower baseline risk of FN in later chemotherapy cycles. ${ }^{1,2}$ We performed, therefore, a phase III study in which breast cancer patients treated with myelosuppressive chemotherapy were randomized to G-CSF prophylaxis during all six chemotherapy cycles or to G-CSF prophylaxis limited to the first two chemotherapy cycles only. ${ }^{6}$ In contrast to what we had expected, G-CSF use limited to the first two chemotherapy cycles was not effective, as in total $36 \%$ of patients developed $\mathrm{FN}$ compared to $10 \%$ in the control arm. Interestingly, we observed that the highest FN incidence in the experimental arm occurred in the third chemotherapy cycle (24\% of patients), which was the first cycle without G-CSF prophylaxis. Remarkably, in the fourth to sixth chemotherapy cycle, the incidence of FN again declined to an average of 5\%. This might possibly have been the result of secondary antibiotic prophylaxis (7\% of patients), secondary G-CSF prophylaxis ( $17 \%$ of patients) or chemotherapy dose-modifications ( $8 \%$ of patients). However, this observation may also be explained by a protective effect of prior chemotherapy or of prior G-CSF on the blood cell counts of the fourth to second chemotherapy cycle. ${ }^{7}$ If indeed this is the case, blood cell counts would gradually increase during subsequent chemotherapy cycles. We therefore studied nadir blood cell counts over the subsequent chemotherapy cycles in patients treated in the above mentioned phase III clinical trial. To prevent confounding, we excluded from our present analysis patients who developed FN event, received secondary G-CSF prophylaxis or chemotherapy dose reductions during later cycles.

\section{Methods}

\section{Clinical phase III study}

Full methods and results of the phase III study have been published before. ${ }^{6,8}$ Patients were randomized to G-CSF prophylaxis during all six chemotherapy cycles or to G-CSF 
prophylaxis limited to the first two chemotherapy cycles only. For the phase III study, breast cancer patients were eligible if treated with 3-weekly chemotherapy and being at risk of FN according to international guidelines. For example, TAC (docetaxel, adriamycin, cyclophosphamide) or AT (adriamycin, docetaxel) are chemotherapy regimes with more than $20 \%$ risk of $\mathrm{FN}$; TC (docetaxel, cyclophosphamide) or docetaxel monotherapy have a $10-20 \%$ risk of $\mathrm{FN}$ and in the presence of one or more patient risk factors, risk of $\mathrm{FN}$ increases to more than $20 \%$. Patients were required to have an absolute neutrophil count $(\mathrm{ANC})>1.5 \times 10^{9} / \mathrm{l}$, adequate renal and hepatic function, no signs of an active uncontrolled infection or other serious co-morbidity before enrolment.

\section{Study design}

We included the data from patients treated according to the aforementioned phase III study, and evaluated the hematologic nadir toxicity for all included patients per treatment arm.

We excluded patients who developed FN, had chemotherapy dose-reductions or chemotherapy delays (more than 3 days from scheduled treatment) during treatment or who did not use G-CSF prophylaxis according to plan (either prematurely ceased GCSF prophylaxis despite randomization to G-CSF prophylaxis during all six chemotherapy cycles, '1-6 G-CSF arm', or who had secondary G-CSF prophylaxis during cycles 3 to 6 in the '1-2 G-CSF arm' because of FN or other reason). In case of missing values in cycles 4 to 6 , patients were considered not-assessable and therefore excluded.

Blood samples were taken on day 1 and nadir blood counts on day 10-14 of each cycle to assess myelotoxicity. In case of FN, daily complete blood cell counts were to be performed until recovery of ANC $\geq 0.5 \times 10^{9} /$.

\section{Study Endpoints}

The hematologic toxicity per cycle per treatment arm was evaluated, which was a prespecified secondary endpoint of the randomized clinical phase III trial. ${ }^{6}$ We analysed nadir white blood cell (WBC), neutrophil and platelet counts in patients treated with primary G-CSF prophylaxis during all chemotherapy cycles and of patients treated with G-CSF prophylaxis during cycles 1 and 2 only.

For the current study, the primary endpoint was the nadir blood cell counts in cycles 1 through 6 for the selected, eligible patients who received G-CSF prophylaxis in cycles 1-6 and the nadir blood cell counts in cycles 3 through 6 for the selected, eligible patients who per protocol did not receive G-CSF prophylaxis in cycles 3-6 (only G-CSF in cycles 1-2). All analyses are descriptive in nature. 


\section{Results}

\section{Patients}

In the clinical phase III trial, in total 167 patients were included. For the present research question, 32 patients in the G-CSF 1-6 arm were eligible and 15 patients in G-CSF 1-2 arm. We excluded patients because of FN (8 and 30 patients, respectively), because of chemotherapy delay or dose reductions (11 and 7, respectively) and because of G-CSF protocol violations ( 2 and 17, respectively). Other patients were excluded due to missing blood nadir values in one or more cycles. There were no interindividual differences regarding albumin, bilirubin, alkaline phosphatase, lactate dehydrogenase and aspartate aminotransferase (data not shown). Baseline characteristics are shown in Table 5.1.

Table $5.1 \quad$ Baseline characteristics.

\begin{tabular}{|c|c|c|c|c|c|c|c|c|}
\hline & \multicolumn{2}{|c|}{$\begin{array}{c}\text { G-CSF 1-6 } \\
n=84\end{array}$} & \multicolumn{2}{|c|}{$\begin{array}{c}\text { G-CSF 1-6 } \\
n=32\end{array}$} & \multicolumn{2}{|c|}{$\begin{array}{c}\text { G-CSF 1-2 } \\
N=83\end{array}$} & \multicolumn{2}{|c|}{$\begin{array}{c}\text { G-CSF } 1-2 \\
n=15\end{array}$} \\
\hline & No. & $(\%)$ & No. & $(\%)$ & No. & $(\%)$ & No. & $(\%)$ \\
\hline \multicolumn{9}{|l|}{ Patient characteristics } \\
\hline Median age, (range) years & \multicolumn{2}{|c|}{$50(26-69)$} & \multicolumn{2}{|c|}{$56(32-73)$} & \multicolumn{2}{|c|}{$50(31-70)$} & \multicolumn{2}{|c|}{$58(39-76)$} \\
\hline$\leq 65$ years & 79 & 94 & 30 & 94 & 78 & 94 & 13 & 87 \\
\hline ECOG PS 0-1 & 81 & 96 & 32 & 100 & 81 & 98 & 15 & 100 \\
\hline (Neo-)adjuvant treatment setting & 84 & 100 & 32 & 100 & 80 & 96 & 14 & 93 \\
\hline Primary antibiotics prophylaxis & 34 & 40 & 17 & 53 & 36 & 43 & 5 & 33 \\
\hline \multicolumn{9}{|l|}{ Baseline blood counts, median (range) } \\
\hline White blood cell count $\left(\times 10^{9} / \mathrm{I}\right)$ & \multicolumn{2}{|c|}{$7.7(3.4-21.1)$} & \multicolumn{2}{|c|}{$7.0(4-19.6)$} & \multicolumn{2}{|c|}{$7.6(4.3-18.0)$} & \multicolumn{2}{|c|}{$6.8(4.3-11.7)$} \\
\hline Absolute neutrophil count (x109/I) & \multicolumn{2}{|c|}{$4.8(2.0-64.3)$} & \multicolumn{2}{|c|}{$4.4(2.1-17.8)$} & \multicolumn{2}{|c|}{$4.5(2.1-16.2)$} & \multicolumn{2}{|c|}{$3.9(2.6-8.4)$} \\
\hline Platelet count (x109/I) & \multicolumn{2}{|c|}{$296(129-541)$} & \multicolumn{2}{|c|}{$297(143-541)$} & \multicolumn{2}{|c|}{$289(160-544)$} & \multicolumn{2}{|c|}{$262(160-544)$} \\
\hline \multicolumn{9}{|l|}{ Chemotherapy } \\
\hline TAC & 81 & 96 & 32 & 100 & 77 & 93 & 14 & 93 \\
\hline FEC-D & 3 & 4 & 0 & 0 & 3 & 4 & 0 & 0 \\
\hline DOC & 0 & 0 & 0 & 0 & 2 & 2 & 1 & 7 \\
\hline $\mathrm{TC}$ & 0 & 0 & 0 & 0 & 1 & 1 & 0 & 0 \\
\hline
\end{tabular}

G-CSF, granulocyte colony stimulating factor; PS, performance Score; TAC, docetaxel, doxorubicin, cyclophosphamide; FEC-D, 5-Fluorouracil, epirubicin, cyclophosphamide-docetaxel; DOC, docetaxel: TC, docetaxel, cyclophosphamide.

\section{Nadir blood cell counts}

In Table 5.2, it is shown that in the selected, eligible patients treated in the G-CSF 1-6 $\operatorname{arm}\left(\mathrm{n}=32\right.$ ), median nadir WBC decreased from $10.8 \times 10^{9} / \mathrm{l}$ in cycle 1 to $7.5 \times 10^{9} / \mathrm{l}$ in cycle 6 and ANC from $7.1 \times 10^{9} / \mathrm{I}$ to $5.5 \times 10^{9} /$ l. Nadir blood cell counts also decreased during treatment in the G-CSF 1-2 arm when primary G-CSF prophylaxis was discontinued conform study protocol in cycle three and further: nadir WBC dropped from $1.2 \times 109 / /$ in cycle 3 to $0.9 \times 10^{9} / /$ in cycle 6 and nadir ANC showed a persistent grade 4 neutropenia of $0.1 \times 109 / 1$ in cycles 3 to 6 . (Table 5.3). 
Of note, when considering the total patient population irrespective of changes in chemotherapy or G-CSF administration, nadir blood cell counts in the G-CSF 1-6 arm gradually decreased during treatment, whereas in the G-CSF 1-2 arm nadir blood cell counts gradually increased from cycle three through six: from $1.2 \times 10^{9} / \mathrm{I}$ to $1.8 \times 10^{9} / \mathrm{I}$ for WBC and from $0.1 \times 10^{9} /$ to $0.5 \times 10^{9} /$ I for ANC (Tables 5.2 and 5.3).

Nadir platelet counts remained stable over the consecutive chemotherapy cycles (data not shown).

Table 5.2 Hematologic Toxicity G-CSF 1-6 arm all patients and subgroup *: Nadir values.

\begin{tabular}{|c|c|c|c|c|}
\hline & \multicolumn{2}{|c|}{$\begin{array}{c}\text { G-CSF 1-6 } \\
\mathrm{N}=84\end{array}$} & \multicolumn{2}{|c|}{$\begin{array}{c}\text { G-CSF 1-6 } \\
\mathrm{N}=32\end{array}$} \\
\hline & Median & IQR & Median & IQR \\
\hline \multicolumn{5}{|c|}{ White blood cell count** } \\
\hline Cycle 1 & 10.3 & $6.2-13.6$ & 10.8 & $5.5-15.2$ \\
\hline Cycle 2 & 10.1 & $8.1-12.3$ & 10.1 & $7.9-15.4$ \\
\hline Cycle 3 & 9.1 & $7.2-11.8$ & 10.1 & $7.4-15.4$ \\
\hline Cycle 4 & 9.1 & $7.4-11.8$ & 9.4 & $5.1-12.0$ \\
\hline Cycle 5 & 8.9 & $6.4-10.7$ & 8.9 & $5.4-11.8$ \\
\hline Cycle 6 & 7.8 & $5.3-9.3$ & 7.5 & $3.4-9.5$ \\
\hline \multicolumn{5}{|c|}{ Neutrophil count** } \\
\hline Cycle 1 & 7.1 & $3.9-9.5$ & 7.1 & $3.9-10.9$ \\
\hline Cycle 2 & 6.7 & $5.3-8.6$ & 7.5 & $5.7-11.0$ \\
\hline Cycle 3 & 6.6 & $4.8-8.8$ & 7.4 & $4.8-12.3$ \\
\hline Cycle 4 & 6.6 & $5.2-8.4$ & 7.0 & $3.4-9.6$ \\
\hline Cycle 5 & 6.5 & $3.8-8.0$ & 6.7 & $3.5-8.8$ \\
\hline Cycle 6 & 5.3 & $3.3-6.8$ & 5.5 & $2.5-7.4$ \\
\hline
\end{tabular}

* Subgroup; patients without FN, chemotherapy dose reductions or delay, G-CSF prophylaxis 'violation' or missing values cycle 3 to $6^{* *} \times 10^{9} /$ l. G-CSF, granulocyte colony stimulating factor; IQR, interquartile range.

\section{Day 1 blood cell counts}

In patients in G-CSF 1-6 arm who used G-CSF prophylaxis during all chemotherapy cycles, the day-one ANC values remained stable throughout cycles 3 to 6 . The median day-one ANC values were on average $5.8 \times 10^{9} /$ I. In contrast, in the G-CSF 1-2 arm without secondary G-CSF prophylaxis in cycles 3 through 6 as defined in the study protocol the median day-one ANC slowly declined from cycles 3 to 6 . (data not shown) 
Table 5.3 Hematologic Toxicity G-CSF 1-2 arm all patients and subgroup*: Nadir values.

\begin{tabular}{|c|c|c|c|c|}
\hline & \multicolumn{2}{|c|}{$\begin{array}{c}\text { G-CSF 1-2 } \\
N=83\end{array}$} & \multicolumn{2}{|c|}{$\begin{array}{c}\text { G-CSF 1-2 } \\
\mathrm{N}=15\end{array}$} \\
\hline & Median & IQR & Median & IQR \\
\hline \multicolumn{5}{|c|}{ White blood cell count** } \\
\hline Cycle 3 & 1.2 & $0.7-1.8$ & 1.2 & $0.8-1.4$ \\
\hline Cycle 4 & 1.5 & $0.9-5.1$ & 1.0 & $0.8-1.5$ \\
\hline Cycle 5 & 1.4 & $1.0-6.3$ & 1.2 & $0.8-1.4$ \\
\hline Cycle 6 & 1.8 & $0.9-5.9$ & 0.9 & $0.7-1.8$ \\
\hline \multicolumn{5}{|c|}{ Neutrophil count** } \\
\hline Cycle 3 & 0.1 & $0-0.5$ & 0.1 & $0-0.2$ \\
\hline Cycle 4 & 0.2 & $0.1-3.6$ & 0.1 & $0-0.1$ \\
\hline Cycle 5 & 0.2 & $0.1-4.3$ & 0.1 & $0.03-0.1$ \\
\hline Cycle 6 & 0.5 & $0.1-4.0$ & 0.1 & $0.05-0.5$ \\
\hline
\end{tabular}

* Subgroup; patients without FN, chemotherapy dose reductions or delay, G-CSF prophylaxis 'violation' or missing values cycle 3 to $6{ }^{* *} \times 10^{9} /$ I. G-CSF, granulocyte colony stimulating factor; IQR, interquartile range.

\section{Discussion}

FN is a serious side effect of cancer treatment. ${ }^{3,4}$ For patients at risk (>20\%) of FN, primary G-CSF prophylaxis is recommended as it reduces the risk of chemotherapyinduced FN. ${ }^{9}$ Previously, the risk of FN was presumed to be highest during the first chemotherapy cycles, but we showed that discontinuation of G-CSF prophylaxis after the first two chemotherapy cycles resulted in a rebound high FN incidence in the next chemo-therapy cycles. ${ }^{6}$ Apparently, a prior chemotherapy cycle in combination with G-CSF prophylaxis seemed not to be myelo-protective for a later chemotherapy cycle. In order to find support for this latter assumption, we looked more in detail to the hematologic toxicity in patients in whom in-patient comparisons were possible e.g. patients without chemotherapy dose modifications or changes in G-CSF prophylaxis during their treatment and without FN event. Here, we show that the median nadir WBC and ANC slowly decreased while continuing on G-CSF prophylaxis, and that the median ANC nadir remained steadily low in cycles 3 to 6 in those who did not receive G-CSF prophylaxis during these cycles. Hence, we conclude that prior G-CSF prophylaxis with pegfilgrastim during 3-weekly chemotherapy and prior chemotherapy have no myeloprotective effect on subsequent chemotherapy cycles.

Pegfilgrastim acts by self-regulated, neutrophil-mediated clearance. ${ }^{10}$ In a doseranging pegfilgrastim study in breast cancer patients, it was demonstrated that the exposure to pegfilgrastim was lower in cycle 3 than in cycle 1, however the ANC nadir improved and the duration of neutropenia decreased in cycle 2 and the subsequent cycles, suggesting an expansion of neutrophil and neutrophil precursors mass in the later cycles that results in an increase in drug clearance. ${ }^{11}$ This suggestion was 
supported by Invernizzi et $\mathrm{al}^{7}{ }^{7}$ who demonstrated not only an increase of ANC (evaluated at day 14 or later and immediately before next chemotherapy) but also an increase of immature myeloid cells in peripheral blood after the first chemotherapy cycle given with G-CSF support with a relatively constant level in the subsequent cycles. Without G-CSF support no increase of the neutrophil count immediately before chemotherapy occurs; the count was the lowest around two weeks after chemotherapy with return to baseline at day one of chemotherapy. Also, progenitor cells apoptosis was significantly higher in case no pegfilgrastim support was given compared with pegfilgrastim support. ${ }^{7,12}$ So, increase of progenitor pool and decrease of apoptosis could be one factor explaining the differences in blood cell counts between both treatment arms. With this mechanism of action of G-CSF we would have expected an increase of blood cell counts in the next chemotherapy cycle, however we observed a decrease.

Of relevance, if the post-nadir ANC recovers $\geq 1.0 \times 10^{9} / /$ before a next chemotherapy cycle - a surrogate marker threshold of pegfilgrastim clearance to subtherapeutic levels - hematopoietic function has recovered and no additional myelosuppression will occur. ${ }^{13,14}$ All our patients experienced an ANC recovery to normal levels $\left(\geq 1.5 \times 10^{9} / \mathrm{I}\right)$ at day one of a new cycle while on G-CSF prophylaxis.

Previously, it was reported that the incidence of FN and of grade IV neutropenia declines during later chemotherapy cycles, and that this cannot entirely be explained by use of secondary G-CSF prophylaxis or chemotherapy dose-reductions. ${ }^{4,15}$ We also noticed a slight increase of nadir WBC and ANC during cycles 3 through 6 in the G-CSF 1-2 arm, but after exclusion of patients who re-initiated G-CSF prophylaxis $(n=17)$ and of patients who had chemotherapy adjustments $(n=7)$, we saw a persistent steady grade 4 neutropenia (data not shown). Of note, we didn't exclude patients with primary antibiotics prophylaxis as its value in reducing grade 4 neutropenia is neglectable.

Factors that increase risk of neutropenia and $\mathrm{FN}$ are patient and treatment related. Patient risk factors are pretreatment, older age, lower weight, vascular comorbidity and baseline low WBC counts and higher bilirubine levels. ${ }^{16-18}$ We couldn't identify any of these pretreatment patient risk factors in our patient population. Of relevance, the occurrence of FN increases the risk for a new FN event, so we excluded the 38 patients that developed FN to exclude possible confounding. Several covariated in relation with interindividual variation in the time course of neutropenia have been investigated. The most relevant predictors for this interindividual variability were albumin, alkaline, bilirubin, phosphatase, lactate dehydrogenase and aspartate aminotransferase. ${ }^{19,20}$ In our population no interindividual differences for these predictors were seen. Treatment related risk factor for neutropenia event are prior chemotherapy and the intensity of chemotherapy. ${ }^{15}$ Only one patient received prior chemotherapy (FEC; 5-Fluorouracil, epirubicin, cyclophosphamide), and almost all 
patients received TAC (docetaxel, adriamycin, cyclophosphamide) chemotherapy. The greater the myelosuppressive potential of chemotherapy the lower the ANC nadir, ${ }^{21}$ which in turn could enhance intrinsic hematopoietic growth factor production and subsequently protect against chemotherapy-induced neutropenia. Little evidence regarding this subject is published. One study demonstrated that in vivo the chemotherapy increases the GM-CSF (granulocyte-macrophage colony stimulating factor), hematopoietic growth factor. ${ }^{5}$ So, if this is true we would have expected, after excluding all possible confounders, chemotherapy itself would increase the blood cell counts in the next cycle. However, no such observation was seen.

In conclusion, we analysed chemotherapy-induced hematologic toxicity after exclusion of possible risk factors of neutropenia, and apart from protective effect of G-CSF for the cycle where G-CSF was given in, we did not find a protective effective effect of G-CSF or chemotherapy on myelotoxicity in subsequent chemotherapy cycles. 


\section{References}

1. Martín M, Lluch A, Seguí MA, Ruiz A, Ramos M, Adrover E, Rodríguez-Lescure A, Grosse R, Calvo L, Fernandez-Chacón C, Roset M, Antón A, Isla D, del Prado PM, Iglesias L, Zaluski J, Arcusa A, LópezVega JM, Muñoz M, Mel JR. Toxicity and health-related quality of life in breast cancer patients receiving adjuvant docetaxel, doxorubicin, cyclophosphamide (TAC) or 5-fluorouracil, doxorubicin and cyclophosphamide (FAC): impact of adding primary prophylactic granulocyte colony stimulating factor to the TAC regimen. Ann Oncol 2006;17:1205-12.

2. von Minckwitz G, Kümmel S, du Bois A, Eiermann W, Eidtmann H, Gerber B, Hilfrich J, Huober J, Costa SD, Jackisch C, Grasshoff ST, Vescia S, Skacel T, Loibl S, Mehta KM, Kaufmann M; German Breast Group. Pegfilgrastim +/- ciprofloxacin for primary prophylaxis with TAC (docetaxel/doxorubicin/ cyclofosphamide) chemotherapy for breast cancer. Results from the GEPARTIO study. Ann Oncol 2008;19:292-8.

3. Vogel CL, Wojtukiewicz MZ, Carroll RR, Tjulandin SA, Barajas-Figueroa $L$, Wiens BL, Neumann TA, Schwartzberg LS. First and subsequent cycle use of pegfilgrastim prevents febrile neutropenia in patients with breast cancer: a multicenter, double-blind, placebo-controlled phase III study. J Clin Oncol 2005;23:1178-84.

4. Timmer-Bonte JN, de Boo TM, Smit HJ, Biesma B, Wilschut FA, Cheragwandi SA, Termeer A, Hensing CA, Akkermans J, Adang EM, Bootsma GP, Tjan-Heijnen VC. Prevention of chemotherapy-induced febrile neutropenia by prophylactic antibiotics plus or minus granulocyte-colony stimulating factor: a Dutch randomized phase III study. J Clin Oncol 2005;23:7974-84.

5. Czygier M, Lawicki S, Szmitkowski M, Mroczko B. Plasma granulocyte-macrophage colony stimulating factor (GM-CSF) and activity of enzymes in granulocytes of breast cancer patients. Przegl Lek 2006;63:654-7.

6. Aarts MJ, Peters FP, Mandigers CM, Dercksen MW, Stouthard JM, Nortier HJ, van Laarhoven HW, van Warmerdam LJ, van de Wouw AJ, Jacobs EM, Mattijssen V, van der Rijt CC, Smilde TJ, van der Velden AW, Temizkan M, Batman E, Muller EW, van Gastel SM, Borm GF, Tjan-Heijnen VC. Primary granulocyte colony-stimulating factor prophylaxis during the first two cycles only or throughout all chemotherapy cycles in patients with breast cancer at risk for febrile neutropenia. J Clin Oncol 2013;31:4290-6.

7. Invernizzi R, Grasso D, Travaglino E, Benatti C, Collovà E, Manzoni M, Livraghi L, Danova M, Riccardi A. Biological effects of pegfilgrastim on circulating neutrophils in breast cancer patients undergoing dose-dens chemotherapy. Oncology 2008;75:237-44.

8. Aarts MJ, Grutters JP, Peters FP, Mandigers CM, Dercksen MW, Stouthard JM, Nortier HJ, van Laarhoven HW, van Warmerdam LJ, van de Wouw AJ, Jacobs EM, Mattijssen V, van der Rijt CC, Smilde TJ, van der Velden AW, Temizkan M, Batman E, Muller EW, van Gastel SM, Joore MA, Borm GF, TjanHeijnen VC. Cost effectiveness of primary pegfilgrastim prophylaxis in patients with breast cancer at risk of febrile neutropenia. J Clin Oncol 2013;31:4283-9.

9. Aapro MS, Bohlius J, Cameron DA, Dal Lago L, Donnelly JP, Kearney N, Lyman GH, Pettengell R, TjanHeijnen VC, Walewski J, Weber DC, Zielinski C; European Organisation for Research and Treatment of Cancer. 2010 update of EORTC guidelines for the use of granulocyte colony-stimulating factor to reduce the incidence of chemotherapy-induced febrile neutropenia in adult patients with lymphoproliferative disorders and solid tumors. Eur J Cancer 2011;47:8-32.

10. Yang BB, Savin MA, Green M. Prevention of chemotherapy-induced neutropenia with pegfilgrastim: Pharmacokinetics and patient outcome. Chemotherapy 2012;58:387-98.

11. Holmes FA, Jones SE, O'Shaughnessy J, Vukelja S, George T, Savin M, Richards D, Glaspy J, Meza L, Cohen G, Dhami M, Budman DR, Hackett J, Brassard M, Yang BB, Liang BC. Comparable efficacy and safety profiles of once-per-cycle pegfilgrastim and daily injection filgrastim in chemotherapy-induced neutropenia: a multicenter dose-finding study in women with breast cancer. Ann Oncol 2002;13: 903-9. 
12. Danova M, Bencardino K, Manzoni M, Grasso D, Mariucci S, Rovati B. In vivo biological effects of pegfilgrastim after myelosuppressive chemotherapy in breast cancer. Anticancer Res 2007;75: 3399-402.

13. Pirker R, Ulsperger E, Messner J, Aigner K, Forstner B, Bacon P, Easton V, Skacel T. Achieving full-dose, on schedule administration of ACE chemotherapy every 14 days for the treatment of patients with extensive small-cell lung cancer. Lung 2006;184:279-85.

14. Engert A, Bredenfeld H, Döhner H, Ho AD, Schmitz N, Berger D, Bacon P, Skacel T, Easton V, Diehl V. Pegfilgrastim support for full delivery of BEACOPP-14 chemotherapy for patients with high risk Hodgkin's lymphoma: results of a phase II study. Haematologica 2006;91:546-9.

15. Crawford J, Glaspy JA, Stoller RG, Tomita DK, Vincent ME, McGuire BW, Ozer H. Final results of a placebo-controlled study of filgrastim in small-cell lung cancer: exploration of risk factors for febrile neutropenia. Support Cancer Ther 2005;3:36-46.

16. Schwenkglenks M, Pettengell R, Jackisch C, Paridaens R, Constenla M, Bosly A, Szucs TD, Leonard R. Risk factors for chemotherapy-induced neutropenia occurrence in breast cancer patients: data from the INC-EU Prospective Observational European neutropenia Study. Support Care Cancer 2011;4: 483-90.

17. Lyman $\mathrm{GH}$, Lyman $\mathrm{CH}$, Agboola O. Risk models for predicting chemotherapy-induced neutropenia. Oncologist 2005;10:427-37.

18. Jenkins P, Freeman S. Pretreatment haematological laboratory values predict for excessive myelosuppression in patients receiving adjuvant FEC chemotherapy for breast cancer. Ann Oncol 2009;20:34-40.

19. Kloft C, Wallin J, Henningsson A, Chatelut E, Karlsson MO. Population pharmacokineticpharmacodynamic model for neutropenia with patient subgroup identification: comparison across anticancer drugs. Clin Cancer 2006;12:5481-90.

20. van Hasselt JG, Gupta A, Hussein Z, Beijnen JH, Schellens JH, Huitema AD. Population pharmacokinetic-pharmacodynamic analysis for erlibulin mesilate associated neutropenia. Brit $\mathrm{J}$ of Clin Pharmacol 2013;76:412-24.

21. Yang BB, Kido A. Pharmacokinetics and pharmacodynamics of pegfilgrastim. Clin Pharmacokinet 2011;50:295-306. 


\section{Chapter 6}

\section{Doxorubicin/cyclophosphamide with concurrent versus sequential docetaxel as neoadjuvant treatment in patients with breast cancer}

Birgit EPJ Vriens, Maureen JB Aarts, B. de Vries, Saskia M van Gastel, J Wals, Tineke J Smilde, Laurence J van Warmerdam, Maaike de Boer, D J van Spronsen, George F Borm, Vivianne CG Tjan-Heijnen

European Journal of Cancer 2013;49:3102-3110 


\section{Abstract}

\section{Background}

This study was designed to determine whether delivering neo-adjuvant chemotherapy at a higher dose in a shorter period of time improves outcome of breast cancer patients.

\section{Patients and methods}

Women with newly diagnosed breast cancer were randomly assigned to neoadjuvant chemotherapy of four cycles of doxorubicin and cyclophosphamide followed by four cycles of docetaxel (AC $60 / 600-$ T $100 \mathrm{mg} / \mathrm{m}^{2}$ ) or six cycles of TAC $\left(75 / 50 / 500 \mathrm{mg} / \mathrm{m}^{2}\right)$ every 3 weeks. The primary endpoint was the pathologic complete response $(\mathrm{pCR})$ rate, defined as no invasive tumour present in the breast.

\section{Results}

In total, 201 patients were included. Baseline characteristics were well balanced. AC-T resulted in pCR in $21 \%$ and TAC in $16 \%$ of patients (odds ratio 1.44 (95\% confidence interval $(\mathrm{Cl}) 0.67-$ 3.10). AC-T without primary granulocyte-colony stimulating factor (G-CSF) prophylaxis was associated with more febrile neutropenia compared to TAC with primary GCSF prophylaxis (23\% versus $9 \%$ ), and with more grade $3 / 4$ sensory neuropathy ( $5 \%$ versus $0 \%$ ).

\section{Conclusion}

With a higher cumulative dose for the concurrent arm, no differences were observed between the two treatment arms with respect to $\mathrm{PCR}$ rate. The differential toxicity profile could partly be explained by different use of primary G-CSF prophylaxis. 


\section{Introduction}

Neoadjuvant chemotherapy has become the standard of care in patients with locally advanced or borderline resectable breast cancer. ${ }^{1}$ Interest has developed in extending this approach to patients with less advanced disease. Neoadjuvant chemotherapy allows observation of clinical response to systemic treatment, has the potential to down-stage the primary tumour which may facilitate breast conserving therapy, and bears the opportunity of down staging the axilla obviating the need of axillary treatment in some patients. ${ }^{2}$ In a trial setting, a neoadjuvant approach is attractive as with far less patients a more rapid outcome is available in comparison to adjuvant trials.

Currently, anthracyclines, cyclophosphamide and taxanes are considered to represent the most potent drugs in breast cancer. ${ }^{3,4}$ The NSABP-B28 and the CALGB-9344 trials were the first and largest studies to show a significant improvement in 5-year diseasefree survival ( $72 \%$ versus $76 \%$ and $65 \%$ versus $70 \%$, respectively), and the CALGB-9344 also in 5-year overall survival, for the addition of 3-weekly paclitaxel in sequence to four cycles of adjuvant doxorubicin and cyclophosphamide. ${ }^{5,6}$ Subsequently, the upfront combination of docetaxel with doxorubicin and cyclophosphamide (TAC) was shown to outperform the combination of 5-fluorouracil, doxorubicin and cyclophosphamide (FAC) as adjuvant treatment in node-positive and node-negative breast cancer patients. $^{7-9}$

In the neoadjuvant setting, the sequential administration of docetaxel after anthracycline-based therapy versus the anthracycline regimen alone was studied in two randomised studies. ${ }^{10,11}$ In the Aberdeen study, patients received four cycles of anthracycline-based chemotherapy; responders were randomised to receive another four cycles of anthracycline-based chemotherapy or four cycles of docetaxel. ${ }^{10}$ Switch to docetaxel showed a substantial improvement in response rate and an increased rate of breast conserving therapy. The NSABP-B27 trial also showed that addition of docetaxel after neoadjuvant anthracycline-based chemotherapy improved outcome with a significant increase in the pathological complete response $(p C R)$ rate $(14 \%$ versus $26 \%)^{11,12}$ Furthermore, relapse-free survival was moderately improved in the neoadjuvant docetaxel-containing arm.

Hence, both the upfront combination of docetaxel with anthracyclines and cyclophosphamide and the sequential use of docetaxel have shown to improve breast cancer outcome. In this study, we hypothesised that the planned chemotherapy dose and dose-intensity may be a critical factor for predicting outcome. This is supported by the hypothesis that delivering chemotherapy within a shorter time frame prevents tumour outgrowth and development of resistance and should thus be more efficacious than sequential regimens in which the chemotherapy is given in a larger time frame. ${ }^{13}$ 


\section{Patients and methods}

\section{Study design}

This was a multicentre, open-label, phase III study in women with newly diagnosed breast cancer. Patients were randomly assigned to neoadjuvant sequential chemotherapy or combination chemotherapy consisting of doxorubicin, cyclophosphamide and docetaxel.

Patients provided written informed consent before enrolment. The study was conducted in accordance with the Declaration of Helsinki and the principles of Good Clinical Practice. The study was approved by the Ethics Committee in agreement with the Dutch law code for medical research on humans.

\section{Patient eligibility}

Women eligible for the study were between 18 and 70 years with a Karnofsky performance score of at least 70\%. Eligible patients had a primary tumour size of $3 \mathrm{~cm}$ or more and/or presence of positive regional lymph nodes. Patients were required to have optimal haematologic, renal and liver functions. No prior history of malignancy or anti-tumour therapy was allowed.

\section{Treatment}

Patients in the AC-T arm received four 3-weekly cycles of doxorubicin and cyclophosphamide at a dose of 60 and $600 \mathrm{mg} / \mathrm{m}^{2}$, respectively, followed by four 3-weekly cycles of docetaxel $\left(100 \mathrm{mg} / \mathrm{m}^{2}\right)$. Patients who were assigned to TAC chemotherapy received six cycles of doxorubicin, cyclophosphamide and docetaxel at doses of 75, 500 and $50 \mathrm{mg} / \mathrm{m}^{2}$, respectively, every 3 weeks. All drugs were administered intravenously. During TAC chemotherapy G-CSF ( $6 \mathrm{mg}$ pegfilgrastim) was recommended as primary prophylaxis. Chemotherapy dose was modified for haematologic and nonhaematologic grade III/IV toxicities.

Next, patients underwent breast surgery and if indicated radiotherapy, endocrine therapy and/or trastuzumab.

\section{Assessments}

Mammography, ultrasound of breast and axillary lymph nodes and magnetic resonance imaging (MRI) breast had to be carried out before start of chemotherapy. Biopsies of the primary tumour were taken for histological analysis, including oestrogen receptor (ER), progesterone receptor (PR) and human epidermal growth factor 2 receptor (HER2) status. In case of clinically suspected axillary lymph nodes, fine needle aspiration was recommended. In case of a clinically negative axilla, a 
sentinel node procedure was recommended. All patients underwent radiologic evaluations to exclude distant metastases.

The clinical tumour response was rated using the response evaluation criteria in solid tumours (RECIST 1.0). ${ }^{14}$ Adverse events were evaluated according to Common Toxicity Criteria version 3.0 (National Cancer Institute).

The pathologic response was locally assessed and in addition centrally reviewed by a breast-dedicated pathologist (BdV) using the Miller and Payne grading system. ${ }^{15}$

\section{Statistics}

The primary outcome measure was the $\mathrm{PCR}$ rate to neoadjuvant chemotherapy, which was defined as no invasive tumour cells present in the breast.

We hypothesised that the TAC regimen, with a higher total dose delivered in an overall shorter time period (that is a higher dose-intensity for the entire schedule), might be more effective than AC followed by $\mathrm{T}$. To achieve $80 \%$ power at a $5 \%$ level of significance for the detection of a difference in proportion of pCR of $16 \%$ in AC-T arm versus $34 \%$ in the TAC arm a total of 180 eligible patients were required. Taking a $10 \%$ ineligibility rate into account, it was decided to enrol a total of 200 patients.

Secondary endpoints included the PCR rate of the axillary nodes, clinical response rates, disease-free and overall survival, the delivered chemotherapy dose and doseintensity and the tolerability (grade 3/4 CTC toxicities) of both chemotherapy regimens. The $\mathrm{PCR}$ rate of the axillary nodes was assessed in patients who had clinically positive lymph nodes at start of chemotherapy (preferably with cytological proof), that were not removed or identified by the sentinel node procedure.

Randomisation procedure was done by inclusion in strata in a 1:1 ratio to a sequential or concomitant taxane regimen. Stratification was for CT-classification (T2 versus $\mathrm{T} 3+\mathrm{T} 4$ ), $\mathrm{cN}$-classification (cNO versus $\mathrm{cN}+$ ), hormone receptor status (positive versus negative) and HER2 status (positive versus negative).

All main analyses were done on the intent-to-treat-population. The primary parameter was analysed using the Cochran-Mantel-Haenszel test, whereas the logrank test was used to analyse disease free and overall survival. Other categorical parameters were analysed using the uncorrected chi-squared test. To investigate the influence of possible predictors (or risk factors) logistic regression was used.

All analyses were done using two-sided tests and level of significance 5\%. The corresponding $95 \%$ confidence intervals $(95 \% \mathrm{Cl})$ were given whenever appropriate. 


\section{Results}

\section{Patient characteristics and treatment}

From February 2006 through April 2009, a total of 202 women from 21 hospitals in the Netherlands were enrolled in this study. The majority of patients were included in the period from April 2008 through April 2009.

After randomisation, treatment data of one patient were not available. Therefore, this analysis is based on 201 patients, of whom 100 were allocated to the AC-T arm and 101 to the TAC arm (Figure 6.1)

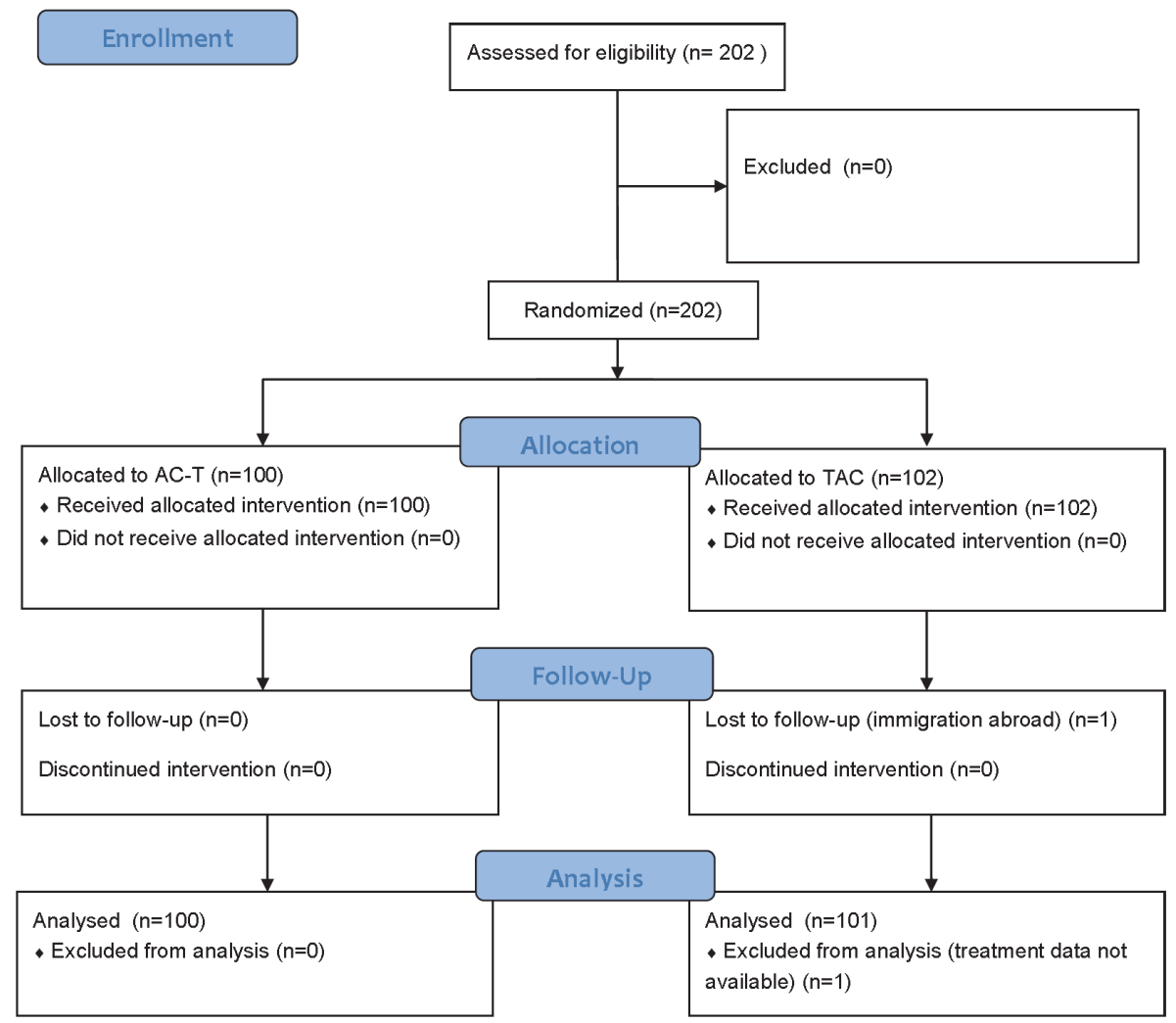

Figure 6.1 Consort diagram.

The two treatment arms were well balanced in terms of demographics and tumour characteristics (Table 6.1). Of 82 patients with a clinical negative axilla, $73 \%$ underwent a sentinel node procedure before start of neoadjuvant chemotherapy. Of 
119 patients with a clinically suspected axilla, nodal metastases were confirmed in 79 patients by fine needle aspiration cytology.

Most patients received the planned number of chemotherapy cycles. Dose reductions and treatment delays were infrequent. In $99 \%$ of patients surgery was performed after completing the last chemotherapy and most patients received additional therapies after surgery (Table 6.2A).

Table 6.1 Baseline patient and tumor characteristics.

\begin{tabular}{lcc}
\hline & AC-T $(n=100)$ & TAC $(n=101)$ \\
& $\%$ & $\%$ \\
\hline Age, years & & 49 \\
Median & 49 & $24-68$ \\
Range & $27-70$ & 5 \\
Initial tumor status & & 45 \\
cT1 & 2 & 30 \\
CT2 & 49 & 20 \\
cT3 & 34 & \\
cT4 & 15 & 26 \\
Initial nodal status & & 68 \\
cN0 & 24 & 4 \\
cN1 & 71 & 2 \\
cN2 & 4 & \\
cN3 & 1 & 65 \\
Receptor status & & 15 \\
ER and/or PR positive & 66 & 8 \\
HER2 positive & 25 & 27 \\
ER and/or PR and HER2 positive & 14 & \\
ER/PR and HER2 negative & 24 & \\
\hline
\end{tabular}

A, doxorubicin; C, cyclophosphamide; T, docetaxel; ER, estrogen receptor; PR, progesterone receptor; HER2, human epidermal growth factor receptor 2 .

\section{Pathologic complete response rate}

By central review, a pCR of the breast tumour was seen in $21 \%$ of 100 patients treated with AC-T and in $16 \%$ of 101 patients treated with TAC at an odds ratio of $1.44(95 \% \mathrm{Cl}$ 0.67-3.10) (Figure 6.2A). Based on the local pathology reports, the $\mathrm{pCR}$ rates were $28 \%$ and $19 \%$, respectively, with an odds ratio of 1.60 (95\% $\mathrm{Cl} 0.90-3.21)$.

In patients with a clinical positive axilla at start of chemotherapy, a pCR in axillary nodes was found in 19 of 60 patients (32\%) treated with AC-T and in 12 of 59 patients (21\%) treated with TAC with an odds ratio of 1.77 (95\% Cl $0.74-4.25)$. In this group a pCR in both breast and axilla was seen in $15 \%$ and $11 \%$, respectively with an odds ratio of 1.53 (95\% Cl 0.48-4.86) (Table 6.2B).

Irrespective of treatment arm, patients with a triple negative tumour had the highest pCR rate (38\%) (Figure 6.2B). 
Table 6.2A pTN classification, and interventions after neoadjuvant chemotherapy.

\begin{tabular}{|c|c|c|}
\hline & $\begin{array}{c}\text { AC-T }(n=99) \\
\%\end{array}$ & $\begin{array}{c}\text { TAC }(n=98) \\
\%\end{array}$ \\
\hline \multicolumn{3}{|l|}{ Tumor status } \\
\hline урто & 21 & 16 \\
\hline урТ1/Т2 & 75 & 71 \\
\hline урт3/4 & 4 & 12 \\
\hline \multicolumn{3}{|l|}{ Nodal status } \\
\hline ypNO & 49 & 42 \\
\hline ypN1 & 31 & 35 \\
\hline ypN2 & 14 & 16 \\
\hline ypN3 & 5 & 7 \\
\hline ypTONO & 17 & 10 \\
\hline \multicolumn{3}{|l|}{ Intervention after chemotherapy } \\
\hline \multicolumn{3}{|l|}{ Surgical intervention } \\
\hline No surgical intervention & 1 & 3 \\
\hline Breast conservation & 34 & 21 \\
\hline Mastectomy & 65 & 77 \\
\hline Radiotherapy & 85 & 80 \\
\hline \multicolumn{3}{|l|}{ First endocrine therapy } \\
\hline Tamoxifen & 48 & 56 \\
\hline Aromatase inhibitor & 28 & 26 \\
\hline Trastuzumab & 28 & 18 \\
\hline
\end{tabular}

A, doxorubicin; C, cyclophosphamide; T, docetaxel.

A.

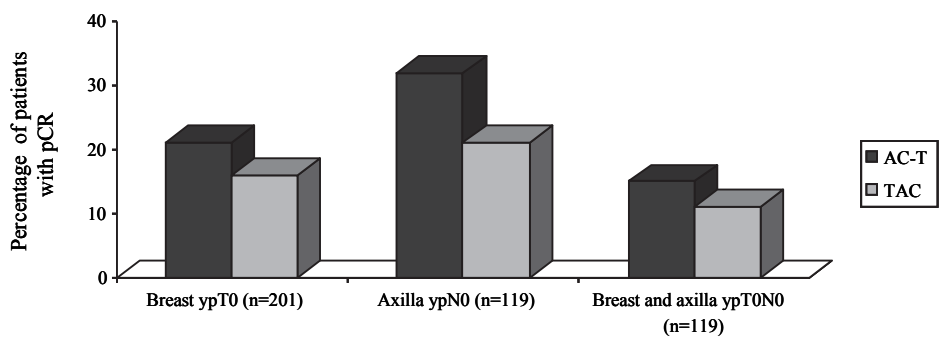

B.

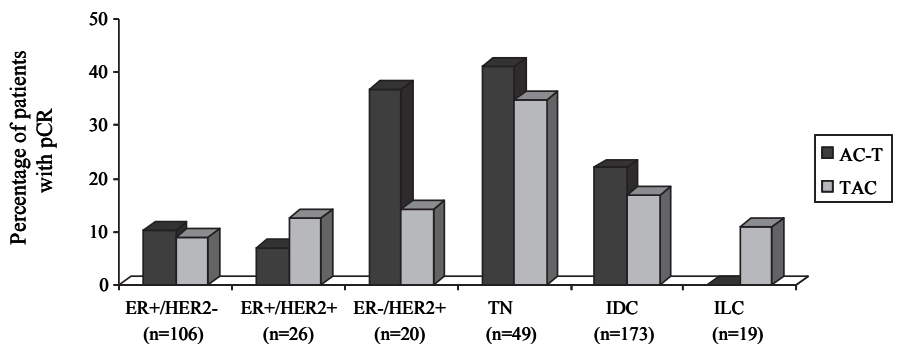

Figure 6.2 A. Percentage of patients with $\mathrm{PCR}$ in breast, axilla and combination in the two treatment arms AC-T and TAC. B. Percentage of patients with $\mathrm{PCR}$ in the breast in relation to the receptor status and morphology in the two treatment arms AC-T and TAC. pCR, pathologic complete response; $\mathrm{A}$, doxorubicin; $\mathrm{C}$, cyclophosphamide, $\mathrm{T}$, docetaxel; $\mathrm{ER}$, estrogen receptor; HER2+, human epidermal growth factor 2 receptor positive; TN, triple negative; IDC, invasive ductal carcinoma; ILC, invasive lobular carcinoma. 
Table 6.2B pTN classification patients with a clinical positive axilla at start of chemotherapy.

\begin{tabular}{lcc}
\hline & AC-T $(n=60)$ & TAC $(n=59)$ \\
& $\%$ & $\%$ \\
\hline ypNO & 32 & 21 \\
ypTONO & 15 & 11 \\
\hline
\end{tabular}

\section{Clinical response rate}

Most patients had a clinical response in the breast after treatment (Figure 6.3). Patients in the TAC arm with clinical stable disease halfway rarely had pCR after six cycles. Patients with a clinical complete response at the end of chemotherapy had a pCR in $58 \%$ and $41 \%$ of patients for AC-T and TAC, respectively. For patients with clinical partial response these rates were $19 \%$ and $15 \%$, respectively, and for patients with clinical stable disease $0 \%$ in both arms.

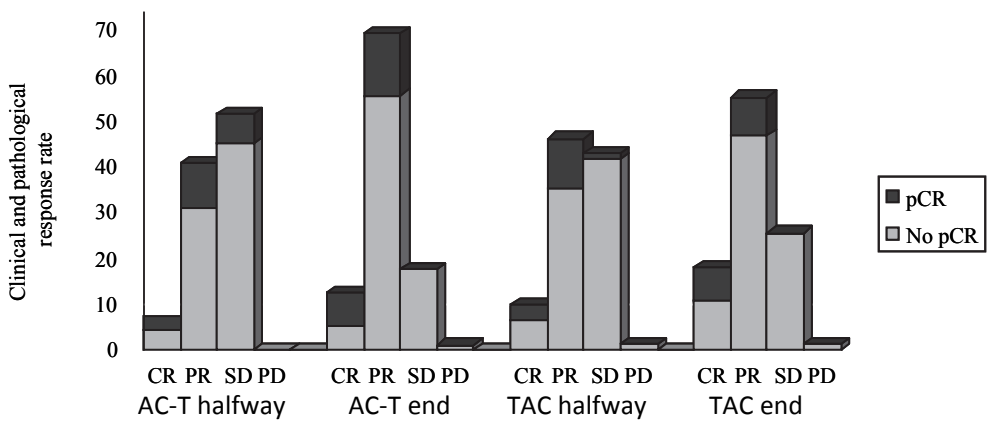

Figure 6.3 Clinical response rate halfway and the end of chemotherapy per treatment regime, related to presence or absence of pCR in the breast at surgery. PCR, pathologic complete response; $A$, doxorubicin; $C$, cyclophosphamide, $T$, docetaxel; $C R$, complete response; $P R$, partial response; $\mathrm{SD}$, stable disease; PD, progressive disease.

\section{Disease-free and overall survival}

The 3-year disease-free survival was $88 \%$ for the AC-T arm and $75 \%$ for the TAC arm $(P=0.21)$. The 3 -year overall survival was $94 \%$ and $78 \%$, respectively $(P=0.11)$ (data not further shown).

\section{Toxicity of neoadjuvant chemotherapy}

Patients in the AC-T arm had more frequently grade 3/4 toxicities as compared to the TAC arm. This was mostly due to the higher incidence of neutropenic fever with AC-T, $23 \%$, as compared to $9 \%$ with TAC (Table 6.3 ). Of note, most of these febrile events during AC-T occurred during docetaxel mono-chemotherapy (82\%). The patients in the 
AC-T arm did not receive primary G-CSF prophylaxis. During treatment, G-CSF prophylaxis was started in $12 \%$ of patients treated with AC-T. In the TAC arm $99 \%$ of the patients started with G-CSF prophylaxis during the first chemotherapy cycle. Of patients with febrile neutropenia while on TAC, 33\% stopped the G-CSF prophylaxis previously.

The most common grade 3-4 non-haematologic toxicities were non-neutropenic fever (AC-T 5\%; TAC 6\%), sensory neuropathy (AC-T 5\%; TAC 0\%) and fatigue (AC-T 9\%; TAC 4\%) (Table 6.3).

Table 6.3 Incidence of CTCAE grade 3 and 4.

\begin{tabular}{|c|c|c|c|}
\hline & \multicolumn{2}{|c|}{ AC-T $(n=100)$} & \multirow{2}{*}{$\begin{array}{l}\text { TAC }(n=101) \\
(\%)\end{array}$} \\
\hline & $\mathrm{AC}(\%)$ & $\mathrm{T}(\%)$ & \\
\hline \multicolumn{4}{|l|}{ Hematologic toxicity (grade 3-4) } \\
\hline Anaemia & 1 & 0 & 1 \\
\hline Neutropenia & 17 & 3 & 0 \\
\hline Trombocytopenia & 2 & 3 & 0 \\
\hline \multicolumn{4}{|l|}{ Non-Hematologic toxicity (grade $3-4$ ) } \\
\hline Febrile neutropenia & 4 & 19 & 9 \\
\hline Fever/infection without neutropenia & 1 & 4 & 6 \\
\hline Nausea & 3 & 0 & 0 \\
\hline Vomiting & 1 & 0 & 0 \\
\hline Diarrhoea & 1 & 3 & 0 \\
\hline Mucositis/Stomatitis & 0 & 3 & 1 \\
\hline Sensory neuropathy & 0 & 5 & 0 \\
\hline Allergic reaction & 0 & 1 & 1 \\
\hline Fatigue & 3 & 7 & 4 \\
\hline Muscle or bone pain & 0 & 2 & 2 \\
\hline Pain (other than muscle/bone pain) & 2 & 2 & 0 \\
\hline Thrombosis/embolism (grade 2-4) & 0 & 1 & 2 \\
\hline
\end{tabular}

A, doxorubicin; C, cyclophosphamide; T, docetaxel; CTCAE, Common Terminology Criteria Adverse Events.

\section{Discussion}

Both the sequential use of docetaxel after anthracyclines and cyclophosphamide (AC-T) and the upfront combination of docetaxel with anthracyclines and cyclophosphamide (TAC) have shown to improve early breast cancer outcome. This present randomised study of the Dutch Breast Cancer Trialists' Group (BOOG) was designed to determine whether higher dosed neoadjuvant chemotherapy, delivered in a shorter time frame, would provide the best outcome. In our study no significant efficacy difference was found between the sequential and upfront combination regimens, with a pCR of the breast tumour in $21 \%$ of patients treated with AC-T and in $16 \%$ of patients treated with TAC chemotherapy. Patients with ER positive tumours had the lowest $\mathrm{PCR}$ rate, whereas patients with triple negative tumours had the 
highest $\mathrm{pCR}$ rate. Clinical response rates showed to be related to pathologic response rates.

Other neoadjuvant trials studying taxane-containing chemotherapy show comparable PCR rates (Table 6.4). Of note, baseline patient and tumour characteristics and definition of $\mathrm{pCR}$ have a large impact on reported $\mathrm{pCR}$ rates. Studying other neoadjuvant breast cancer studies with $\mathrm{pCR}$ as primary endpoint, it becomes clear that there is no consensus on the definition of $\mathrm{pCR}$. Absence of residual invasive disease after neoadjuvant chemotherapy in the breast, lymph nodes or both, including or excluding the in situ component is used (Table 6.4). ${ }^{27}$ In the GeparQuinto trial pCR rates vary from $30 \%$ to $49 \%$ depending on definition of pCR used (Table 6.4). ${ }^{26}$

Table 6.4 Different used definitions of pCR in other trials.

\begin{tabular}{|c|c|c|c|c|c|}
\hline Study & $\mathrm{N}$ & cTN-status & Scheme & pCR definition & $\%$ pCR (ypTN) \\
\hline \multirow[t]{2}{*}{ GeparQuinto $^{16}$} & 1948 & $\mathrm{cT}_{1-4} \mathrm{~N}_{0 /+}$ & EC-D+Bev & урт ${ }_{0} \mathrm{~N}_{0}$ & 18.4 \\
\hline & & & EC-D & & 14.9 \\
\hline \multirow[t]{2}{*}{ GeparQuinto $^{16}$} & 1948 & $\mathrm{cT}_{1-4} \mathrm{~N}_{0 /+}$ & $\mathrm{EC}-\mathrm{D}+\mathrm{Bev}$ & $\mathrm{ypT}_{0} \mathrm{~N}_{0 /+}$ & 20.5 \\
\hline & & & EC-D & & 16.5 \\
\hline \multirow[t]{2}{*}{ GeparQuinto $^{16}$} & 1948 & $\mathrm{cT}_{1-4} \mathrm{~N}_{0 /+}$ & $E C-D+B e v$ & $\mathrm{ypT}_{0 / \mathrm{is}} \mathrm{N}_{0}$ & 21.7 \\
\hline & & & EC-D & & 18.3 \\
\hline \multirow[t]{2}{*}{ GeparQuinto $^{16}$} & 1948 & $\mathrm{cT}_{1-4} \mathrm{~N}_{0 /+}$ & $E C-D+B e v$ & $\mathrm{ypT}_{0 / \text { is }} \mathrm{N}_{0 /+}$ & 24.6 \\
\hline & & & $E C-D$ & & 20.6 \\
\hline \multirow[t]{2}{*}{ Prepare $^{17}$} & 733 & $\mathrm{cT}_{2-4} \mathrm{~N}_{0 /+}$ & $E(d d)-P(d d)-C M F$ & ypT ${ }_{0} \mathrm{~N}_{0 /+}$ & 18.7 \\
\hline & & & EC-P & & 13.2 \\
\hline \multirow[t]{3}{*}{ GeparQuattro $^{18}$} & 1421 & $\mathrm{cT}_{1-4} \mathrm{~N}_{0 /+}$ & EC-D & ypT $_{0} \mathrm{~N}_{0 /+}$ & 22.3 \\
\hline & & & EC-DX & & 19.5 \\
\hline & & & EC-D-X & & 22.3 \\
\hline \multirow[t]{2}{*}{ Gepartrio $^{19}$} & 1390 & $\mathrm{cT}_{1-4} \mathrm{~N}_{0 /+}$ & 6 cycles DAC & урт ${ }_{0} \mathrm{~N}_{0}$ & 21 \\
\hline & & & 8 cycles DAC & & 23.5 \\
\hline \multirow[t]{2}{*}{ Gepartrio $^{19}$} & 1390 & $\mathrm{cT}_{1-4} \mathrm{~N}_{0 /+}$ & 6 cycles DAC & $\mathrm{ypT}_{0} \mathrm{~N}_{0 /+}$ & 23.7 \\
\hline & & & 8 cycles DAC & & 25.4 \\
\hline \multirow[t]{2}{*}{$\mathrm{ACCOGS}^{20}$} & 342 & $c T_{\geq 3 \mathrm{~cm}} \mathrm{~N}_{0 /+}$ & $\mathrm{AC}$ & $\mathrm{ypt}_{0} \mathrm{~N}_{0 /+}$ & 15 \\
\hline & & & $A D$ & & 16 \\
\hline \multirow[t]{2}{*}{$\mathrm{ACCOGS}^{20}$} & 342 & $\mathrm{cT}_{\geq 3 \mathrm{~cm}} \mathrm{~N}_{0 /+}$ & $A C$ & ypT $_{0 / i s} \mathrm{~N}_{0 /+}$ & 24 \\
\hline & & & $A D$ & & 21 \\
\hline \multirow[t]{2}{*}{$\mathrm{ACCOGS}^{20}$} & 342 & $\mathrm{cT}_{\geq 3 \mathrm{~cm}} \mathrm{~N}_{0 /+}$ & $A C$ & $\mathrm{ypT}_{0 / \mathrm{is}} \mathrm{N}_{0}$ & 16 \\
\hline & & & $A D$ & & 12 \\
\hline \multirow[t]{2}{*}{ Aberdeen trial $^{10}$} & 168 & $\mathrm{cT}_{\geq 3 \mathrm{~cm}} \mathrm{~N}_{\mathrm{O} /+}$ & CVAP & $\mathrm{ypT}_{0 / i s} \mathrm{~N}_{0 /+}$ & 15.4 \\
\hline & & & CVAP-D & & 16.3 \\
\hline \multirow[t]{2}{*}{ MDACC $^{21}$} & 221 & $\mathrm{cT}_{1-3} \mathrm{~N}_{0 /+}$ & Pw-FEC100 & $\mathrm{ypT}_{0 / \mathrm{is}} \mathrm{N}_{0}$ & 16.4 \\
\hline & & & $D+X d 1-14-F E C 100$ & & 19.8 \\
\hline \multirow[t]{2}{*}{ Untch $^{22}$} & 668 & $\mathrm{cT}_{1-4} \mathrm{~N}_{0 /+}$ & EP & ypT $_{0 / i s} \mathrm{~N}_{0 /+}$ & 18 \\
\hline & & & EPdd & & 10 \\
\hline \multirow[t]{2}{*}{ Untch $^{22}$} & 668 & $\mathrm{cT}_{1-4} \mathrm{~N}_{0 /+}$ & EP & урт ${ }_{0} \mathrm{~N}_{0}$ & 12 \\
\hline & & & EPdd & & 6 \\
\hline \multirow[t]{2}{*}{ Geparduo $_{23}$} & 913 & $\mathrm{CT}_{2-3} \mathrm{~N}_{0 /+}$ & $A C-D$ & урт ${ }_{0} \mathrm{~N}_{0}$ & 14.3 \\
\hline & & & $A D$ & & 7 \\
\hline \multirow[t]{2}{*}{ NSABP-B $27^{11}$} & 2411 & $\mathrm{cT}_{1 \mathrm{c}-3} \mathrm{~N}_{0 /+}$ & $A C$ & $\mathrm{ypT}_{0 / \text { is }} \mathrm{N}_{0 /+}$ & 13.7 \\
\hline & & & $A C-D$ & & 26.1 \\
\hline
\end{tabular}


Table 6.4 (continued)

\begin{tabular}{|c|c|c|c|c|c|}
\hline Study & $\mathrm{N}$ & cTN-status & Scheme & pCR definition & $\%$ pCR (ypTN) \\
\hline \multicolumn{6}{|c|}{ HER2 targeted therapy } \\
\hline \multirow[t]{2}{*}{ HannaH study ${ }^{24}$} & 596 & $\mathrm{cT}_{1-4} \mathrm{~N}_{0 /+}$ & D-FEC+TrsC & $\mathrm{ypT}_{0 / \text { is }} \mathrm{N}_{0 /+}$ & 45.4 \\
\hline & & & D-FEC+Triv & & 40.7 \\
\hline \multirow[t]{2}{*}{ HannaH study ${ }^{24}$} & 596 & $\mathrm{cT}_{1-4} \mathrm{~N}_{0 /+}$ & D-FEC+Trsc & $\mathrm{ypT}_{0 / \mathrm{is}} \mathrm{N}_{0}$ & 39.2 \\
\hline & & & D-FEC+Triv & & 34.2 \\
\hline \multirow[t]{3}{*}{ NeoALTTO $^{25}$} & 355 & $\mathrm{cT}_{2-4} \mathrm{~N}_{\mathrm{O} /+}$ & L-P & $\mathrm{ypT}_{0 / \text { is }} \mathrm{N}_{0 /+}$ & 24.7 \\
\hline & & & Tr-P & & 29.5 \\
\hline & & & $\mathrm{L} / \mathrm{Tr}-\mathrm{P}$ & & 51.3 \\
\hline \multirow[t]{3}{*}{ NeoALTTO ${ }^{25}$} & 355 & $\mathrm{CT}_{2} \mathrm{~N}_{\mathrm{O} /+}$ & $L-P$ & $\mathrm{ypT}_{0 / \mathrm{is}} \mathrm{N}_{0}$ & 20.0 \\
\hline & & & Tr-P & & 27.6 \\
\hline & & & $\mathrm{L} / \mathrm{Tr}-\mathrm{P}$ & & 46.8 \\
\hline \multirow[t]{2}{*}{ GeparQuinto $^{26}$} & 620 & $\mathrm{cT}_{1-4} \mathrm{~N}_{0 /+}$ & ECTr-DTr & урт ${ }_{0} \mathrm{~N}_{0}$ & 30.3 \\
\hline & & & ECL-DL & & 22.7 \\
\hline \multirow[t]{2}{*}{ GeparQuinto $^{26}$} & 620 & $\mathrm{cT}_{1-4} \mathrm{~N}_{0 /+}$ & ECTr-DTr & ypT $\mathrm{T}_{0} \mathrm{~N}_{0 /+}$ & 34.2 \\
\hline & & & ECL-DL & & 26 \\
\hline \multirow[t]{2}{*}{ GeparQuinto $^{26}$} & 620 & $\mathrm{cT}_{1-4} \mathrm{~N}_{0 /+}$ & ECTr-DTr & $\mathrm{ypT}_{0 / \mathrm{is}} \mathrm{N}_{0}$ & 44.6 \\
\hline & & & ECL-DL & & 30.2 \\
\hline \multirow[t]{2}{*}{ GeparQuinto $^{26}$} & 620 & $\mathrm{CT}_{1-4} \mathrm{~N}_{0 /+}$ & ECTr-DTr & $\mathrm{ypT}_{0 / \text { is }} \mathrm{N}_{0 /+}$ & 49.8 \\
\hline & & & ECL-DL & & 35.7 \\
\hline
\end{tabular}

A, doxorubicin; Bev, bevacizumab; C, cyclophosphamide; D, docetaxel; dd, dose dense; E, epirubicin; F, 5-fluorouracil; L, lapatinib; M, methotrexaat; P, paclitaxel; pCR, pathologic Complete Response; $\mathrm{P}$, prednisolon; Tr, trastuzumab; Triv, trastuzumab intravenous; Trsc, trastuzumab subcutaneous; $\mathrm{V}$, vincristine; w, weekly; $\mathrm{X}$; capecitabine.

For calculating $\mathrm{pCR}$ rates of axillary nodes it seems not correct to include patients with clinically negative nodes or patients in whom positive nodes have been removed by a sentinel node procedure. Therefore, for $\mathrm{pCR}$ of the lymph nodes we included only patients with clinical positive lymph nodes (preferably with cytological proof) at start of chemotherapy that were not removed by the sentinel node procedure. In most trials, all patients are included in the denominator, hence, leading to (incorrect) low axillary $\mathrm{pCR}$ rates.

So far, only three early breast cancer trials compared sequential versus concurrent use of taxanes, all in the adjuvant setting. ${ }^{28-30}$ In the BIG 2-98 trial, sequential A-T for a total of six cycles after CMF was compared with concurrent doxorubicin-docetaxel (AT) for four cycles, resulting in a hazard ratio of 0.83 (95\% $\mathrm{Cl} 0.69-1.00)$ for 5 -year disease-free survival in favour of the sequential arm. ${ }^{28}$ In the NSABP-B30 trial, AC-T for eight cycles compared to AT for four cycles, showed an improved 5-year disease-free survival for the AC-T arm, with a hazard ratio of 0.80 (95\% $\mathrm{Cl} 0.70-0.91) .{ }^{29}$ In this trial, AC-T for eight cycles was also compared to 4 TAC, again showing an improved 5 -year disease-free survival for the sequential arm with a hazard ratio of $0.83(95 \% \mathrm{Cl}$ 0.73-0.95)..$^{29}$ In contrast, in the BCIRG-005 trial, eight cycles of AC-T did not improve 5 -year disease-free survival when compared to six cycles of TAC (hazard ratio of 1.00; $95 \% \mathrm{Cl} \mathrm{0.86-1.16).}{ }^{30}$ In our neo-adjuvant trial, we also compared eight cycles of AC-T 
with six cycles of TAC. Similar to our observation, others also have shown that sequential treatment at a lower dose per cycle in a modestly higher number of cycles compared to concurrent chemotherapy ( 6 versus 4 , and 8 versus 6 ) seems equally effective, which from a cost-effective viewpoint may be attractive.

The toxicity of both regimes was manageable. In our study febrile neutropenia was the most frequent side effect. It was seen in $23 \%$ of patients treated with AC-T and in 9\% treated with TAC, whereas in the BCIRG 005 study these figures were $8 \%$ and $18 \%$, respectively. ${ }^{30}$ Different use of primary G-CSF prophylaxis probably explains the observed difference. In our study, 99\% of TAC patients started with G-CSF prophylaxis during the first chemotherapy cycle, compared to only $17 \%$ of TAC patients in the BCIRG 005 study. In both trials none of the patients in the AC-T arm received primary G-CSF prophylaxis. We noticed that $83 \%$ of febrile neutropenic events in the AC-T arm occurred during docetaxel monotherapy, i.e. in 19\% of patients on docetaxel. Interestingly, others reported, that this high rate was not observed when docetaxel was administered upfront before AC chemotherapy. ${ }^{31}$ The mechanism remains unclear. To prevent this side effect, one might consider reversing the sequential treatment order, to reduce the docetaxel dose or to offer primary G-CSF prophylaxis during docetaxel monotherapy. The international guidelines do recommend primary G-CSF prophylaxis during chemotherapy if the risk of febrile neutropenia is more than $20 \% .^{32}$ We observed no toxic deaths. In our study no left ventricular ejection fraction (LVEF) was done routinely, in contrast to the BCIRG 001 study (TAC versus FAC). ${ }^{33}$ Annually in years 5-10 after treatment the LVEF was measured to explore long term cardiac effects. They conclude that a substantial percentage (16\%) of patients had a decrease in LVEF, probably caused by anthracycline therapy. This may be an advantage of sequential therapy, because of a lower cumulative dose of anthracyclines.

Nowadays, most would prefer to give trastuzumab sequentially after anthracyclines and concurrently with taxanes, also in the neo-adjuvant setting. ${ }^{34,35}$ At that time, guidelines recommended to administer trastuzumab after surgery. Moreover, our trial design prevented imbalance between treatment arms as safety data on concurrent trastuzumab-TAC were lacking. This might be considered a limitation of our study. We tested in an unplanned analysis, whether exclusion of the HER2 positive group would impact the study outcome. This was not the case (pCR 22\% for AC-T and 16\% for TAC). In conclusion, it becomes evident that both AC-T and TAC are potent regimens currently available as (neo)adjuvant chemotherapy of breast cancer. Both treatment schedules have manageable toxicities. From our study results we argue there are some advantages for using AC-T over TAC, because of the lower cumulative dose per agent which makes it the most cost-effective approach, and also because sequential treatment results in a quick recognition of the in vivo response per drug, offering a rapid switch to another drug in case of lack of response. 


\section{References}

1. Kaufmann M, von Minckwitz G, Bear HD, Buzdar A, McGale P, Bonnefoi H, Colleoni M, Denkert C, Eiermann W, Jackesz R, Makris A, Miller W, Pierga JY, Semiglazov V, Schneeweiss A, Souchon R, Stearns V, Untch M, Loibl S. Recommendations from an international expert panel on the use of neoadjuvant (primary) systemic treatment of operable breast cancer: new perspectives 2006. Ann Oncol 2007;18:1927-34.

2. Kaufmann M, von Minckwitz G, Mamounas EP, Cameron D, Carey LA, Cristofanilli M, Denkert C, Eiermann W, Gnant M, Harris JR, Karn T, Liedtke C, Mauri D, Rouzier R, Ruckhaeberle E, Semiglazov V, Symmans WF, Tutt A, Pusztai L. Recommendations from an international consensus conference on the current status and future of neoadjuvant systemic therapy in primary breast cancer. Ann Surg Oncol 2012;19:1508-16.

3. Vriens BE, Lobbezoo DJ, de Hoon JP, Veeck J, Voogd AC, Tjan-Heijnen VC. If there is no overall survival benefit in metastatic breast cancer: does it imply lack of efficacy? Taxanes as an example. Cancer Treat Rev 2013;39:189-98.

4. Early Breast Cancer Trialists' Collaborative Group (EBCTCG), Peto R, Davies C, Godwin J, Gray R, Pan HC, Clarke M, Cutter D, Darby S, McGale P, Taylor C, Wang YC, Bergh J, Di Leo A, Albain K, Swain S, Piccart M, Pritchard K. Comparisons between different polychemotherapy regimens for early breast cancer: meta-analyses of long-term outcome among 100,000 women in 123 randomised trials. Lancet 2012;379:432-44.

5. Mamounas EP, Bryant J, Lembersky B, Fehrenbacher L, Sedlacek SM, Fisher B, Wickerham DL, Yothers G, Soran A, Wolmark N. Paclitaxel after doxorubicin plus cyclophosphamide as adjuvant chemotherapy for node-positive breast cancer: results from NSABP B-28. J Clin Oncol 2005;23:368696.

6. Henderson IC, Berry DA, Demetri GD, Cirrincione CT, Goldstein LJ, Martino S, Ingle JN, Cooper MR, Hayes DF, Tkaczuk KH, Fleming G, Holland JF, Duggan DB, Carpenter JT, Frei E 3rd, Schilsky RL, Wood WC, Muss HB, Norton L. Improved outcomes from adding sequential paclitaxel but not from escalating doxorubicin dose in an adjuvant chemotherapy regimen for patients with node-positive primary breast cancer. J Clin Oncol 2003;21:976-83.

7. Martin M, Pienkowski T, Mackey J, Pawlicki M, Guastalla JP, Weaver C, Tomiak E, Al-Tweigeri T, Chap L, Juhos E, Guevin R, Howell A, Fornander T, Hainsworth J, Coleman R, Vinholes J, Modiano M, Pinter T, Tang SC, Colwell B, Prady C, Provencher L, Walde D, Rodriguez-Lescure A, Hugh J, Loret C, Rupin M, Blitz S, Jacobs P, Murawsky M, Riva A, Vogel C; Breast Cancer International Research Group 001 Investigators. Adjuvant docetaxel for node-positive breast cancer. N Engl J Med 2005;352:2302-13.

8. Martín M, Seguí MA, Antón A, Ruiz A, Ramos M, Adrover E, Aranda I, Rodríguez-Lescure A, Grosse R, Calvo L, Barnadas A, Isla D, Martinez del Prado P, Ruiz Borrego M, Zaluski J, Arcusa A, Muñoz M, López Vega JM, Mel JR, Munarriz B, Llorca C, Jara C, Alba E, Florián J, Li J, López García-Asenjo JA, Sáez A, Rios MJ, Almenar S, Peiró G, Lluch A; GEICAM 9805 Investigators. Adjuvant docetaxel for high-risk, node-negative breast cancer. N Engl J Med 2010;363:2200-10.

9. Mackey JR, Martin M, Pienkowski T, Rolski J, Guastalla JP, Sami A, Glaspy J, Juhos E, Wardley A, Fornander T, Hainsworth J, Coleman R, Modiano MR, Vinholes J, Pinter T, Rodríguez-Lescure A, Colwell B, Whitlock P, Provencher L, Laing K, Walde D, Price C, Hugh JC, Childs BH, Bassi K, Lindsay MA, Wilson V, Rupin M, Houé V, Vogel C; TRIO/BCIRG 001 investigators. Adjuvant docetaxel, doxorubicin, and cyclophosphamide in node-positive breast cancer: 10-year follow-up of the phase 3 randomised BCIRG 001 trial. Lancet Oncol 2013;14:72-80.

10. Smith IC, Heys SD, Hutcheon AW. Neoadjuvant chemotherapy in breast cancer: significantly enhanced response with docetaxel. J Clin Oncol 2002;20:1456-66.

11. Bear HD, Anderson S, Brown A, Smith R, Mamounas EP, Fisher B, Margolese R, Theoret H, Soran A, Wickerham DL, Wolmark N; National Surgical Adjuvant Breast and Bowel Project Protocol B-27. The effect on tumor response of adding sequential preoperative docetaxel to preoperative doxorubicin and cyclophosphamide: preliminary results from National Surgical Adjuvant Breast and Bowel Project Protocol B-27. J Clin Oncol 2003;21:4165-74. 
12. Bear HD, Anderson S, Smith RE, Geyer CE Jr, Mamounas EP, Fisher B, Brown AM, Robidoux A, Margolese R, Kahlenberg MS, Paik S, Soran A, Wickerham DL, Wolmark N. Sequential preoperative or postoperative docetaxel added to preoperative doxorubicin plus cyclophosphamide for operable breast cancer: National Surgical Adjuvant Breast and Bowel Project Protocol B-27. J Clin Oncol 2006;24:2019-27.

13. Fornier M, Norton L. Dose-dense adjuvant chemotherapy for primary breast cancer. Breast Cancer Res 2005;7:64-9.

14. Therasse P, Arbuck SG, Eisenhauer EA, Wanders J, Kaplan RS, Rubinstein L, Verweij J, Van Glabbeke M, van Oosterom AT, Christian MC, Gwyther SG. New guidelines to evaluate the response to treatment in solid tumors. J Natl Cancer Inst 2000;92:205-16.

15. Ogston KN, Miller ID, Payne S, Hutcheon AW, Sarkar TK, Smith I, Schofield A, Heys SD. A new histological grading system to assess response of breast cancers to primary chemotherapy: prognostic significance and survival. Breast 2003;12:320-7.

16. von Minckwitz G, Eidtmann $H$, Rezai M, Fasching PA, Tesch H, Eggemann $H$, Schrader I, Kittel K, Hanusch C, Kreienberg R, Solbach C, Gerber B, Jackisch C, Kunz G, Blohmer JU, Huober J, Hauschild M, Fehm T, Müller BM, Denkert C, Loibl S, Nekljudova V, Untch M; German Breast Group; Arbeitsgemeinschaft Gynäkologische Onkologie-Breast Study Groups. Neoadjuvant chemotherapy and bevacizumab for HER2-negative breast cancer. NEJM 2012;366:299-309.

17. Untch M, Fasching PA, Konecny GE, von Koch F, Conrad U, Fett W, Kurzeder C, Lück HJ, Stickeler E, Urbaczyk H, Liedtke B, Salat C, Harbeck N, Müller V, Schmidt M, Hasmüller S, Lenhard M, Schuster T, Nekljudova V, Lebeau A, Loibl S, von Minckwitz G; Arbeitsgemeinschaft Gynäkologische Onkologie PREPARE investigators. PREPARE trial: a randomized phase III trial comparing preoperative, dosedense, dose-intensified chemotherapy with epirubicin, paclitaxel and CMF versus a standard-dosed epirubicin/cyclophosphamide followed by paclitaxel \pm darbepoetin alfa in primary breast cancer results at the time of surgery. Ann Oncol 2011;22:1988-98.

18. von Minckwitz G, Rezai M, Loibl S, Fasching PA, Huober J, Tesch H, Bauerfeind I, Hilfrich J, Eidtmann H, Gerber B, Hanusch C, Kühn T, du Bois A, Blohmer JU, Thomssen C, Dan Costa S, Jackisch C, Kaufmann M, Mehta K, Untch M. Capecitabine in addition to anthracycline- and taxane-based neoadjuvant treatment in patients with primary breast cancer: phase III Gepar Quattro study. J Clin Oncol 2010;28:2015-23.

19. von Minckwitz G, Kümmel S, Vogel P, Hanusch C, Eidtmann H, Hilfrich J, Gerber B, Huober J, Costa SD, Jackisch C, Loibl S, Mehta K, Kaufmann M; German Breast Group.. Intensified neoadjuvant chemotherapy in early-responding breast cancer: phase III randomized GeparTrio study. J Natl Cancer Inst 2008;100:552-62.

20. Evans TR, Yellowlees A, Foster E, Earl H, Cameron DA, Hutcheon AW, Coleman RE, Perren T, Gallagher CJ, Quigley M, Crown J, Jones AL, Highley M, Leonard RC, Mansi JL. Phase III randomized trial of doxorubicin and docetaxel versus doxorubicin and cyclophosphamide as primary medical therapy in women with breast cancer: an Anglo-Celtic Cooperative Oncology Group study. J Clin Oncol 2005;23:2988-95.

21. Kelly CM, Green MC, Broglio K, Thomas ES, Brewster AM, Valero V, Ibrahim NK, Gonzalez-Angulo AM, Booser DJ, Walters RS, Hunt KK, Hortobagyi GN, Buzdar AU. Phase III trial evaluating weekly paclitaxel versus docetaxel in combination with capecitabine in operable breast cancer. J Clin Oncol 2012;30:930-5.

22. Untch M, Möbus V, Kuhn W, Muck BR, Thomssen C, Bauerfeind I, Harbeck N, Werner C, Lebeau A, Schneeweiss A, Kahlert S, von Koch F, Petry KU, Wallwiener D, Kreienberg R, Albert US, Lück HJ, Hinke A, Jänicke F, Konecny GE. Intensive dose-dense compared with conventionally scheduled preoperative chemotherapy for high-risk primary breast cancer. J Clin Oncol 2009;20:2938-45.

23. von Minckwitz G, Raab G, Caputo A, Schütte M, Hilfrich J, Blohmer JU, Gerber B, Costa SD, Merkle E, Eidtmann $H$, Lampe D, Jackisch C, du Bois A, Kaufmann M. Doxorubicin with cyclophosphamide followed by docetaxel every 21 days compared with doxorubicin and docetaxel every 14 days as preoperative treatment in operable breast cancer: the GEPARDUO study. J Clin Oncol 2005;23:267685. 
24. Ismael G, Hegg R, Muehlbauer S, Heinzmann D, Lum B, Kim SB, Pienkowski T, Lichinitser M, Semiglazov V, Melichar B, Jackisch C. Subcutaneous versus intravenous administration of (neo)adjuvant trastuzumab in patients with HER2-positive, clinical stage I-III breast cancer (HannaHstudy): a phase 3, open-label, multicentre, randomised trial. Lancet Oncol 2012;13:869-78.

25. Baselga J1, Bradbury I, Eidtmann H, Di Cosimo S, de Azambuja E, Aura C, Gómez H, Dinh P, Fauria K, Van Dooren V, Aktan G, Goldhirsch A, Chang TW, Horváth Z, Coccia-Portugal M, Domont J, Tseng LM, Kunz G, Sohn JH, Semiglazov V, Lerzo G, Palacova M, Probachai V, Pusztai L, Untch M, Gelber RD, Piccart-Gebhart M; NeoALTTO Study Team. Laptinib with trastuzumab for HER2-positive early breast cancer (NeoALTTO): a randomised, open-label, multicentre, phase 3 trial. Lancet 2012;379:633-40.

26. Untch M, Loibl S, Bischoff J, Eidtmann H, Kaufmann M, Blohmer JU, Hilfrich J, Strumberg D, Fasching PA, Kreienberg R, Tesch H, Hanusch C, Gerber B, Rezai M, Jackisch C, Huober J, Kühn T, Nekljudova V, von Minckwitz G; German Breast Group (GBG); Arbeitsgemeinschaft Gynäkologische OnkologieBreast (AGO-B) Study Group. Lapatinib versus trastuzumab in combination with neoadjuvant anthracycline-taxane-based chemotherapy: a randomised phase 3 trial. Lancet Oncol 2012;13:13544.

27. Fumagalli D, Bedard PL, Nahleh Z, Michiels S, Sotiriou C, Loi S, Sparano JA, Ellis M, Hylton N, Zujewski JA, Hudis C, Esserman L, Piccart M; BIG-NABCG collaboration. A common language in neoadjuvant breast cancer clinical trials: proposals for standard definitions and endpoints. Lancet Oncol 2012;13:e240-8.

28. Francis P, Crown J, Di Leo A, Buyse M, Balil A, Andersson M, Nordenskjöld B, Lang I, Jakesz R, Vorobiof D, Gutiérrez J, van Hazel G, Dolci S, Jamin S, Bendahmane B, Gelber RD, Goldhirsch A, CastiglioneGertsch M, Piccart-Gebhart M; BIG 02-98 Collaborative Group. Adjuvant chemotherapy with sequential or concurrent anthracycline and docetaxel: Breast International Group 02-98 randomized trial. J Natl Cancer Inst 2008;100:121-33.

29. Swain SM, Jeong JH, Geyer CE Jr, Costantino JP, Pajon ER, Fehrenbacher L, Atkins JN, Polikoff J, Vogel VG, Erban JK, Rastogi P, Livingston RB, Perez EA, Mamounas EP, Land SR, Ganz PA, Wolmark N. Longer therapy, iatrogenic amenorrhea, and survival in early breast cancer. N Engl J Med 2010;362:2053-65.

30. Eiermann W, Pienkowski T, Crown J, Sadeghi S, Martin M, Chan A, Saleh M, Sehdev S, Provencher L, Semiglazov V, Press M, Sauter G, Lindsay MA, Riva A, Buyse M, Drevot P, Taupin H, Mackey JR. Phase III study of doxorubicin/cyclophosphamide with concomitant versus sequential docetaxel as adjuvant treatment in patients with human epidermal growth factor receptor 2-normal, node-positive breast cancer: BCIRG-005 trial. J Clin Oncol 2011;29:3877-84.

31. Wildiers $\mathrm{H}$, Forceville $\mathrm{K}$, Paridaens $\mathrm{R}$, Joensuu $\mathrm{H}$. Taxanes and anthracyclines in early breast cancer: which first? Lancet Oncol 2010;11:219-20.

32. Aapro MS, Bohlius J, Cameron DA, Dal Lago L, Donnelly JP, Kearney N, Lyman GH, Pettengell R, TjanHeijnen VC, Walewski J, Weber DC, Zielinski C; European Organisation for Research and Treatment of Cancer. 2010 update of EORTC guidelines for the use of granulocyte-colony stimulating factor to reduce the incidence of chemotherapy-induced febrile neutropenia in adult patients with lymphoproliferative disorders and solid tumours. Eur J Cancer 2011;47:8-32.

33. Mackey JR, Martin M, Pienkowski T, Rolski J, Guastalla JP, Sami A, Glaspy J, Juhos E, Wardley A, Fornander T, Hainsworth J, Coleman R, Modiano MR, Vinholes J, Pinter T, Rodríguez-Lescure A, Colwell B, Whitlock P, Provencher L, Laing K, Walde D, Price C, Hugh JC, Childs BH, Bassi K, Lindsay MA, Wilson V, Rupin M, Houé V, Vogel C; TRIO/BCIRG 001 investigators. Adjuvant docetaxel, doxorubicin, and cyclophosphamide in node-positive breast-cancer: 10 year follow up of the phase 3 randomized BCIRG001 trial. Lancet Oncol 2013;14:72-80.

34. Perez EA, Romond EH, Suman VJ. Four-year follow-up of trastuzumab plus adjuvant chemotherapy for operable human epidermal growth factor receptor 2-positive breast cancer: joint analysis of data from NCCTG N9831 and NSABP B-31. J Clin Oncol 2011;29:3366-73.

35. von Minckwitz G, Untch M, Blohmer JU. Definition and impact of pathologic complete response on prognosis after neoadjuvant chemotherapy in various intrinsic breast cancer subtypes. J Clin Oncol 2012;30:1796-804. 


\section{Chapter 7}

Summary, discussion and future perspectives 
Chapter 7 
Over the past decade mortality of early breast cancer has significantly decreased due to earlier detection, and more effective and more frequent use of (neo-)adjuvant systemic treatment, i.e., chemotherapy, HER2 targeted therapy and endocrine therapy. ${ }^{1}$ With current third generation chemotherapy schedules, with the addition of taxanes to anthracyclines and cyclophosphamide, overall survival has clearly improved. ${ }^{2}$ However, anthracycline/taxane combination chemotherapy is associated with an increased risk of myelotoxicity and febrile neutropenia (FN). Acknowledging the fact that FN may cause life-threatening infections, it was (inter)nationally agreed to offer primary G-CSF prophylaxis to patients at risk of FN (a risk of at least $20 \%$ per patient) in order to reduce the risk of FN. ${ }^{3,4}$ Actually, an increased risk of $\mathrm{FN}$ is the case when docetaxel is combined with anthracyclines or trastuzumab, or when given to patients $\geq 65$ years of age as monotherapy. As a result (neo-) adjuvant chemotherapy or chemo-immunotherapy in breast cancer comes with consirable additional costs because of prophylactic treatments, also at a macro economic level because of the high incidence of breast cancer. In a time of rapidly increasing overall cancer care costs, considering ways to reduce costs without jeopardizing the quality of care becomes more and more important.

In Chapter one, a general introduction and outline of the thesis is presented.

As, our research group had shown before, that FN incidence was generally the highest during the first two chemotherapy cycles, irrespective of tumor and chemotherapy type, with a rapid decline thereafter, we hypothesized that the benefit of G-CSF prophylaxis may largely disappear during later chemotherapy cycles. ${ }^{5}$

In this thesis we focussed on breast cancer patients treated with chemotherapy schedules with increased risk of FN. The aims of the studies presented were to investigate the effectiveness of primary G-CSF prophylaxis during the first two chemotherapy cycles only compared to primary G-CSF prophylaxis throughout all chemotherapy cycles; to assess the cost-effectiveness between the two treatment strategies; to describe the economic impact when quality-adjusted life-years (QALYs) and secondary G-CSF prophylaxis were incorporated in a model-based economic evaluation; to report the hematologic toxicity and to determine if there was a protective effect of prior chemotherapy or of prior G-CSF on the next cycle blood cell counts; and, to investigate whether concurrent or sequential use of docetaxel after doxorubicin/cyclophosphamide provides the best outcome in early stages and locally advanced breast cancer.

In Chapter 2, we report the main results of the 'Two-to-Six' study, in which the effectiveness of primary G-CSF prophylaxis during the first two chemotherapy cycles only (experimental arm, G-CSF 1-2 arm) was compared to primary G-CSF prophylaxis throughout all chemotherapy cycles (standard arm, G-CSF 1-6 arm) in patients at risk of FN. In this nationwide study, we included breast cancer patients with an indication 
for 3-weekly chemotherapy in the adjuvant, neo-adjuvant or advanced setting and more than $20 \%$ risk of FN. G-CSF (pegfilgrastim) was administered 24-30 hours after chemotherapy in a $6 \mathrm{mg}$ fixed dose. Primary endpoint was the percentage of patients who developed FN in both treatment arms. The incidence of FN was $36 \%$ (30 out of 83 patients) in the experimental arm as compared to $10 \%$ ( 8 out of 84 patients) in the standard treatment arm (relative risk $0.26(95 \% \mathrm{Cl}, 0.13$ to 0.54$)$, with a peak incidence of $24 \%$ in the third cycle, i.e. the first cycle without G-CSF prophylaxis. Therefore, we conclude that primary G-CSF prophylaxis during all chemotherapy cycles is of clinical relevance.

To determine the cost-effectiveness of primary G-CSF prophylaxis in breast cancer patients at risk (>20\%) of FN, an economic analysis based on patient data derived from the 'Two-to-Six' study is described in Chapter 3. Primary outcome was costeffectiveness expressed as costs per patient with episodes of FN prevented. The analysis was carried out using a health care perspective. The mean total costs were $€ 20,658(95 \% \mathrm{Cl} € 20,049$ to $€ 21,247)$ in the G-CSF $1-6$ arm and $€ 17,168(95 \% \mathrm{Cl}$ $€ 16,239$ to $€ 18,029)$ in the G-CSF $1-2$ arm per patient. Costs of G-CSF and of chemotherapy determined $80 \%$ of the total costs. FN-related costs were higher in the G-CSF 1-2 arm, mainly dominated by hospitalization costs. The incremental costeffectiveness ratio for G-CSF 1-6 cycles compared with G-CSF 1-2 cycles arm was $€ 13,112$ per patient with episode of FN prevented. We conclude that continued G-CSF is more effective, but more costly. Whether continued G-CSF prophylaxis is considered cost-effective depends on the willingness to pay per patient with episodes of FN prevented.

The threshold of the willingness to pay (WTP) per patient with FN episode prevented is not well established. However, for quality-adjusted life-years (QALYs) informal WTP values exist. We therefore developed a probabilistic decision-analytic Markov cohort model, described in Chapter 4, to compare the cost-effectiveness of primary G-CSF prophylaxis during the first two chemotherapy cycles only (without or with secondary prophylaxis) with primary G-CSF prophylaxis throughout all six chemotherapy cycles in breast cancer patients who had an increased risk (>20\%) of FN. The QALYs ranged from 0.213 to 0.215 for all three strategies, whereas the costs were $€ 17,014, € 18,842$ and $€ 22,778$ respectively. G-CSF prophylaxis limited to the first two chemotherapy cycles without secondary G-CSF prophylaxis is the most cost-effective strategy.

In Chapter 5 we evaluated the hematologic toxicity for both treatment arms. A possible protection against FN during later chemotherapy cycles could be due to intrinsic hematopoietic growth factor production as a result of chemotherapy-induced myelosuppression. On the other hand continued use of G-CSF prophylaxis may be less effective because of the lower baseline risk of FN in later chemotherapy cycles, as was 
suggested from prior studies. The primary objective therefore was to analyze, whether there is indeed a protective effect of prior chemotherapy or of prior G-CSF on the next cycle blood cell counts. We investigated nadir blood cell counts over cycles 1 to 6 for patients in G-CSF 1-6 arm and over cycles 3 to 6 for patients in G-CSF 1-2 arm We excluded patients with FN and patients with G-CSF or chemotherapy treatment modifications. In the G-CSF 1-6 arm, the median white blood cell count (WBC) slowly decreased from $10.8 \times 10^{9} / \mathrm{l}$ in cycle 1 to $7.5 \times 10^{9} / \mathrm{I}$ in cycle 6 and absolute neutrophil count (ANC) nadir decreased from $7.1 \times 10^{9} /$ I to $5.5 \times 10^{9} /$. The median WBC nadir in GCSF $1-2$ arm decreased from $1.2 \times 10^{9} / \mathrm{I}$ in cycle 3 to $0.9 \times 10^{9} / \mathrm{I}$ in cycle 6 and ANC nadir showed a grade 4 neutropenia of $0.1 \times 10^{9} / \mathrm{I}$ in cycle 3 through 6 . We conclude that there is no protective effect of prior G-CSF or prior chemotherapy use on nadir blood counts in subsequent cycles, substantially confirming the results of the main trial.

Neoadjuvant chemotherapy is currently more applied; not only in locally advanced or borderline resectable disease but also in less advanced disease stages. The advantage of neoadjuvant therapy is the possibility of down-staging the primary tumor and the axilla, and therefore facilitates breast conserving therapy and/or obviates the need of completion axillary treatment. In Chapter 6 we investigated whether concurrent versus sequential use of docetaxel with or after doxorubicin/cyclophosphamide (TAC or AC-T, respectively) improves breast cancer outcome. For TAC chemotherapy primary G-CSF prophylaxis was recommended. AC-T resulted in a pCR in $21 \%$ and TAC in $16 \%$ of patients (odds ratio $\mathrm{PCR}$ was $1.44 ; 95 \% \mathrm{Cl} 0.67-3.10$ ). In the AC-T arm without primary G-CSF prophylaxis the FN incidence was $23 \%$, compared to $9 \%$ in the TAC arm with primary G-CSF prophylaxis. We conclude that both regimens are equally effective in achieving $\mathrm{PCR}$, althought this was reached at a lower cumulative dose per chemotherapeutic agent for patients treated with AC-T compared to those treated with TAC chemotherapy.

\section{Discussion and future perspectives}

Most of the chapters in this thesis are derived from data from the phase III 'Two-toSix'study. In this study we investigated several aspects of primary G-CSF prophylaxis in breast cancer patients at risk of $\mathrm{FN}$; clinical effectiveness, trial-based costeffectiveness based on a clinical outcome, model-based cost-effectiveness with QALYS as outcome, myelotoxicity pattern, and comparison of efficacy and toxicity of two different chemotherapy regimes (same drugs, different schedule). Overall, we can conclude that continuation of primary G-CSF prophylaxis from the first to the last cycle is from a clinical viewpoint the most effective for patients being at risk of developing FN (>20\%). But, it comes with considerable extra costs. 
There may be several possible solutions for this dilemma.

When looking at international guidelines, ASCO (American Society of Clinical Oncology), EORTC (European Organisation for Research and Treatment of Cancer) and NCCN (National Comprehensive Cancer Network), we conclude that the economic impact of G-CSF prophylaxis is not explicitly taken into account in the recommendations. ${ }^{3,4,6}$ The guidelines state that consideration should be given to the elevated risk of FN when using certain chemotherapy regimens. Primary G-CSF support is recommended for regimens with a risk of FN of more than $20 \%$ by itself, whereas individual patient-related risk factors should be considered for regimens with a risk of $\mathrm{FN}$ of $10-20 \%$, when evaluating the patient's overall risk level. For regimens with a risk of $\mathrm{FN}$ of less than $10 \%$, there is generally no indication for primary G-CSF prophylaxis.

A breast cancer chemotherapy regimen with increased risk of $\mathrm{FN}$ - that is frequently used in the Netherlands - is TAC. The GEICAM 9805 study, comparing TAC with FAC (5 fluorouracil, doxorubicin, cyclophosphamide) in high-risk NO breast cancer, reported on toxicity of TAC with versus without primary G-CSF support (nonrandomised cohorts). ${ }^{7}$ Incidence of FN was $7 \%$ versus $25 \%$, respectively. In the BCIRG 001 study, comparing TAC with FAC in $\mathrm{N}+$ breast cancer, primary G-CSF was not permitted, whereas secondary G-CSF prophylaxis was mandatory. Moreover, all patients received primary antibiotic prophylaxis (ciprofloxacin). FN rate was $25 \%$ in the TAC arm. ${ }^{8}$ Secondary G-CSF prophylaxis can, however, not reduce the incidence of $\mathrm{FN}$, as it is given after a prior episode of FN (which determines the FN rate already). Brain et al. reported on the results of the RAPP-01 trial of adjuvant doxorubicin plus docetaxel without primary G-CSF prophylaxis. ${ }^{9}$ Three cases of life-threatening sepsis were described, of which two occurred during the first chemotherapy cycle, both with a fatal outcome. In the GEPARTRIO study on 6 versus 8 cycles of TAC as neoadjuvant chemotherapy in breast cancer, the first cohort of patients received primary filgrastim prophylaxis, the second cohort primary pegfilgrastim prophylaxis, the third cohort primary pegfilgrastim combined with ciprofloxacin prophylaxis, and the fourth cohort only antibiotic prophylaxis. ${ }^{10} \mathrm{FN}$ was reported in $18 \%, 7 \%, 5 \%$, and $22 \%$ of patients, respectively. In the BCIRG 004 study, incidence of $\mathrm{FN}$ was $7 \%$ with primary G-CSF prophylaxis while on TAC chemotherapy in advanced breast cancer. ${ }^{11}$ So, it is well conceived that especially doxorubicin-docetaxel containing regimens are associated with a high incidence of FN. And, that from a clinical viewpoint primary G-CSF prophylaxis is highly effective in preventing FN.

However, the high unit cost price of G-CSF generally prohibits cost-savings at standard-dose chemotherapy. ${ }^{12-15}$ In that respect, it is important to realize that hospitalization costs, the main cost driver in $\mathrm{FN}$, differ to a great extent among countries. Thresholds for most European countries are likely higher than US thresholds as FN-related hospitalization costs in Europe in general are considerably 
lower than in the US (e.g. 3,300 euro in the Netherlands compared with 12,000 US dollars in the USA). Of note, nearly all economic evaluations on G-CSF prophylaxis come from the USA. Another issue that needs to be emphasized, is the fact that most economic evaluations on FN prophylaxis took the first chemotherapy cycle into account and not the whole treatment period. For the Netherlands, a study on G-CSF prophylaxis demonstrated it to be cost-neutral for the first chemotherapy cycle in patients having a baseline risk of FN of $24 \%$ (a non-significant increase of 680 euro). But, due to a declining FN rate during later chemotherapy cycles, G-CSF prophylaxis came with considerable extra costs for the overall treatment period (costminimization analysis: mean extra costs 5,123 euro, 95\% Cl 3,908-6,337 euro), despite a high overall FN rate of $32 \%$ per patient. ${ }^{15}$ In an editorial by Adams et al., economic analyses on G-CSF prophylaxis were nicely summarized, stressing the impact of lowered FN threshold levels on costs. ${ }^{16}$

Of relevance, not only the cost but also the benefit of an intervention to an episode of care needs to be clarified. ${ }^{17}$ One of the ways to solve this issue is to accept that patients develop FN. Generally, most patients only need to be admitted to the hospital for a few inpatient days in case of FN and can leave the hospital in a good condition. However, patients are at risk of complicated FN which could result in death. For patients, an unexpected hospital admission, often in the evening, night or weekend, is a negative life-event, even though it has hardly any impact on the QALY when taking the entire treatment into account. We are uncertain what the impact is of these experiences on the long run. Moreover, some patients may decide to cease treatment prematurely, whereas the aim of the (neo-)adjuvant treatment is cure. In our study, we observed that none of the patients who developed FN ceased treatment prematurely. Furthermore, if G-CSF would also not be given as a secondary prophylactic measure, the alternative is applying chemotherapy dose-reductions. Not much is known about the impact of chemotherapy dose-reductions, but based on observations with older chemotherapy regimes it is commonly accepted that dosereductions in the curative setting should be prevented as it may reduce survival outcome. ${ }^{18,19}$ If we conclude that FN should be prevented without chemotherapy dose reductions, an alternative way to reduce costs is to use other forms of prophylaxis or to lower hospitalisation rate, as these two are the main cost drivers.

Other forms of prophylaxis may be the use of antibiotics. However, we already incorporated antibiotics in our Two-to-Six study, and as a single prophylactic measure this proofed to be ineffective. Moreover, broad implementation of prophylactic antibiotics bears the risk of increased resistance. Another option for effective prophylaxis at a lower cost prize would be the use of biosimilars. Although biosimilars are highly similar and biological equivalent, they wil never be identical and these subtle differences may result in clinical consequense. ${ }^{20}$ 
In the Netherlands current practice is generally to admit every patient with FN despite the MASCC risk score in order to prevent toxic death. ${ }^{21}$ When we consider (neo-) adjuvant chemotherapy to increase the change of cure for example by $3 \%$, than a risk on FN-related mortality in a similar range would be a too high price. Our patient population was mainly young, had a good performance score, with few comorbidities and therefore had a low MASCC risk score for FN-related complications. Indeed we observed no complicated FN or death. In the aforementioned studies when using $\mathrm{TAC}^{7,8,11}$ with G-CSF prophylaxis no FN-related mortality occured. In the GEPARTIO study and NSABP B38 study this was $0.44 \%$ and $0.31 \%$ respectively. ${ }^{10,22}$ In the BCIRG 005 study one patient died of sepsis in TAC arm, $0.01 \% .{ }^{23}$ In-hospital mortality for breast cancer patients admitted with FN was $0.36 \%$ if G-CSF was not given, but no FNrelated death occured if G-CSF prophylaxis was used. ${ }^{9}$ In a 'real-world'setting, in unselected patients, the hazard ratio of incidence of overall mortality (12 months after start chemotherapy) was 2.9 with FN and 2.4 without FN and for early mortality (1 month after first cycle) this was 1.3 vs 1.1 respectively. G-CSF reduced early mortality with $45 \% .{ }^{24}$ Hence, the risk of FN-related mortality is depending on patient selection (clinical trial versus daily practice setting) and on the use of G-CSF prophylaxis (use of prophylaxis results in less pronounced myeloxicity and less risk of mortality). The latter implies that if a patient who had received G-CSF prophylaxis yet develops FN, may be at a lower risk of FN-related complications than those without GCSF prophylaxis, and in the presence of a low MASCC risk score admission may be safely disregarded. However, as most complications occur within 24 hours of admission a more carefull approach within this group treated with curative intend might be to admit a patient for a 24-hours observation and to dismiss the patient if the FN course is uncomplicated. ${ }^{25}$

Currently, anthracyclines and taxanes are the most commonly used drugs in the neoadjuvant treatment setting. In the 'Two-to-Six' study most patients were treated with TAC chemotherapy in a (neo-)adjuvant treatment setting. Another way of giving the same chemotherapeutic drugs is to administer it sequentially: AC followed by docetaxel $(T)$ or paclitaxel $(P)$. In chapter 6 , we reported the results of the national INTENS study, in which we concluded that AC-T is at least as effective as TAC chemotherapy in the neo-adjuvant setting with $\mathrm{pCR}$ as primary endpoint. Others, also showed a comparable efficacy between the two chemotherapy regimes. ${ }^{23,26}$ Of relevance, in our study we observed that FN incidence was $23 \%$ for AC-T without primary G-CSF prophylaxis, and in the BCIRG-005 study, the FN incidence was $8 \%$ with recommended primary G-CSF prophylaxis. ${ }^{24}$ The FN mainly occured during the four cycles of docetaxel and to a lesser extent during the AC-part of the chemotherapy schedule in our study. Moreover, the risk of FN during AC-T without G-CSF prophylaxis is generally lower than the risk of FN during TAC without G-CSF prophylaxis, ${ }^{27}$ so that it falls within the EORTC category of moderate increased risk of FN (10-20\%). That 
implies that primary G-CSF prophylaxis for AC-T is only required during the four docetaxel cycles and only in selected patients ( $\geq 65$ years of age or those who are in addition treated with HER2-targeted therapy). As a result, costs of G-CSF prophylaxis can be reduced by more than $50 \%$ of current costs. Additional arguments in favour of not using TAC anymore, are the recent results of the 10 year follow up data of the E1199 study presented by Sparano at the San Antonio Breast Cancer Symposium. ${ }^{28}$ It was shown that for patients with triple negative breast cancer, weekly paclixel after AC chemotherapy was the most effective strategy, 10 year disease-free survival improved from $59 \%$ to $69 \%$ and overall survival from $66 \%$ to $75 \%$ compared to both weekly paclitaxel and 3-weekly docetaxel. Therefore, we recently decided to switch from TAC to AC-paclitaxel for patients with triple negative disease. During paclitaxel the risk of $\mathrm{FN}$ is less than $10 \%$, without need of primary G-CSF prophylaxis. For patients with HER2 positive disease, AC-docetaxel/trastuzumab was already implemented. ${ }^{29}$ As trastuzumab increases the risk of docetaxel-induced FN, these patients routinely receive primary G-CSF prophylaxis during the four docetaxel/ trastuzumab cycles. Considering the fact, that with sequential chemotherapy a lower cumulative dose of anthracylines is reached, which is associated with a lower risk of long-term toxicities (reduced cardiac function and development of leukemia), ${ }^{30}$ we decided also to implement the sequential schedule for patients with ER/PR positive, HER2 negative disease. For these, we choose AC-docetaxel as in the aforementioned E1199 study 3-weekly docetaxel seemed slightly superior above weekly paclitaxel for this subgroup of patients. ${ }^{28}$ In agreement with EORTC guidelines, showing that docetaxel monotherapy is associated with a moderate risk of $\mathrm{FN}(10-20 \%)$ that may increase above $20 \%$ in the presence of another risk factor, we recommend primary G-CSF prophylaxis for patients on AC-docetaxel only during docetaxel if for instance age is 65 or higher.

In conclusion, we have shown that primary G-CSF prophylaxis throughout all cycles is the most effective strategy in reducing the $\mathrm{FN}$ incidence in breast cancer patients treated with TAC chemotherapy, but the most costly. If G-CSF prophylaxis would be limited to the first two chemocycles than $€ 3,491$ (95\% $\mathrm{Cl} € 2,461$ to $€ 4,548)$ per patient would be saved. But, limiting G-CSF prophylaxis to the first chemotherapy cycles only, increases FN incidence again above $20 \%$. From a clinical viewpoint this is not a benefit. We also demonstrated that AC-T is at least as effective as TAC chemotherapy for breast cancer outcome. In some breast cancer subgroups, the sequential approach was shown to be superior. In addition, sequential chemotherapy is associated with a lower risk of FN per cycle and also has a better long-term toxicity profile.

Therefore, based on the results of our two intervention studies and results from others, we recently implemented sequential chemotherapy for all patients with newly diagnosed breast cancer. We estimate that the use of G-CSF will hereby be reduced by more than $50 \%$ with a significant impact on Dutch health care costs. 


\section{References}

1. http://www.cijfersoverkanker.nl

2. Martin M, Pienkowski T, Mackey J, Pawlicki M, Guastalla JP, Weaver C, Tomiak E, Al-Tweigeri T, Chap L, Juhos E, Guevin R, Howell A, Fornander T, Hainsworth J, Coleman R, Vinholes J, Modiano M, Pinter T, Tang SC, Colwell B, Prady C, Provencher L, Walde D, Rodriguez-Lescure A, Hugh J, Loret C, Rupin M, Blitz S, Jacobs P, Murawsky M, Riva A, Vogel C; Breast Cancer International Research Group 001 Investigators. Adjuvant Docetaxel for node-positive breast cancer. N Engl J Med 2005;22:2302-13.

3. Smith TJ, Khatcheressian J, Lyman GH, Ozer H, Armitage JO, Balducci L, Bennett CL, Cantor SB, Crawford J, Cross SJ, Demetri G, Desch CE, Pizzo PA, Schiffer CA, Schwartzberg L, Somerfield MR, Somlo G, Wade JC, Wade JL, Winn RJ, Wozniak AJ, Wolff AC. 2006 Update of recommendations for the use of white blood cell growth factors: an evidence-based clinical practice guideline. J Clin Oncol 2006;24:3187-205.

4. Aapro MS, Bohlius J, Cameron DA, Dal Lago L, Donnelly JP, Kearney N, Lyman GH, Pettengell R, TjanHeijnen VC, Walewski J, Weber DC, Zielinski C; European Organisation for Research and Treatment of Cancer. 2010 update of EORTC guidelines for the use of granulocyte colony-stimulating factor to reduce the incidence of chemotherapy-induced febrile neutropenia in adult patients with lymphoproliferative disorders and solid tumors. Eur J Cancer 2011;47:8-32.

5. Timmer-Bonte JN, de Boo TM, Smit HJ, Biesma B, Wilschut FA, Cheragwandi SA, Termeer A, Hensing CA, Akkermans J, Adang EM, Bootsma GP, Tjan-Heijnen VC. Prevention of chemotherapy-induced febrile neutropenia by prophylactic antibiotics plus or minus granulocyte-colony stimulating factor: a Dutch randomized phase III study. J Clin Oncol 2005;23:7974-84.

6. National Comprehensive Cancer Network. Myeloid growth factors. Practice guidelines in the oncology v.1.2010. Available at http://www.nccn.org/professionals/physician_gls/f_guidelines.asp\#supportive .

7. Martín M, Lluch A, Seguí MA, Ruiz A, Ramos M, Adrover E, Rodríguez-Lescure A, Grosse R, Calvo L, Fernandez-Chacón C, Roset M, Antón A, Isla D, del Prado PM, Iglesias L, Zaluski J, Arcusa A, LópezVega JM, Muñoz M, Mel JR. Toxicity and health-related quality of life in breast cancer patients receiving adjuvant docetaxel, doxorubicin, cyclophosphamide (TAC) or 5-fluorouracil, doxorubicin and cyclophosphamide (FAC): impact of adding primary prophylactic granulocyte colony stimulating factor to the TAC regimen. Ann Oncol 2006;17:1205-12.

8. Martin M, Pienkowski T, Mackey J, Pawlicki M, Guastalla JP, Weaver C, Tomiak E, Al-Tweigeri T, Chap L, Juhos E, Guevin R, Howell A, Fornander T, Hainsworth J, Coleman R, Vinholes J, Modiano M, Pinter T, Tang SC, Colwell B, Prady C, Provencher L, Walde D, Rodriguez-Lescure A, Hugh J, Loret C, Rupin M, Blitz S, Jacobs P, Murawsky M, Riva A, Vogel C; Breast Cancer International Research Group 001 Investigators. Adjuvant docetaxel for node-positive breastcancer. N Engl J Med 2005;352;2302-13.

9. Brain EG, Bachelot $T$, Serin D, Kirscher S, Graic $Y$, Eymard JC, Extra JM, Combe M, Fourme E, Noguès $C$, Rouëssé J; RAPP-01 Trial Investigators. Life-threatening sepsis associated with adjuvant doxorubicin plus docetaxel for intermediate-risk breast cancer. JAMA 2005;293:2367-71.

10. von Minckwitz G, Kümmel S, du Bois A, Eiermann W, Eidtmann H, Gerber B, Hilfrich J, Huober J, Costa SD, Jackisch C, Grasshoff ST, Vescia S, Skacel T, Loibl S, Mehta KM, Kaufmann M; German Breast Group. Pegfilgrastim +/- ciprofloxacin for primary prophylaxis with TAC (docetaxel/doxorubicin/ cyclofosphamide) chemotherapy for breast cancer. Results from the GEPARTIO study. Ann Oncol 2008;19:292-8.

11. Nabholtz JM, Cantin J, Chang J, Guevin R, Patel R, Tkaczuk K, Vodvarka P, Lindsay MA, Reese D, Riva A, Mackey J. Phase III Trial Comparing Granulocyte Colony-Stimulating Factor to Leridistim in the Prevention of Neutropenic Complications in Breast Cancer Patients Treated with Docetaxel/ Doxorubicin/Cyclophosphamide: Results of the BCIRG 004 Trial. Clinical Breast Cancer 2002;3: 268-75.

12. Potosky AL, Malin JL, Kim B, Chrischilles EA, Makgoeng SB, Howlader N, Weeks JC. Use of colonystimulating factors with chemotherapy: opportunities for cost savings and improved outcomes. J Natl Cancer Inst 2011;103:979-82.

13. Adams JR, Bennett CL. When the risk of febrile neutropenia is $20 \%$, prophylactic colony stimulating factor use is clinically effective, but is it cost-effective? J Clin Oncol 2006;24:2975-6. 
14. Numnum TM, Kimball KJ, Rocconi RP, Kilgore LC, Straughn JM Jr. Pegfilgrastim for the prevention of febrile neutropenia in patients with epithelial ovarian carcinoma--a cost-effectiveness analysis. Int J Gynecol Cancer 2007;17:1019-24.

15. Timmer-Bonte JN, Adang EM, Smit HJ, Biesma B, Wilschut FA, Bootsma GP, de Boo TM, Tjan-Heijnen VC. Cost-effectiveness of adding granulocyte-colony stimulating factor to primary prophylaxis with antibiotics in patients with small cell lung cancer. J Clin Oncol 2006;24:2991-7.

16. Adams JR, Angelotta C and Bennet CL. When the risk of febrile neutropenia is $20 \%$, prophylactic colony-stimulating factor use is clinically effective, but is it cost-effective? J Clin Oncol 2006;24: 2975-7.

17. Dinan MA, Hirsch BR, Lyman GH. Management of chemotherapy-induced neutropenia: measuring quality, cost, and value. J Nath Compr Canc Netw 2015;13:1-7.

18. Ottevanger PB, De Mulder PH, Grol RP, Van Lier H, Beex LV. Effects of quality of treatment on prognosis in primary breast cancer patients treated in daily practice. Anticancer Res 2002;22:459-65.

19. Bonadonna G, Valagussa P, Moliterni A, Zambetti M, Brambilla C. Adjuvant cyclophosphamide, metotrexate, and fluorouracil in node-positive breast cancer. The results of 20 years of follow-up. $\mathrm{N}$ Engl J Med 1995;332:901-6.

20. Abi-Raad R, Smith BR. Biosimilar biologics: never identical but close enough. Transfusion 2015;55: 229-31.

21. Klastersky J, Paesmans M, Rubenstein EB, Boyer M, Elting L, Feld R, Gallagher J, Herrstedt J, Rapoport $B$, Rolston K, Talcott J. The multinational association for supportive care in cancer risk index: A multinational scoring system for identifying low-risk febrile neutropenic cancer patients. J Clin Oncol 2000;18:3038-51.

22. Swain SM, Tang G, Geyer CE Jr, Rastogi P, Atkins JN, Donnellan PP, Fehrenbacher L, Azar CA, Robidoux A, Polikoff JA, Brufsky AM, Biggs DD, Levine EA, Zapas JL, Provencher L, Northfelt DW, Paik S, Costantino JP, Mamounas EP, Wolmark N. Definitive Results of a Phase III Adjuvant Trial Comparing Three Chemotherapy Regimens in Women With Operable, Node-Positive Breast Cancer: The NSABP B-38 Trial. Clin Oncol 2013;31:3197-204.

23. Eiermann W, Pienkowski T, Crown J, Sadeghi S, Martin M, Chan A, Saleh M, Sehdev S, Provencher L, Semiglazov V, Press M, Sauter G, Lindsay MA, Riva A, Buyse M, Drevot P, Taupin H, Mackey JR. Phase III study of doxorubicin/cyclophosphamide with concomitant versus sequential docetaxel as adjuvant treatment in patients with human epidermal growth factor receptor 2-normal, node-positive breast cancer: BCIRG-005 trial. J Clin Oncol 2011;229:3877-84.

24. Lyman GH, Michels SL, Reynolds MW, Barron R, Tomic KS, Yu J. Risk of mortality in patients with cancer who experience febrile neutropenia Cancer 2010;116:5555-63.

25. Talcott JA, Siegel RD, Finberg R, Lee Goldman L. Risk Assessment in Cancer Patients With Fever and Neutropenia:A Prospective, Two-Center Validation of a Prediction Rule. J Clin Oncol 1992;10:316-22.

26. Swain SM, Jeong JH, Geyer CE Jr, Costantino JP, Pajon ER, Fehrenbacher L, Atkins JN, Polikoff J, Vogel VG, Erban JK, Rastogi P, Livingston RB, Perez EA, Mamounas EP, Land SR, Ganz PA, Wolmark N. Longer therapy, iatrogenic amenorrhea, and survival in early breast cancer. N Engl J Med 2010;362:2053-65.

27. Burnell M, Levine MN, Chapman JA, Bramwell V, Gelmon K, Walley B, Vandenberg T, Chalchal H, Albain KS, Perez EA, Rugo H, Pritchard K, O'Brien P, Shepherd LE. Cyclophosphamide, epirubicin, and Fluorouracil versus dose-dense epirubicin and cyclophosphamide followed by Paclitaxel versus Doxorubicin and cyclophosphamide followed by Paclitaxel in node-positive or high-risk node-negative breast cancer. J Clin Oncol 2010;28:77-82.

28. Sparano JA, Wang M, Martino S, Jones V, Perez EA, Saphner T, Wolff AC, Sledge GW Jr, Wood WC, Davidson NE. Weekly paclitaxel in the adjuvant treatment of breast cancer. 2008;358:1663-71

29. Perez EA, Romond EH, Suman VJ, Jeong JH, Sledge G, Geyer CE Jr, Martino S, Rastogi P, Gralow J, Swain SM, Winer EP, Colon-Otero G, Davidson NE, Mamounas E, Zujewski JA, Wolmark N. Trastuzumab plus adjuvant chemotherapy for human epidermal growth factor receptor 2-positive breast cancer: planned joint analysis of overall survival from NSABP B-31 and NCCTG N9831. J Clin Oncol 2014;32:3744-52. 
30. Mackey JR, Martin M, Pienkowski T, Rolski J, Guastalla JP, Sami A, Glaspy J, Juhos E, Wardley A, Fornander T, Hainsworth J, Coleman R, Modiano MR, Vinholes J, Pinter T, Rodríguez-Lescure A, Colwell B, Whitlock P, Provencher L, Laing K, Walde D, Price C, Hugh JC, Childs BH, Bassi K, Lindsay MA, Wilson V, Rupin M, Houé V, Vogel C; TRIO/BCIRG 001 investigators. Adjuvant docetaxel, doxorubicin, and cyclophosphamide in node-positive breast cancer: 10-year follow-up of the phase 3 randomised BCIRG 001 trial. Lancet Oncol 2013; 14: 72-80. 
Valorisation 


\section{Valorisation}

In addition to the scientific value of this thesis presented in Chapters 2-6, the results of the research have also economic and societal value. In this chapter we put the results into a broader perspective and highlight its potential for policymakers and clinicians.

In the Netherlands, the annual incidence of invasive breast cancer is approximately 14,000 patients and for women between 30 and 50 years of age it's number one cause of death. During the past decade the mortality has cleary decreased. ${ }^{1}$ The additional systemic treatment options, i.e., chemotherapy, HER2 targeted therapy and endocrine therapy, explain to a large extend the reduced risk of distant metastasis in more recent years. At least $40 \%$ of the patients diagnosed with invasive breast cancer are expected to be offered (neo-) adjuvant chemotherapy, nowadays consisting of a combination of cyclophosphamide, anthracyclines and taxanes. ${ }^{2}$ However, this combination is associated with an increased risk of FN, which can sometimes cause life-threatening infections. G-CSF prophylaxis reduces this risk, but comes with considerable costs. Approximately $50 \%$ of early breast cancer patients treated with (neo-) adjuvant chemotherapy are assumed to have an indication for G-CSF prophylaxis. In case of use of TAC chemotherapy, G-CSF prophylaxis is administered during all six chemotherapy cycles. However, as we noticed that FN incidence is the highest in the first two chemotherapy cycles, we hypothesized that to improve the cost-effectiveness of primary G-CSF prophylaxis, G-CSF use may be limited to the first two chemotherapy cycles opposed to the current practice of continued G-CSF prophylaxis. Therefore, we performed a randomized trial in which breast cancer patients were treated with chemotherapy with a more than $20 \%$ risk for $\mathrm{FN}$ with primary G-CSF prophylaxis during the first two chemotherapy cycles only (G-CSF 1-2) or to primary G-CSF prophylaxis throughout all chemotherapy cycles (G-CSF 1-6). Main clinical results showed that the incidence of FN was $10 \%$ in the G-CSF 1-6 cycles arm versus $36 \%$ in the G-CSF $1-2$ cycles arm, with a peak incidence of $24 \%$ in cycle three, the first cycle without G-CSF prophylaxis. However, in the accompanying costeffectiveness analysis, we demonstrated a major cost reduction of $€ 3,500$ per patient, if G-CSF prophylaxis is limited to the first two chemotherapy cycles. When extrapolated to the 2.800 breast cancer patients treated with prophylactic G-CSF during (neo-)adjuvant chemotherapy in the Netherlands, this would result in a yearly cost-saving of $€ 9.8$ million per year. Moreover, we must take into account the increasing incidence of breast cancer which negatively affects the total cancer care costs further.

However, the development of an FN event affects patients' Health-related Quality of Life (QoL). FN disrupts normal life activities such as employment and childcare, and thus has financial and social implications for patients and their families. By reducing 
the FN incidence with G-CSF prophylaxis subsequently QoL improves. ${ }^{3}$ Although we did not include the costs due to productivity loss, as most patients stop working during chemotherapy (equal for both treatment arms), the financial consequences if those aspects would have been considered lower the incremental outcome based on the different $\mathrm{FN}$ incidence.

In addition, in the Netherlands the willingness to pay (WTP) threshold of $€ 80,000$ per quality-adjusted life-years (QALY) is accepted. But, no survival benefit was shown from G-CSF prophylaxis in breast cancer patients. Hence, the dilemma is that from a cost viewpoint primary G-CSF prophylaxis will never be cost-effective, but from a clinical and societal viewpoint the question remains open whether we are willing to pay the loss in health benefit and whether we are willing to accept a small rate of neutropenic deaths that might otherwise have been prevented.

Very recently, new data came available showing the efficacy of sequential chemotherapy schedules that are associated with a lower risk of FN, thereby obviating the need of primary G-CSF prophylaxis in most patients. Only in patients treated with sequential AC-docetaxel above 60 years of age we would now recommend the use of G-CSF prophylaxis during the four docetaxel cycles. This implies a major cost reduction as we estimate that the use of G-CSF prophylaxis will be reduced by more than $50 \%$. In conclusion, this thesis has an economical as well as societal impact. It offers more information about different G-CSF prophylaxis and chemotherapy regimens for early breast cancer patients and its effect on bone marrow function and FN episodes. Whether we are willing to pay the loss in health benefit remains a societal discussion. 


\section{References}

1. http://www.cijfersoverkanker.nl

2. Geurts SM, van Dijck JAAM, de Vegt F, et al. Huge decrease in risk of breast cancer relapse in the Netherlands over the last 3 decades. Eur J Cancer 2012:48 (suppl 1):S82-S83

3. Martín M, Lluch A, Seguí MA, Ruiz A, Ramos M, Adrover E, Rodríguez-Lescure A, Grosse R, Calvo L, Fernandez-Chacón C, Roset M, Antón A, Isla D, del Prado PM, Iglesias L, Zaluski J, Arcusa A, López-Vega JM, Muñoz M, Mel JR. Toxicity and health-related quality of life in breast cancer patients receiving adjuvant docetaxel, doxorubicin, cyclophosphamide (TAC) or 5-fluorouracil, doxorubicin and cyclophosphamide (FAC): impact of adding primary prophylactic granulocyte-colony stimulating factor to the TAC regimen. Ann Oncol 2006;17:1205-1212. 
Curriculum vitae 
Maureen (Joanna Bettina) Aarts werd geboren op 1 juni 1972 in Maastricht. Na haar VWO opleiding (Atheneum) aan het Sint Maartenscollege te Maastricht begon zij aan haar studie Geneeskunde aan de Universiteit Maastricht. Na het behalen van haar artsexamen in 1999 was ze werkzaam als arts-assistent gynaecologie in het Orbis ziekenhuis te Sittard en later in het Atrium te Heerlen (beide thans Zuyderland). Vanaf mei 2003 werkte zij als arts-assistent op de afdeling Interne Geneeskunde in het Orbis ziekenhuis te Sittard. Per oktober 2003 begon zij met haar opleiding tot internist (opleiders: dr. B.J. Looij (Orbis) en prof. dr. C.D.A. Stehouwer (Academisch Ziekenhuis Maastricht)). In 2007 werd de opleiding tot internist-oncoloog (opleider: prof. dr. V.C.G. Tjan-Heijnen) gestart in azM (thans Maastricht Universitair Medisch Centrum), waarna registratie in dit vakgebied volgde in 2010. Sedertdien werkt zij als medisch oncoloog in Maastricht UMC+ en is zij sinds 2013 aldaar staflid. Haar aandachtsgebieden zijn uro-genitale oncologie en huid-oncologie.

Maureen begon in 2009 aan haar promotietraject onder de supervisie van prof. dr. V.C.G. Tjan-Heijnen. Naar aanleiding van de resultaten van de hoofdstudie 'Two-toSix' ontving zij de Young Investigator Award tijdens de MASCC convention in Vancouver in 2010. Daarnaast werden de publicaties van de 'Two-to-Six'-studie uitgeroepen tot de Best Paper Award van de GROW Science Day 2014 te Maastricht. Samen met Roy heeft zij drie kinderen, Lisa (2006), Joshua (2008) en Meira (2009). 
Dankwoord 
Mijn laatste stuk tekst, mijn dankwoord.

Vanzelfsprekend was dit proefschrift niet tot stand gekomen zonder de patiënten die hebben geparticipeerd aan dit onderzoek. De ondersteuning van de Borstkanker Onderzoek Groep (BOOG) zorgde voor een breed draagvlak voor deze studie. Door financiële ondersteuning van ZonMw en Sanofi bv is dit project mogelijk geworden. Daarnaast hebben vele anderen bijgedragen aan het tot stand komen van dit proefschrift.

Graag wil ik een aantal mensen in het bijzonder bedanken.

Allereerst dank aan mijn promotor, opleider en collega prof. dr. V.C.G. Tjan-Heijnen. Beste Vivianne, ik ken maar weinig mensen die zo gedreven, kordaat en efficiënt zijn. Jij was altijd beschikbaar voor vragen (op de meest onmogelijke tijden kreeg ik vrijwel direct antwoord) en je was razendsnel met correcties. Ik kan alleen maar zeggen dat de samenwerking en begeleiding super was. Inmiddels werk ik al 5 jaar als medisch oncoloog in Maastricht UMC+ en zie dat wij, onder jouw leiding, als team enorm gegroeid zijn en ook een duidelijke visie hebben betreffende de oncologische zorg. Maar daarnaast is er ruimte om je als medisch oncoloog verder te ontwikkelen en ook daarbij sta je altijd open voor 'tops en tips'. Ik wil je enorm bedanken voor alle steun, begeleiding maar ook inspiratie!

Mijn copromotor dr. M. Joore, beste Manuela, dank voor jouw bijdrage aan dit proefschrift. Met name het analyseren van de kosten-effectiviteit was voor mij nieuw en heeft mij de nodige hoofdbrekens bezorgd. Je hebt me hierin wegwijs gemaakt en dat zal zeker van pas komen bij de verdediging van mijn proefschrift.

Prof. dr. Manon van Engeland, beste Manon, wij zien elkaar regelmatig bij het 'epigenitica' overleg, waarbij ik gaande weg meer wijzer wordt over 'genome wide' en 'whole genome' sequencing. Jouw enthousiasme voor dat vak werkt aanstekelijk en ik hoop op vele jaren van vruchtbare samenwerking. Dank voor jouw bijdrage als voorzitter van de beoordelingscommissie.

Dr. G. Vreugdenhil, beste Art, ook jij bedankt dat je tijd en aandacht hebt willen besteden aan de beoordeling van mijn manuscript. Wij spreken elkaar wekelijks betreffende ons aandachtsgebied melanomen en ons contact is buitengewoon prettig. Ik hoop dat wij in de toekomst onze samenwerking blijven voorzetten zoals we dat nu doen.

Dr. E. Heuts, beste Esther, inmiddels spreken wij elkaar niet meer zo vaak gezien mijn huidige aandachtsgebieden. Echter ik heb de samenwerking altijd als heel prettig ervaren en denk nog wel eens terug aan de reis naar San Antonio. 24 uur onderweg 
en dan na het congres even wat drinken bij de kerstboom met een engelachtig kinderkoor op de achtergrond en dat met 30 graden. Wat een bijzondere ervaring.

Prof. dr. Epie Boven en prof. dr. Carmen Dirksen, hartelijk dank voor het beoordelen van mijn proefschrift.

Prof. Liesbeth Boersma en prof. Harry Schouten dank dat ook jullie op deze voor mij heel bijzondere dag aanwezig zijn en zitting nemen in de corona.

Alle mede-auteurs, dank voor jullie onmisbare bijdrage, in het bijzonder drs. Janneke Grutters, drs. Bram Ramaekers, drs. Birgit Vriens. Maar ook dank aan alle co-auteurs van de artikelen in dit proefschrift, Saskia van Gastel, prof. dr. George Borm, dr. Tineke Smilde, dr. Yes van de Wouw, prof. dr. Carin van de Rijt, dr. Jacqueline Stouthard, dr. Esther Jacobs, prof. dr. Hanneke van Laarhoven, dank voor jullie kritische blik.

Wim Lemmens, beste Wim, zonder jouw input en hulp bij de data-analyse zou het zeker niet gelukt zijn. Bedankt voor al je geduld, ondanks al mijn vragen bleef je altijd even vriendelijk. Heel veel dank!

Tiny Wouters, beste Tiny dank voor het maken van de lay-out van mijn proefschrif. Een enorme klus waar men niet altijd bij stilstaat.

Mijn collegae medisch oncologen, dr. Maaike de Boer, drs. Ingeborg Vriens en dr. Roy Lalisang, dank voor de prettige samenwerking. Dr. Patricia Soetekouw, dank voor je steun in mijn opleidingstijd en al je tips om dit vak nog beter te kunnen uitoefenen. Dr. Rob Jansen, ik heb veel geleerd van jouw praktijkervaring. Drs. Judith de Vos, mijn kamergenote, dank je voor de nodige sparmomenten en steun, maar ook je praktische tips! Succes met jouw promotietraject.

Lilian Wishaupt, beste Lilian dank voor alle secretariële ondersteuning. Ondanks alle drukte weet je altijd weer een gaatje vrij te maken als ik wat vraag. Gewoon super.

Trialbureau Medische oncologie, het indienen tot het weer afsluiten van een studie is enorm veel werk en wordt vaak onderschat. Het kan niet genoeg benadrukt worden dat we zonder jullie steun dit niet zouden kunnen. Heel veel dank daarvoor, in het bijzonder dank aan Myra.

Oncologiecentrum, en in het bijzonder de medewerkers van de polikliniek, dank voor jullie ondersteuning. Mijn drukke spreekuren verlopen altijd prettig en efficiënt, dank daarvoor. Maar vooral ook dank voor jullie lach en gezelligheid. Vooral Jip en Janneke, jullie zijn een supercombi en helemaal top! 
Alle overige medewerkers van Medische Oncologie, verpleegkundigen en secretaressen van verpleegafdeling $A 5$ en van het dagcentrum: dank voor de fijne samenwerking.

Vervolgens wil ik alle leden van de tumorwerkgroep Uro-genitale tumoren en Melanomen bedanken voor de prettige samenwerking. Wij zullen nog veel tijd samen doorbrengen in kader van directe patiëntenzorg, maar hopelijk ook in kader van wetenschappelijk onderzoek.

Dr. Ann Hoeben, mijn collega, beste Ann, op een gegeven moment hebben wij elkaar gevonden en daar ben ik nu nog blij om. Wij brengen de nodige uurtjes ook buiten ons werk samen door en ik vind dit supergezellig. De diverse culinaire keukens moeten nog worden uitgeprobeerd! Ik hoop in de toekomst dat onze vriendschap zal blijven, ongeacht wat op jouw pad zal gaan komen. Dank dat je mijn paranimf wilde zijn.

Cindy, wij gaan al heel ver terug, ik ken jou al sinds de kleuterschool en nog steeds staan we voor elkaar klaar. 'Vrienden voor het leven' noemt men dat. Bedankt daarvoor!

Patricia, wij hebben een zodanige invloed op elkaar die in een woord bijzonder is te noemen. Zoveel dingen hebben wij gemeen, soms een beetje te eng voor woorden. We denken en zeggen vaak hetzelfde, zelfs bepaalde gewoontes nemen we van elkaar over... Alles kunnen we aan elkaar kwijt, en dat is juist het mooie aan deze vriendschap. Pieken en dalen zijn er in het leven en een ding is zeker, wij zijn er voor elkaar!

Roy, al 23 jaar kennen wij elkaar en hebben veel meegemaakt. Heel veel mooie momenten, maar ook verdrietige momenten. We hebben samen 3 prachtige kinderen. Ik wil je bedanken voor al je steun die je me hebt gegeven.

Leonard, mijn broertje zeg ik nog altijd, maar je bent een kop groter dan ik! Ik vind het top dat je mijn paranimf wilt zijn. Meestal steun ik jou, echter nu zijn de rollen voor het eerst eens omgedraaid. Ik kijk terug op zeer mooie momenten, teveel om op te noemen, zoals samen naar het park gaan, jou leren fietsen, in de avond bordspel spelen en dan altijd die competitiedrang. Gewoon super. Inmiddels heb je al een aantal jaar een vaste relatie met Tiffny. Ze is geweldig. Ik wens je veel succes in de toekomst, samen met haar. 
Inge, mijn zus, wat hebben wij veel lol samen gehad. Urenlang samen spelen, later gezellig op stap (vrijdagavond was onze avond en deden we afsluiten met....jij weet wel wat ik bedoel). Maar ook konden we elkaar alles vertellen, menig uurtjes hebben we al kletsend doorgebracht op onze kamer. Tjee, door het schrijven van dit stuk tekst komen zoveel leuke herinneringen boven. Ik wil je bedanken voor al je steun en wens je veel geluk samen met Padraig en jullie 3 kinderen Lorcan, Maeve en Megan.

Mijn ouders, lieve pap en mam. Pap, bedankt voor alle wijze raad. Voor elk probleem was er altijd een oplossing, hoe lang je er ook naar moest zoeken. In de afgelopen jaren heb jij, maar ook wij samen veel geklust in en rond het huis waarvan ik veel heb geleerd. Heel erg bedankt dat je altijd voor me hebt klaar gestaan. Gewoon super. Mam, altijd kunnen wij ons verhaal aan elkaar kwijt, gewoon heerlijk. Jouw praktische tips zijn onmisbaar. Ik zal nooit de leuke momenten vergeten, zoals de pannenkoekjes met kersen, heerlijk. Maar ook de mooie dingen die je maakt, ook voor de kleinkinderen. Heel veel dank voor wat jullie beiden allemaal voor mij hebben gedaan.

Lisa, Joshua en Meira, ik ben zo blij dat jullie in mijn leven zijn. Ik geniet iedere dag van jullie. Lisa, je wordt al zo groot al een echt dametje met wijze uitspraken. Heerlijk hoe jij kunt kletsen. Joshua, je bent de echte knuffelbeer, de lieverd, miene sjat. Meira, je bent een echte spring in het veld, weet precies wat je wilt, zo leuk om te zien, zo anders. Ik hou heel veel van jullie. 